UNIVERSIDADE DE SÃO PAULO

PREVISÃO DE VIDA EM FADIGA ISOTÉRMICA E TERMOMECÂNICA EM FERRO FUNDIDO VERMICULAR

Autor: Felipe Jaime de Pina

Orientador: Prof. Tit. Waldek Wladimir Bose Filho Coorientador: Prof. Dr. Ricardo Afonso Angélico

São Carlos / SP 

FELIPE JAIME DE PINA

\section{Previsão de Vida em Fadiga Isotérmica e Termomecânica em Ferro Fundido Vermicular}

\section{Versão Corrigida}

Dissertação apresentada ao programa de PósGraduação em Ciência e Engenharia de Materiais da Universidade de São Paulo, para obtenção do título de Mestre em Ciências e Engenharia de Materiais.

Área de Concentração: Desenvolvimento, caracterização e Aplicação de Materiais

Orientador: Prof. Tit. Waldek Wladimir Bose Filho Coorientador: Prof. Dr. Ricardo Afonso Angélico

São Carlos - SP 


\section{AUTORIZO A REPRODUCÃO TOTAL OU PARCIAL DESTE TRABALHO, POR QUALQUER MEIO CONVENCIONAL OU ELETRÔNICO, PARA FINS DE ESTUDO E PESQUISA, DESDE QUE CITADA A FONTE.}

Ficha catalográfica elaborada pela Biblioteca Prof. Dr. Sérgio Rodrigues Fontes da EESC/USP com os dados inseridos pelo(a) autor(a).

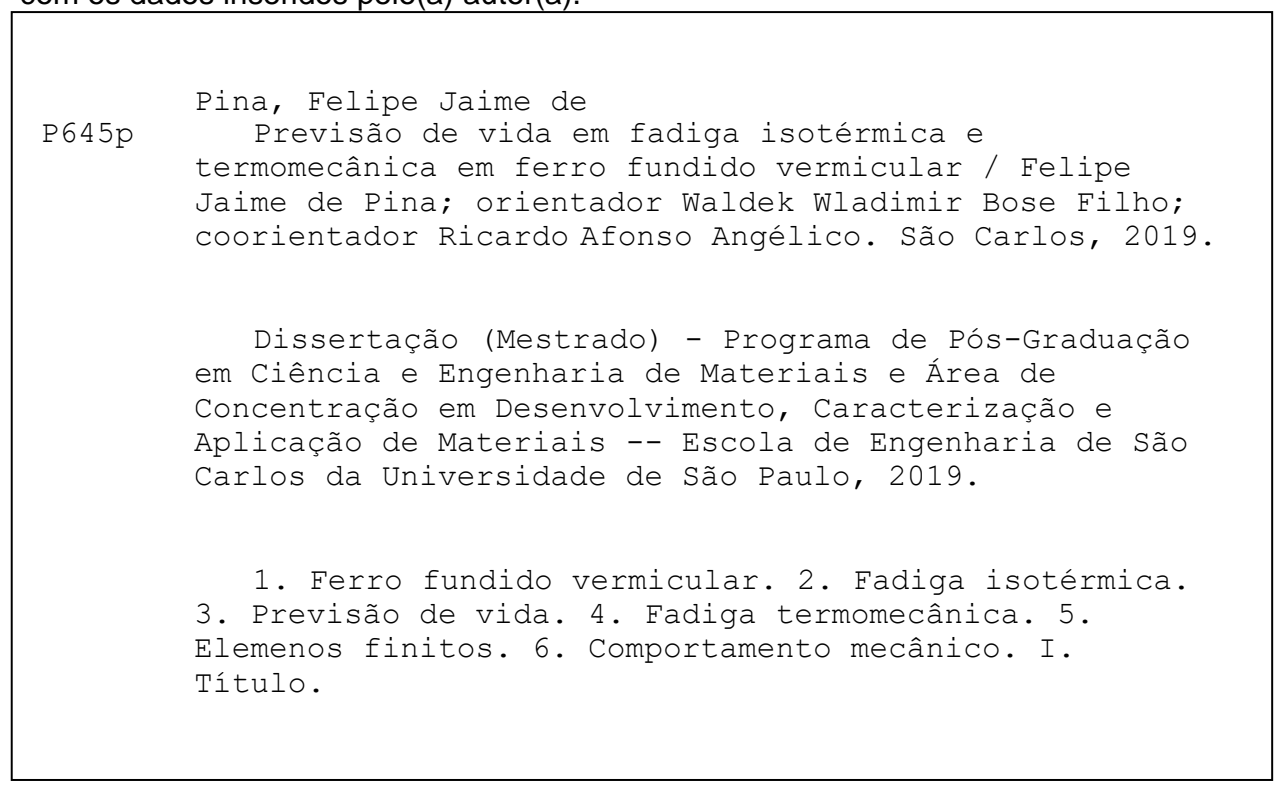

Eduardo Graziosi Silva - CRB - 8/8907 


\section{FOLHA DE JULGAMENTO}

Candidato: Engenheiro FELIPE JAIME DE PINA.

Título da dissertação: "Previsão de vida em fadiga termomecânica em ferros fundidos vermiculares".

Data da defesa: 06/09/2019.

\section{Comissão Julgadora:}

Prof. Dr. Ricardo Afonso Angélico

(Coorientador)

(Escola de Engenharia de São Carlos/EESC)

Prof. Dr. Wilson Luiz Guesser

(Universidade do Estado de Santa Catarina/UDESC)

Prof. Associado Jonas de Carvalho

(Escola de Engenharia de São Carlos/EESC)
Resultado:

APROVADO
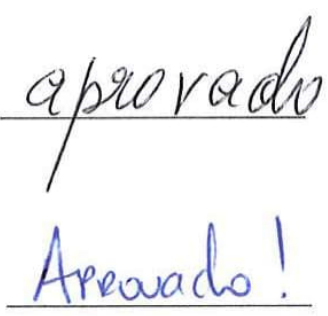

Coordenador do Programa de Pós-Graduação em Ciências e Engenharia de Materiais:

Prof. Associado Marcelo Falcõo de Oliveira

Presidente da Comissão de Pós-Graduação:

Prof. titular Murilo Araujo Romero 

Dedico este trabalho aos meus pais Joaquim e Renatta, aos meus irmãos Tiago e Gabriel e minha noiva Alice. 



\section{AGRADECIMENTO}

Agradeço primeiramente a minha família por sempre me apoiar.

Ao Prof. Tit. Waldek Wladimir Bose Filho, pela oportunidade de realizar este trabalho, na orientação e suporte.

Ao Prof. Dr. Ricardo Afonso Angélico, pela orientação e grande contribuição e apoio neste trabalho.

Ao Prof. Dr. Wilson Luiz Guesser, pelo suporte e conhecimento agregado neste trabalho.

Ao MSc. Márcio Henrique Ferreira, pelo apoio, resultados e discussões que possibilitaram esse trabalho.

Ao Douglas Giovanni Bon, pelo auxílio, companheirismo e sempre disposto a ajudar.

À MSc. Alice Raabe, por sempre me apoiar no processo deste trabalho e a revisão do mesmo.

A todos os meus professores que me ajudaram a seguir o meu caminho, desde pequeno até agora, mas principalmente os professores do Departamento de Engenharia de Materiais, que criei um grande apreço.

E a todos os funcionários e grupos do Departamento de Engenharia de Materiais. À Empresa TUPY, pelo fornecimento dos corpos de provas utilizados nos ensaios.

O presente trabalho foi realizado com apoio do CNPq, Conselho Nacional de Desenvolvimento Científico e Tecnológico - Brasil, a quem apresentamos nossos agradecimentos. 

"O sucesso consiste em ir de derrota em derrota sem perder o entusiasmo."

Winston Churchill 



\section{RESUMO}

PINA, F. J. Previsão de vida em fadiga isotérmica e termomecânica em ferro fundido vermicular. 2019. 93 f. Dissertação (Mestrado em Ciências e Engenharia de Materiais) - Escola de Engenharia de São Carlos, Universidade de São Paulo, São Carlos, 2019.

Com excelentes propriedades de fundição, boa condutividade térmica e desempenho mecânico adequado, os ferros fundidos vermiculares são amplamente utilizados em motores a diesel. O motor geralmente funciona em condições operacionais transientes, como partida, carga e descarga súbitas e parada. A falha por fadiga termomecânica é um dos principais problemas do cabeçote de motores, pois durante o funcionamento do motor, este é submetido a variações combinadas de temperatura e carga. No presente trabalho são feitas previsões de comportamento mecânico de um tipo de ferro fundido, denominado de ferro fundido vermicular, classe 450 , usando um modelo constitutivo elasto-plástico do programa comercial de elementos finitos ABAQUS ${ }^{\circledR}$. Os parâmetros desse modelo são identificados a partir de ensaios com carregamento cíclicos crescentes, de fadiga isotérmica e ensaios de tração. São caracterizados os parâmetros da curva de Wöhler em fadiga isotérmica, e com esses parâmetros é proposto uma caracterização para o caso de fadiga termomecânica da mesma curva. Os resultados da simulação computacional apresentam bons resultados em caso de carregamento constantes em fadiga isotérmicos enquanto em carregamentos de fadigas termomecânicos o modelo constitutivo não leva em consideração o efeito da relaxação de tensão que o material apresenta, carecendo assim de um modelo mais adequado que considera efeitos viscosos. O modelo de plasticidade que melhor se adaptou aos ensaios de fadiga é na forma de inserção dos parâmetros $C_{k}$ e $\gamma_{k}$, pois esses parâmetros apresentam melhor flexibilidade para descrever a curva de encruamento comparado com a equação de Ramberg-Osgood. Foi possível obter a previsão de vida em fadiga em condições isotérmicas utilizando a equação de Wöhler. Nos carregamentos termomecânicos, foi possível prever a vida utilizando as equações modificadas de Wöhler, que dependem da variação da 
deformação mecânica e da utilização de parâmetros encontrados a partir de ensaios isotérmicos realizados na temperatura máxima do ciclo termomecânico.

Palavras-chaves: Ferro fundido vermicular. Fadiga isotérmica. Previsão de vida. Fadiga termomecânica. Elementos finitos. Comportamento mecânico. 


\begin{abstract}
PINA, F. J. Life prediction in isothermal and thermomechanical fatigue in vermicular cast iron. 2019. 93 f. Dissertação (Mestrado em Ciências e Engenharia de Materiais) - Escola de Engenharia de São Carlos, Universidade de São Paulo, São Carlos, 2019.
\end{abstract}

With outstanding casting properties, good thermal conductivity and appropriate mechanical performance, compacted cast irons are widely used in the cylinder head of diesel engine. The engine usually works under transient operating conditions, such as starting, suddenly loading and unloading and shutting down. The processes usually leads to large temperature variation and serious fatigue damage. Therefore, the components are submitted during long periods to a large number of heating and cooling cycles, making thermo-mechanical fatigue (TMF) one of the most common failure mechanism. In the present work predictions of mechanical behavior of vermicular cast iron, 450 class, are made, using an elasto-plastic constitutive model of the commercial finite element software ABAQUS ${ }^{\circledR}$. The parameters of this model are identified from the cyclic increasing loading test, isothermal fatigue, and tensile tests. The parameters of the Wöhler curve in isothermal fatigue are characterized, and with these parameters, a characterization is proposed for the case of thermomechanical fatigue of the same curve. The results of the computational simulation present good results in the case of constant loading in isothermal fatigue while in thermomechanical fatigue the constitutive model cannot represent the stress relaxation effect of the material, thus lacking a more adequate model that reproduce the viscous effects. The prediction of life presents a reasonable result that depends on further statistical studies to prove its efficiency. The best input method to the plasticity model that fits the fatigue tests is using parameters $C_{k}$ and $\gamma_{k}$, because these parameters present better flexibility to describe the hardening curve compared to the Ramberg-Osgood equation. It was possible to obtain the fatigue life prediction under isothermal conditions using the Wöhler equation. While in the thermomechanical loads, it was possible to predict life using the modified Wöhler equations, which depend on the variation of the mechanical 
deformation and the use of parameters found from isothermal tests performed at the maximum temperature of the thermomechanical cycle.

Keywords: Compacted cast iron. Isothermal fatigue. Life prediction. Thermomechanical fatigue. Finite elements. Mechanical behavior. 


\section{LISTA DE FIGURAS}

Figura 1 - Tipos de ciclos de fadiga termomecânica aplicados (a) em fase, (b) fora de

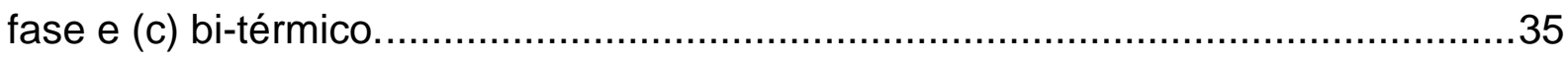

Figura 2 - Curva de tensão-deformação uniaxial para um metal típico. .40

Figura 3 - Identificação dos coeficientes de encruamento característicos do aço 316 $\mathrm{L}$ à temperatura ambiente.

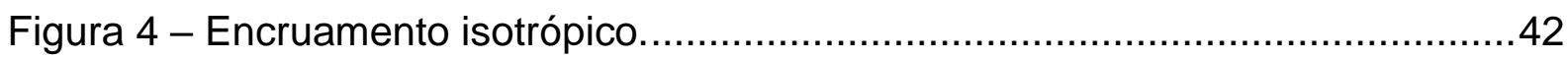

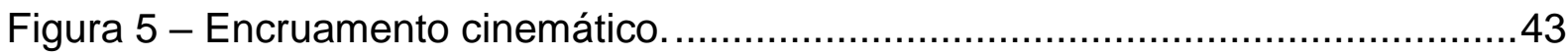

Figura 6 - Modelo de encruamento cinemático com três "backstress". ..................45

Figura 7 - Exemplo de dados de tensão e deformação de meia vida.....................46

Figura 8 - Exemplo de dados de curva tensão deformação estabilizado. ...............47

Figura 9 - Microestrutura do FFV testado nos experimentos, na imagem da esquerda apresenta o material sem ataque químico enquanto na imagem da direita com ataque.

Figura 10 - Esquema representando o sistema de ensaio .52

Figura 11 - Máquina de ensaio MTS com (A) tubo de ventilação, (B) pirômetro, (C) garras refrigeradas, (D) bobina de indução e (E) extensômetro.

Figura 12 - Corpo de prova utilizado no ensaio de tração, fadiga isotérmica e termomecânica.

Figura 13 - Ensaio característico de fadiga isotérmica em controle de deformação, a) histerese do ensaio (Tensão $x$ deformação), b) deformação conforme o tempo, c) Tensão encontrada no ensaio.

Figura 14 - Exemplo de fadiga termomecânica com 75\% de restrição, a) tensão vs. deformação total, b) deformação mecânica total aplicada vs. tempo, c) Tensão vs.

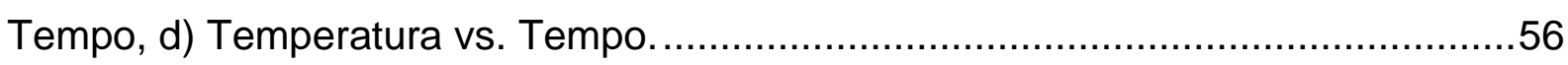

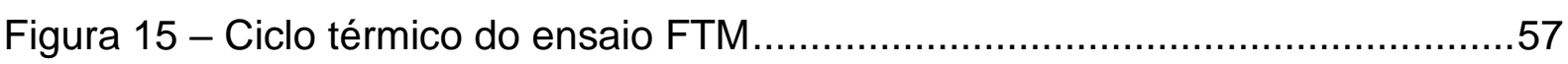

Figura 16 - Tensões aplicadas no ensaio de carregamento cíclico crescente. .58 
Figura 17 - a) Corpo de prova, b) Modelo axissimétrico e condições de contorno e c) malha do modelo.

Figura 18 - Curva tensão de escoamento por deformação plástica .......................... 61

Figura 19 - Fluxograma utilizando para o ajuste dos parâmetros.

Figura 20 - Resultado do ensaio de carregamento e descarregamento, a) tensão $x$ deformação, b) deformação $x$ tempo e c) tensão $x$ tempo.

Figura 21 - Ajuste dos parâmetros do modelo a partir de dados experimentais. ..... 68

Figura 22 - Comparação entre a simulação e o ensaio de carregamento cíclico crescente, considerando os dados estabilizados com um "backstress". 69

Figura 23 - Comparação entre a simulação e ensaio de carregamento cíclico crescente, considerando os dados de meia vida com a) um "backstress", b) dois "backstress" e c) três "backstress". .70

Figura 24 - Comparação entre a simulação e ensaio de carregamento cíclico crescente, considerando os dados de parametrizado com a) dois "backstress" e b) três "backstress".

Figura 25 - Ensaio de fadiga isotérmica com variação de deformação de 0,3\% sem modelo plástico dos três primeiros ciclos a a) $50^{\circ} \mathrm{C}$ e b) $420^{\circ} \mathrm{C}$. 74

Figura 26 - Ensaio de fadiga isotérmica a $50^{\circ} \mathrm{C}$ com variação de deformação de $0,7 \%$ dos três primeiros ciclos comparação com simulação de a) dados parametrizados com três "backstress", b) dados de meia vida com três "backstress".

Figura 27 - Ensaio de fadiga isotérmica a $420^{\circ} \mathrm{C}$ com variação de deformação de $0,7 \%$ dos três primeiros ciclos comparação com simulação de a) dados parametrizados com três "backstress", b) dados de meia vida com três "backstress". 76 Figura 28 - Ensaio de tração a $250^{\circ} \mathrm{C}$ comparação com simulação de dados parametrizados com três "backstress". 78

Figura 29 - Ensaio de fadiga termomecânica com $75 \%$ de restrição do corpo de prova em comparação a simulação com dados parametrizados com três "backstress" dos três primeiros ciclos. 80 
Figura 30 - Ensaio de fadiga termomecânica com 100\% de restrição do corpo de prova em comparação a simulação com dados parametrizado com três "backstress" dos três primeiros ciclos.

Figura 31 - Representação da relaxação de tensão que o material apresenta no ensaio de fadiga termomecânica com $100 \%$ de restrição do CP a) dos três primeiros ciclos, b) do primeiro ciclo.

Figura 32 - Gráfico de deformação mecânica total pelo número de ciclos até a fadiga em fadiga isotérmica a $50^{\circ} \mathrm{C}$ comparado as curvas da equação 17 considerando e não considerando o ponto 0,3 . .83

Figura 33 - Gráfico de deformação mecânica total pelo número de ciclos até a fadiga em fadiga isotérmica a $420^{\circ} \mathrm{C}$ comparado as curvas da equação 17 considerando e não considerando o ponto 0,3 



\section{LISTA DE TABELAS}

Tabela 1 - Tensões geradas no corpo de prova no carregamento cíclico crescente59

Tabela 2 - Tabela dos ensaios e o controle utilizado na máquina de ensaio. .63

Tabela 3 - Tabela comparativa entre a forma de inserir os dados e os parâmetros. 64 Tabela 4 - Parâmetros da Equação 8 obtidos do ensaio. 68

Tabela 5 - Parâmetros obtidos nos ensaios de tração em diversas temperaturas e a média na temperatura. .79 Tabela 6 - Comparação da deformação com a vida em fadiga isotérmica a $50^{\circ} \mathrm{C}$ de diversos corpos de prova. .84

Tabela 7 - Vida em fadiga isotérmica a $420^{\circ} \mathrm{C}$ de diversos corpos de prova. 85

Tabela 8 - Dados da Equação 15 e 16 para o ensaio FTM e isotérmico 86 



\section{LISTA DE ABREVIATURAS E SIGLAS}

ASTM - American Society for Testing Materials;

$\mathrm{CP}$ - Corpo de prova;

FAC - Fadiga de alto ciclo;

FBC - Fadiga de baixo ciclo;

FEM - Finite element method, método dos elementos finitos;

FFC - Ferro fundido cinzento;

FFV - Ferro fundido vermicular;

FFN - Ferro fundido nodular;

FTM - Fadiga termomecânica;

FTM-FF - Fadiga termomecânica fora de fase;

PID - Proporcional integral derivativo;

PhyBaLSIT - Physically based fatigue life calculation method. 



\section{LISTA DE SÍMBOLOS}

$\varepsilon$ : Deformação;

$t:$ Tempo;

$T:$ Temperatura;

$\varepsilon_{\text {total }}:$ Deformação total;

$\varepsilon_{e}$ : Deformação elástica;

$\varepsilon_{p}$ : Deformação plástica;

$\varepsilon_{t}$ : Deformação térmica;

$\sigma:$ Tensão;

$\sigma_{Y}$ : Tensão de escoamento inicial do material;

$\sigma_{i j}:$ Tensor de tensões;

$f_{0}$ : Função inicial de escoamento;

$W_{i}$ : Parâmetro de encruamento;

$\sigma_{s}:$ Tensão de escoamento;

$k$ : Parâmetro do material da equação de encruamento;

$b$ : Parâmetro do material da equação de encruamento;

$\rho_{d}$ : Densidade de deslocamento;

$\rho_{d_{0}}:$ Densidade de deslocamento inicial;

$K_{Y}$ : Parâmetro de encruamento da equação de Ramberg-Osgood;

$M_{Y}$ : Expoente de encruamento da equação de Ramberg-Osgood;

$K_{0}$ : Parâmetro de encruamento da equação reescrita de Ramberg-Osgood;

$n$ : Expoente de encruamento da equação reescrita de Ramberg-Osgood;

$\alpha_{i j}:$ Tensor de "backstress";

K: Parâmetro de encruamento escalar;

$\alpha$ : "Backstress" geral; 
$\sigma_{0}$ : Superfície de encruamento inicial;

$C_{k}$ : Módulos iniciais de encruamento cinemático;

$\dot{\varepsilon}^{p l}$ : Taxa de deformação plástica;

$\gamma_{k}$ : Taxa da mudança dos módulos de encruamento cinemático;

$\alpha_{k}:$ :Backstress";

$\Delta \varepsilon$ : Variação de deformação.

$\varepsilon_{a, t}:$ Amplitude total de deformação;

$\varepsilon_{B, M(F A C)}^{\prime}$ : Coeficiente de resistência de fadiga no regime de fadiga de alto ciclo;

$N_{f}$ : Número de ciclos para a falha;

$b_{M}$ : Expoente da resistência de fadiga generalizada;

$\varepsilon_{B, M(F B C)}^{\prime}$ : Coeficiente de ductilidade da fadiga no regime de fadiga de baixo ciclo;

$c_{M}$ : Expoente de ductilidade de fadiga generalizada;

$\varepsilon_{a, t}^{m e}:$ Amplitude total de deformação mecânica;

$\varepsilon_{B, M(F B C)}^{\prime F T M}$ : Coeficiente de ductilidade da fadiga no regime de fadiga de baixo ciclo em fadiga termomecânica;

$c_{M(F T M)}$ : Expoente de ductilidade de fadiga generalizada no caso de fadiga termomecânica;

R: Razão de deformação;

E: Módulo elástico;

$v$ : Coeficiente de Poisson;

$p$ : Parâmetros dos materiais a ser minimizados;

$\chi(p)$ : Função de minimização dos parâmetros $p ;$

$t_{i}$ : Variável tempo;

$y_{\text {exp }}$ : Dados experimentais;

$y_{f e m}$ : Dados do programa de elementos finitos:

$J_{i j}$ : Matriz Jacobiana; 
$\alpha$ : Coeficiente de expansão térmica linear. 

1 INTRODUÇÃO _ 29

2 OBJETIVO _ 31

3 REVISÃO BIBLIOGRÁFICA____ 33

3.1 Ferros fundidos na indústria automobilística ___ 33

3.2 Fadiga termomecânica __ 34

3.3 Desafios na modelagem do comportamento mecânico____ 36

3.4 Modelos da plasticidade __ 38

3.5 Encruamento _ 39

3.5.1 Lei de encruamento isotrópico.___ 42

3.5.2 Lei de encruamento cinemático ___ 43

3.5.3 Lei de encruamento combinado.__ 44

3.6 Formas de inserção dos parâmetros do modelo no Abaqus ${ }^{\circledR}$

3.6.1 Inserção de dados: parametrizado ___ 44

3.6.2 Inserção de dados: Meia vida ___ 45

3.6.3 Inserção de dados: estabilizado __ 46

3.7 Combinação de modelos constitutivos __ 47

3.8 Previsão de vida em fadiga___ 48

4 METODOLOGIA

4.1 Material__ 51

4.2 Equipamentos utilizados nos ensaios e CP

4.3 Ensaio de tração __ 54

4.4 Ensaio de fadiga isotérmica ___ 54

4.5 Ensaio de fadiga termomecânica ___ 56

4.6 Ensaios com carregamento cíclico crescente __ 58

4.7 Modelo computacional _ 59

4.7.1 Modelo em elementos finitos _ 59 
4.7.2 Parâmetros dos materiais dos modelos constitutivos. 60

4.7.3 Modelo de previsão de vida___ 61

4.7.4 Ajuste dos parâmetros. __ 62

5 RESULTADOS E DISCUSSÃO _ 67

5.1 Ensaios com carregamento cíclico crescente____ 67

5.1.1 Dados estabilizado __ 68

5.1.2 Dados de meia vida__ 69

5.1.3 Dados parametrizado __ 71

5.2 Ensaio de fadiga isotérmica __ 73

5.3 Ensaio de tração

5.4 Ensaio de fadiga termomecânica ___ 78

5.5 Previsão de vida em fadiga em temperatura constante ___ 83

6 CONCLUSÃO E RECOMENDAÇÕES PARA TRABALHOS FUTUROS_ 87

REFERÊNCIAS 


\section{INTRODUÇÃO}

Vários componentes mecânicos e estruturais estão sujeitos a variações de temperatura durante o período de operação. Os gradientes térmicos assim induzidos dentro desses componentes podem causar tensões internas e a repetição desses "ciclos térmicos" pode causar a nucleação e propagação de trincas por um processo de fadiga de baixo ciclo (FBC). [1]

Assim, no motor em funcionamento, o material sofrerá cargas mecânicas, térmicas e corrosivas devido à combustão e às explosões resultantes de calor e pressão. Consequentemente, as partes mais próximas da câmara de combustão, no bloco do motor e na cabeça do cilindro, ficam quentes e o calor é conduzido para as partes mais distantes, resultando no desenvolvimento de um gradiente térmico nos componentes. Com uma expansão térmica heterogênea as tensões térmicas se desenvolvem como consequência à medida que a expansão em cada ponto é restringida de maneira diferente dependente da região próxima.

Propriedades térmicas como elevada condutividade térmica e baixo coeficiente de expansão térmica, tornam os ferros fundidos candidatos ideais para aplicações industriais em que é necessária uma combinação destas propriedades, como em motores a diesel para geração de energia usados nas indústrias automotivas, marítima e ferroviária. [2]

Nessas aplicações, os componentes do motor, como cabeçotes e coletores de escape, são submetidos a ciclos de temperatura elevada durante sua vida útil. Sob essas condições, a alta condutividade térmica, que permite o rápido transporte de calor, é necessária para reduzir os gradientes térmicos dentro do componente. [2] Conhecendo a distribuição da temperatura e sua variação com o tempo de forma precisa pode aumentar a exatidão da análise térmica. A previsão fiel da temperatura do motor é crucial e para aumenta a confiabilidade dos resultados da análise mecânica e da estimativa da vida em fadiga na simulação.

Um bom desempenho dos cabeçotes em altas temperaturas é essencial para o aumento da eficiência do motor. O desempenho de qualquer componente está inerentemente relacionado às propriedades do material e, portanto, à sua composição química e microestrutura. Qualquer variação nos aspectos microestruturais levará a 
uma variação de propriedades mecânicas, como resistência e tenacidade à fratura, mas também pode alterar propriedades físicas importantes como a condutividade térmica. [3]

Alta capacidade de produção energética, baixo consumo de combustível, baixa emissão e redução do custo de manutenção estão entre as restrições que tornam o projeto de cabeçotes uma tarefa de alta complexidade. [4,5] Assim, análise detalhada e projeto bem executado são essenciais. $O$ aumento das preocupações relacionadas ao meio ambiente e aos custos de combustível enfatiza a necessidade de pesquisas sobre motores mais eficientes, com menor dissipação de energia e de gases poluentes. [5,6] Uma maneira de diminuir os custos com combustível é reduzir o peso dos veículos. [6,7] Por isso a necessidade de melhorias em projetos com foco na redução do peso dos componentes, sem diminuir a expectativa de vida.

Os projetistas de motores estão usando cada vez mais técnicas de simulação mais avançadas para reduzir o tempo e os custos de projeto e, ao mesmo tempo, melhorar a precisão do trabalho para limitar o número de testes de validação necessários. [8]

Desenvolvimentos foram alcançados em diferentes campos em motores de combustão interna: exemplos podem ser encontrados nos seguintes artigos de geometria de pistão / fluxo de combustão [9,10], materiais / comportamento mecânico e térmico [11-13], materiais / desgaste e lubrificação (revestimentos) [14,15], ferramentas analíticas - FEA [16,17], tecnologias de processamento [18,19], etc, ou seja, a combinação de novos conhecimentos na área de materiais e programas computacionais de apoio a projetos de engenharia conseguiram aumentar a eficiência dos motores e agilidade em desenvolvimento de novos motores. 


\section{OBJETIVO}

Este projeto de pesquisa objetiva estudar o comportamento mecânico acoplado com a modelagem computacional para se obter uma previsão de vida em fadiga de ferros fundidos de alta resistência em condições de fadiga isotérmica e fadiga termomecânica fora de fase (FTM-FF), utilizando de modelos constitutivos disponibilizados em programas comerciais. Ainda, foram realizados ensaios de carregamentos cíclicos crescente, de tração a quente, fadiga isotérmica e termomecânica para avaliar o comportamento mecânico em altas temperaturas nas diferentes condições de carregamentos, bem como obter os parâmetros dos modelos para a execução de simulação computacional, provendo os coeficientes de expansão térmica linear e a simulação do transiente térmico gerado no aquecimento e no resfriamento da peça. Para tanto, é de importância fundamental a determinação dos critérios de falha, que por sua vez foram obtidos dos ensaios experimentais de fadiga termomecânica, realizados em corpos de prova laboratoriais, fabricados a partir de um ferro fundido vermicular (FFV) classe 450, produzido pela Fundição TUPY.

Este trabalho se propõe a tratar do problema de fadiga termomecânica dos componentes estudando sua influência em condições de carregamento mais próximas dos carregamentos reais de operação. Deste modo, o estudo do comportamento mecânico e de equações constitutivas para estes materiais é indispensável para uma eventual determinação da vida residual e da execução mais responsável de projetos destes componentes. Os resultados deste estudo serão utilizados para determinar um modelo constitutivo adequado para ser aplicado em um programa de elementos finitos para as áreas de desenvolvimento de produto, permitindo a empresa nacional uma maior competitividade no mercado internacional, certificando seus produtos quanto a este tipo de falha, desenvolvimento de projetos de motores mais compactos e de maior eficiência, sem limitar a vida do componente. 


\section{REVISÃO BIBLIOGRÁFICA}

\subsection{Ferros fundidos na indústria automobilística}

Os Ferro fundidos utilizados na indústria automobilística são ligas de ferro, carbono e silício que normalmente a quantidade de carbono está entre 3,0-3,8\% e silício 2-4\% em porcentagem de peso. A alta quantidade de carbono induz a formação de grafita na microestrutura envolta em matriz de ferrita ou perlita, sendo que a morfologia da grafita é definida pela composição química e pela taxa de resfriamento do fundido. Dependendo da morfologia, o ferro fundido pode ser classificado como: ferro fundido nodular ou esferoidal (FFN), ferro fundido vermicular ou compacto (FFV) e ferro fundido cinzento (FFC), que a grafita possui a forma em flocos ou em lamelas. A morfologia da grafita tem um papel fundamental nas propriedades mecânicas e térmicas do ferro fundido [20,21].

Em FFV e FFC, a grafita forma uma rede interligada tridimensionalmente, juntamente com sua alta condutividade térmica, leva a propriedade térmicas que superam as propriedades encontradas no FFN. Entretanto a rede interconectada tridimensionalmente de grafita demonstra ser prejudicial para as respostas mecânicas do material. Devido a incompatibilidade elástica e térmica da matriz e da grafita, além destas grafitas apresentarem arestas angulosas, ocorre concentração de tensão na interface matriz grafita, através do qual a interface é um local preferencial para a início e propagação de trincas. Durante a propagação da trinca, a fraca interface entre matriz e grafita se transforma o caminho natural para o crescimento da trinca. Isso caracteriza o FFV e FFC, em geral, mais frágeis que os aços. Em contrapartida, a inclusão de grafita no FFN está presente em forma nodular e isolada, conferindo ao material maior ductilidade e resistência, porém com propriedades térmicas similares aos de aços. [2]

Além da morfologia da grafita, a microestrutura da matriz tem influência fundamental na propriedade mecânica do ferro fundido. O teor de ferrita ou perlita altera a resistência, a ductilidade, estabilidade microestrutural e a resistência a fluência da matriz de ferro. A predominância de matriz ferrítica reduz o limite de resistência a tração, porém aumenta a ductilidade. À medida que a quantidade de perlita aumenta, a resposta do ferro fundido desloca de dúctil para frágil, onde uma 
matriz somente perlítica revela um alto limite de resistência a tração e uma baixa ductilidade $[22,23]$. Em temperaturas acima da temperatura ambiente, a resistência a fluência e estabilidade microestrutural se torna relevante no comportamento mecânico do ferro fundido. Por esta razão, uma matriz perlítica com resistência a fluência maior do que a ferrita é preferível para aplicações em alta ou elevadas temperaturas. Entretanto, uma desvantagem da perlita é que em temperaturas acima de $500^{\circ} \mathrm{C}$ a microestrutura tende a ficar instável [24-31]. Dependendo da magnitude da temperatura e tempo de permanência, a perlita pode ser decomposta em ferrita e grafita o qual enfraquece a matriz. Os ferros fundidos ferríticos são mais estáveis micro estruturalmente em temperaturas acima de $500{ }^{\circ} \mathrm{C}$, pois não são afetadas por esse fenômeno.

\subsection{Fadiga termomecânica}

Componentes que operam em alta temperatura em motores de combustão interna devem suportar ciclos térmicos e mecânicos severos ao longo de sua vida útil. Tensões locais e deformações inelásticas são resultados das distribuições térmicas heterogêneas durante o ciclo aliadas à interação com os componentes adjacentes que restringem a expansão e a contração dimensional. A combinação de temperatura transiente com ciclos de carregamentos conduz a fadiga de baixo ciclo (FBC) e fadiga termomecânica (FTM) do material. Além disso, carregamentos de alta frequência aparecem concomitantemente como por exemplo durante a ignição ou oscilação da força inicial: estes dois fenômenos podem contribuir adicional para o dano do material com a fadiga de alto ciclo (FAC). Após um certo número de ciclo FTM superposto com a FAC, o componente mecânico falha. Portanto, são necessários diversos ensaios de bancadas, muito morosos e de alto custo, para encontrar o material e o projeto que garanta a integridade do componente durante sua vida útil. Em virtude destes fatores, há uma demanda por modelos de predição de vida em fadiga em condições de FBC superposta com FAC e FTM em superposição com FAC. [32]

Regimes de alta amplitude de deformação em FBC e FTM proporcionam a iniciação de microtrincas nos primeiros ciclos, onde o cálculo de vida destes componentes são determinados pela velocidade de crescimento destas microtrincas. 
A superposição de ciclos de FAC com pequenas amplitudes de deformação inferiores ao limite de fadiga do respectivo material podem contribuir também, para a redução do tempo de vida [32].

O ensaio FTM, é caracterizado pela superposição, de maneira independente e simultânea, de um ciclo de deformação em função do tempo, $\varepsilon(t)$, e um ciclo de temperatura em função do tempo, $T(t)$, segundo uma história termomecânica previamente estabelecida, ver Figura 1. A deformação externa, imposta por uma máquina de ensaio especialmente adaptada. O ensaio é uniaxial e deve ser realizado em baixas frequências, de modo que gradientes de temperatura sejam evitados ao longo do corpo de prova. A deformação total é a soma das parcelas de deformação elástica, plástica e térmica, i. e.:

$$
\varepsilon_{\text {total }}=\varepsilon_{e}+\varepsilon_{p}+\varepsilon_{t}
$$

Apesar de sua complexidade e de seu custo elevado, o ensaio de FTM é mais científico, pois todos os parâmetros de importância para o ensaio são controlados. Entretanto esse ensaio é útil para a caracterização do comportamento mecânico dos materiais mais próximas da realidade (variação térmica do componente), e deste modo, auxiliar no desenvolvimento de modelos matemáticos para o cálculo de tensões e deformações em componentes reais ou em corpos de provas (CP) de FTM [33, 34].

Figura 1 - Tipos de ciclos de fadiga termomecânica aplicados (a) em fase, (b) fora de fase e (c) bi-térmico.

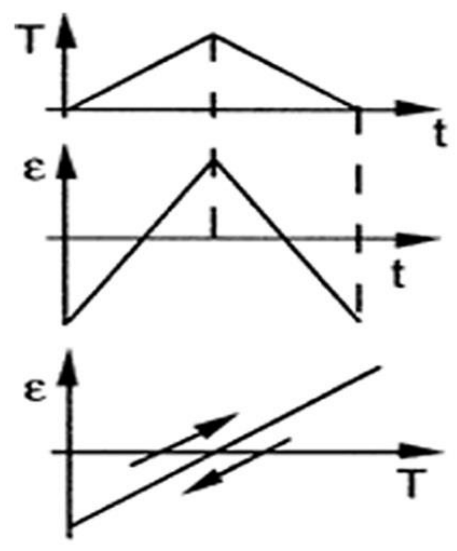

a) Em fase (EF)
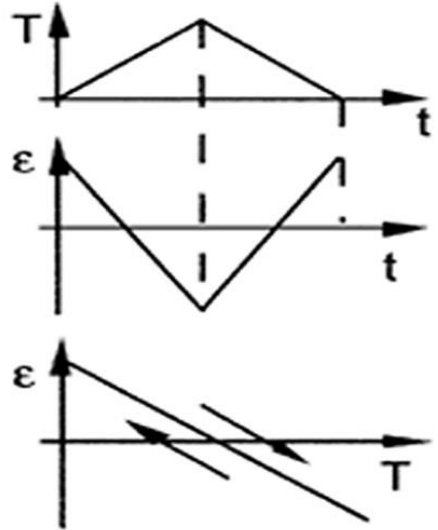

b) Fora de fase (FF)

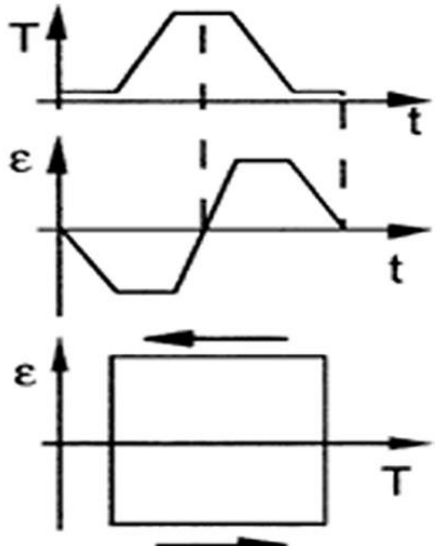

c) Bi-térmico (BT)

Fonte: Adaptado de Engler-Pinto Jr [35]. 


\subsection{Desafios na modelagem do comportamento mecânico}

A fadiga de ferro fundido grafítico é intensamente influenciada pela fração volumétrica de partículas de grafita. Em solicitações trativas essas partículas podem ser consideras como defeitos internos ou até mesmo entalhes. Assim sendo, a iniciação da trinca por fadiga é acelerada pela presença da grafita. As partículas de grafita em ferros fundidos diminui a resistência do material a tração devido a redução da rigidez, uma vez que ocorre delaminação das partículas de grafita da matriz. Em tensões compressivas, as microtrincas são suprimidas, conferindo ao material maior rigidez, sendo caracterizado, portanto como assimétrico em termos de resistência a tração e compressão. Dentre as diversas abordagens para a previsão de vida em FTM, destacam-se três: modelo fenomenológico, modelo de dano cumulativo e modelo de crescimento de trinca. [36]

Se o campo da temperatura transiente no componente é conhecido através de cálculos ou instrumentação, métodos computacionais para previsão de vida em FTM desenvolvem-se em dois principais passos: o campo de temperatura transiente é analisado em elementos finitos para cálculo dos campos de tensão e deformação transiente. Em seguida, as deformações e tensões locais calculadas são inseridas em um modelo de previsão de vida para previsão da vida em fadiga. [37]

Para obter campos de tensão e deformação representativos em simulação, são necessários modelos constitutivos para a descrição da dependência do tempo e temperatura na plasticidade cíclica. Em particular, o modelo viscoplástico oriundo do trabalho de Chaboche [38-40] contempla os fenômenos físicos relevantes (dependência da taxa de deformação, fluência, relaxação e recuperação) assim como o efeito Bauschinger, endurecimento e amolecimento cíclico. Como dito anteriormente, em tensões trativas, as inclusões de grafita fragilizam o material, entretanto em compressão elas são relativamente rígidas, resultando em uma assimetria tensão-compressão do material, onde modelos constitutivos disponíveis em softwares como ABAQUS ${ }^{\circledR} /$ Standard [41] ou ANSYS ${ }^{\circledR}$ [42] não consideram esta assimetria, dependência em tempo e leis de encruamento. A dependência do tempo e temperatura no modelo de plasticidade cíclica para ferros fundidos são objeto de estudos a serem desenvolvidos. [37] 
Um modelo de plasticidade cíclico para ferro fundido em condições de carregamentos termomecânicos precisa combinar características de modelo de plasticidade cíclica, para descrever a resposta do carregamento cíclico, e um modelo de plasticidade poroso, para descrever o efeito da porosidade causado pelas partículas de grafita. O modelo de plasticidade porosa de Gurson [43] descreve o efeito poroso causado pela inclusão de grafita.

Modelos de previsão de vidas para problemas de FTM são raros. Modelos de previsão de vidas puramente fenomenológico, como a relação de Manson-Coffin, o parâmetro de Smith-Watson-Topper ou o parâmetro de Ostergren, geralmente não reproduzem propriamente a dependência do dano no histórico de tensão e temperatura. [37]

Um modelo de previsão de vida em FTM comercialmente disponível é o modelo de Sehitoglu [44-47]. O modelo é implementado pelo pacote de software FEMFAT HEAT, desenvolvido com base em observações microestruturais de dano em experimentos FTM e FBC isotérmicos, incorporando dano cumulativo de fadiga, oxidação e fluência. Dano em fadiga é descrito pela relação Mason-Coffin. O crescimento de trinca induzido por oxidação é descrito pela repetição da formação da camada de óxido (crescimento parabólico de oxidação) e sua ruptura, expondo uma nova camada de material metálico ao ambiente. $O$ dano em fluência na forma de cavidades de fluência em contornos de grãos é modelado com uma lei fenomenológica. A previsão de vida em FBC e FTM de aço, superligas com base em níquel e ligas de alumínios são representativas utilizando o modelo de Sehitoglu [42], porém esta demanda um número relativamente grande de parâmetros do material os quais sua obtenção é uma tarefa não trivial e onerosa. Ademais, o dano mecânico em componentes de motores de combustão, nomeados de fadiga de crescimento de trinca, é modelado puramente fenomenologicamente carecendo, portanto, de estudos e equações mais elaboradas.

Os modelos de previsão de vida devem referir aos atuais mecanismos de dano. O tempo de ciclo de combustão do motor é relativamente pequeno, então os danos por fluências são minoritários. Entretanto, altas amplitudes de deformação surgem nestas aplicações devido à restrição da deformação térmica, então a trinca nucleia nos primeiros estágios de vida, normalmente nos planos de deslizamento na superfície ou nas inclusões da superfície. Então o mecanismo de limitação da vida é 
o crescimento das trincas em carregamentos mecânicos cíclicos [48,49]. A taxa de crescimento da trinca é dependente do tempo do ciclo, amplitude de deformação, tensão média, temperatura e meio. [50-52]

\subsection{Modelos da plasticidade}

A teoria da plasticidade é usada para calcular deformações permanentes de estruturas, prever o colapso plástico de estruturas, investigar a estabilidade, calcular forças necessárias em operações de conformação de metal, etc. [53]

A teoria da plasticidade é a teoria matemática das deformações irreversíveis independentes do tempo, para metais e suas ligas, envolve principalmente 0 movimento de discordâncias sem a influência de fenômenos viscosos ou a presença de descoesão que danifica o material. Seu domínio de validade é, portanto, restrito pelas duas limitações a seguir:

- Uso em baixa temperatura: uma convenção estimada é limitar a temperatura de uso do modelo a um quarto da temperatura de fusão absoluta do material em consideração; [53]

- Cargas que não gerem dano: para cargas monotônicas, as deformações devem permanecer abaixo de aproximadamente metade das que estão em fratura. Para cargas cíclicas, o limite depende da condição de estabilização. A plasticidade cíclica é aplicável sem modificação, desde que o número de ciclos permaneça abaixo do número que corresponde à estabilização (meia vida). [53]

Essas limitações apenas dão indícios. Em um problema de viscoplasticidade, por exemplo, se é conhecido a priori que o processo de deformação ocorre com um campo de deformação quase uniforme, é possível resolver este problema pela teoria da plasticidade independente do tempo, desde que equação constitutiva seja identificada por experimentos conduzidos na taxa de deformação considerada e (e na temperatura considerada). Em contraste, o relaxamento do aço à temperatura ambiente (evoluindo em função do tempo) só pode ser explicado por uma teoria elastoviscoplástica. [53] 


\subsection{Encruamento}

No nível físico, o encruamento é devido a um aumento na densidade de discordâncias: as discordâncias têm uma tendência a se interligar e bloquear um ao outro. Na primeira aproximação, o aumento do limite de escoamento segue o aumento da tensão, e é essa aproximação que constitui a base teórica da plasticidade clássica. Assim, para carregamento monotônico, o limite de escoamento atual, também chamado de limite de plasticidade ou tensão de escoamento, é igual ao valor mais alto da tensão anteriormente alcançada. Para um material com encruamento positivo, $d \sigma / d \varepsilon_{p}>0$, a tensão de escoamento 'natural' $\sigma_{Y}$ é o menor valor da tensão de escoamento aparente (que é uma função da história das deformações plásticas). [53]

No caso unidimensional (teste uniaxial), uma amostra deformará até o limite de escoamento e então encrua que está representada na Figura 2. Também é mostrada na figura a idealização de uma deformação perfeitamente plástica. No caso perfeitamente plástico, uma vez que a tensão atinge o ponto de escoamento $(A)$, ocorre deformação plástica, desde que a tensão seja mantida em Y. Se a tensão é reduzida, tem-se um descarregamento elástico.

No caso de encruamento, uma vez que o escoamento ocorre, a tensão precisa ser crescente para impulsionar a deformação plástica. Se a tensão for mantida constante, por exemplo, em B, nenhuma deformação plástica adicional ocorrerá; ao mesmo tempo, não haverá descarregamento elástica. Esta condição não pode ocorrer no caso perfeitamente plástico, pois neste caso só pode ocorrer uma deformação plástica ou um descarregamento elástico.

Essa ideia pode ser estendida a casos multiaxial, onde a superfície de escoamento inicial pode ser da forma da Equação 2:

$$
f_{0}\left(\sigma_{i j}\right)=0
$$

onde $\sigma_{i j}$ é o tensor de tensão. No caso perfeitamente plástico, a superfície de encruamento permanece inalterada. No caso mais geral, a superfície de escoamento pode mudar de tamanho, forma e posição, e pode ser descrita por: 
Figura 2 - Curva de tensão-deformação uniaxial para um metal típico.

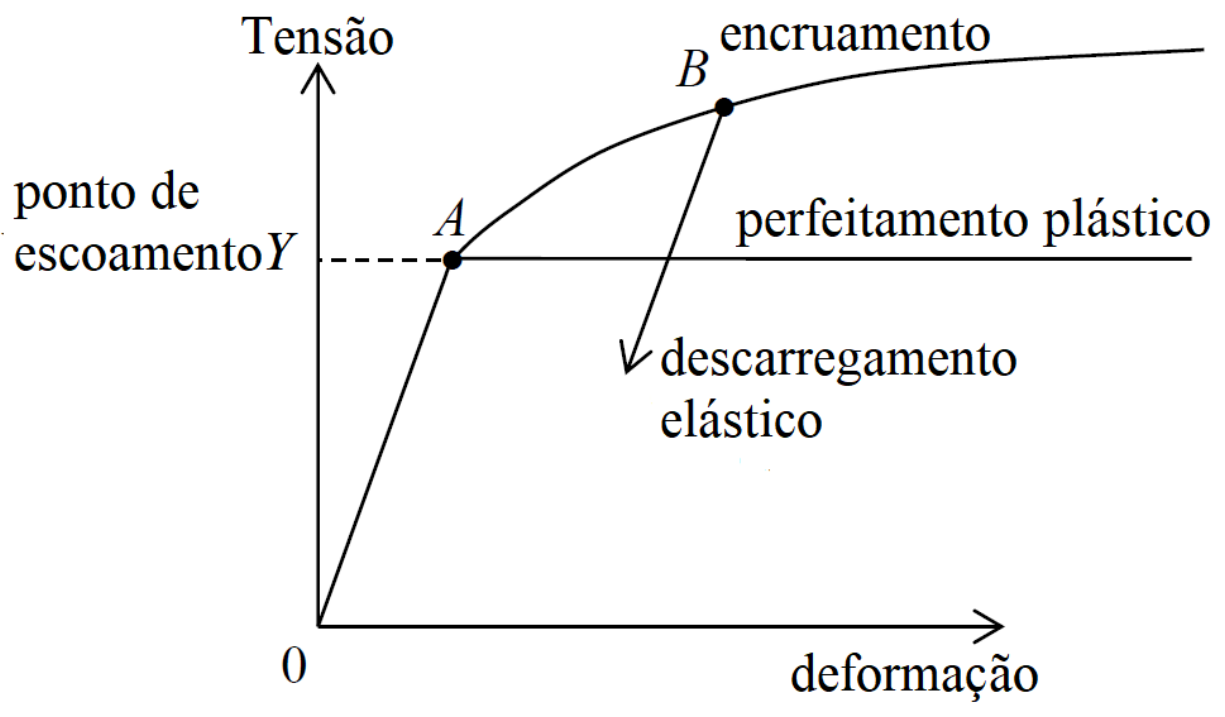

Fonte: Adaptado de Kelly, PA [54]

$$
f\left(\sigma_{i j}, W_{i}\right)=0
$$

Onde $W_{i}$ representa um ou mais parâmetros de encruamento, que mudam durante a deformação plástica e determinam a evolução da superfície de escoamento. Eles podem ser escalares ou tensores de ordem superior. No primeiro encruamento, os parâmetros de encruamento são zero, e $f\left(\sigma_{i j}, 0\right)=f_{0}\left(\sigma_{i j}\right)$.

A descrição de como a superfície de encruamento muda com a deformação plástica, Equação 3, é chamada de lei de encruamento que pode ser escrita como:

$$
\sigma_{s}=g^{-1}\left(\varepsilon_{p}\right)
$$

onde $\sigma_{s}$ é a de tensão de escoamento e $\varepsilon_{p}$ é a deformação plástica. Uma série de expressões analíticas foram propostas para modelar a função de encruamento. Usaremos a que resulta de um cálculo baseado na teoria de deslocamento, na qual tensão de escoamento é proporcional à raiz quadrada da densidade de deslocamentos $\rho_{d}$, i. e.:

$$
\sigma_{s}=k b \rho_{d}^{1 / 2}
$$


$\mathrm{Na}$ realidade, a densidade de deslocamentos nunca é zero. Assim, deixando $p_{d_{0}}$ ser a densidade de deslocamento no estado inicial correspondente ao limite elástico $\sigma_{Y}$, podemos escrever como na Equação 6:

$$
\sigma_{s}=\sigma_{Y}+k b\left(\rho_{d}-\rho_{d_{0}}\right)^{1 / 2}
$$

Em termos de deformações macroscópicas, podemos, em analogia com a relação acima, escrever o modelo proposto por Ramber-Osgood, que está representado na Figura 3:

$$
\sigma_{s}=\sigma_{Y}+K_{Y} \varepsilon_{p}^{1 / M_{Y}}
$$

Figura 3 - Identificação dos coeficientes de encruamento característicos do aço $316 \mathrm{~L}$ à temperatura ambiente.

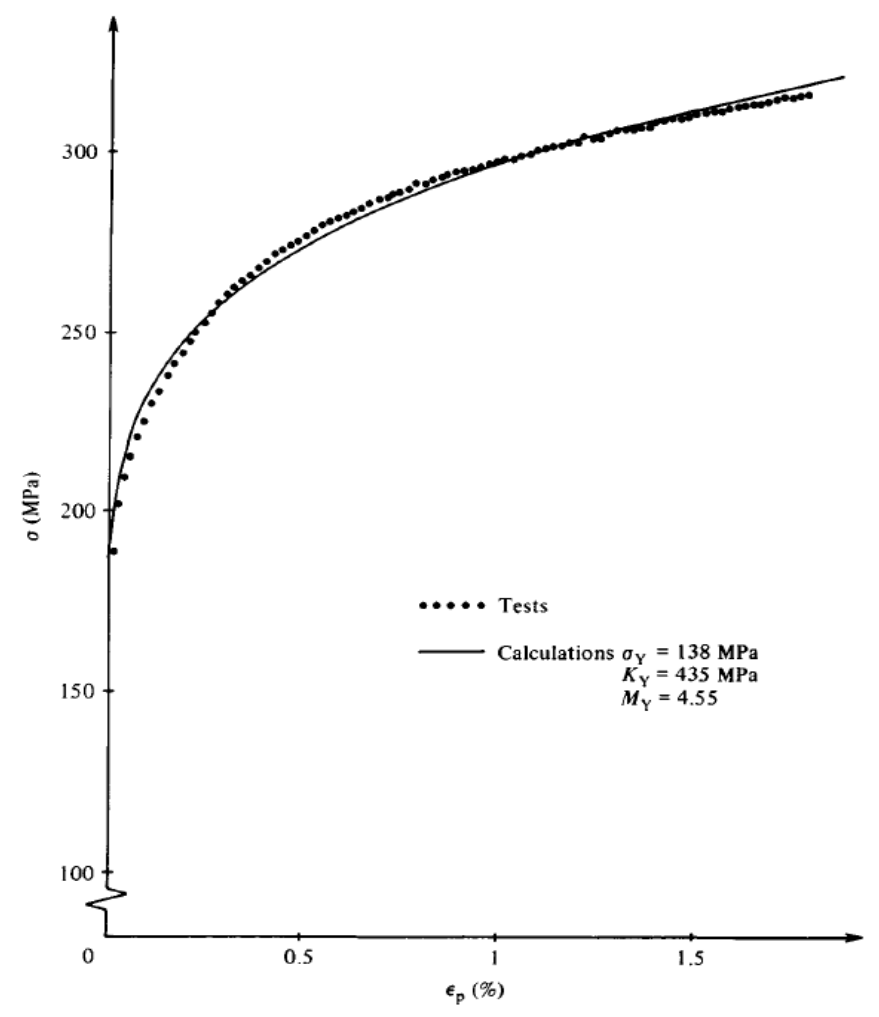

Fonte: Lemaitre J, Chaboche J. L. [53]

Reescrevendo a Equação 7, tem-se: 


$$
\sigma_{S}=\sigma_{Y}\left(1+K_{0} \varepsilon_{p}^{n}\right)
$$

3.5.1 Lei de encruamento isotrópico.

O encruamento isotrópico é aquele em que a superfície de escoamento permanece da mesma forma, mas se expande com o aumento da tensão, Figura 4.

Figura 4 - Encruamento isotrópico.

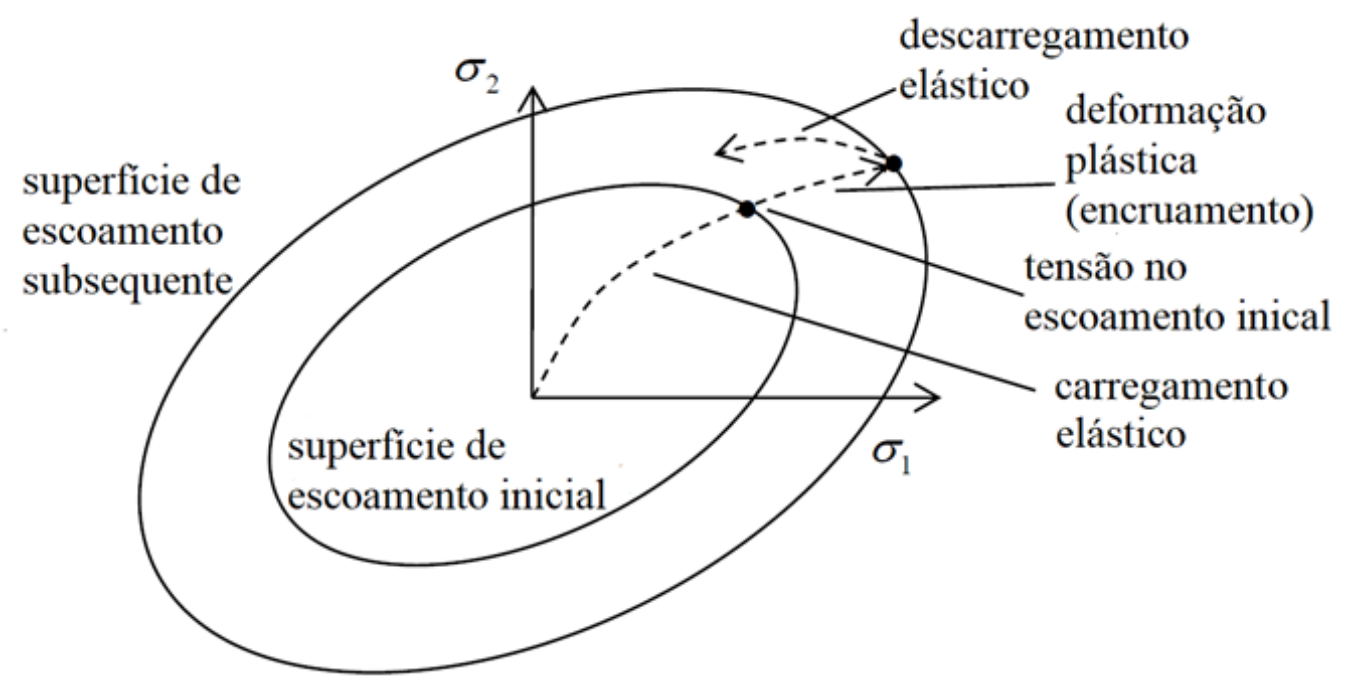

Fonte: Adaptado de Kelly, PA [54].

A forma da função de escoamento é especificada pela função de escoamento inicial e seu tamanho muda à medida que o parâmetro de encruamento $\mathrm{W}$ muda. Em particular a função do escoamento toma a forma da Equação 9:

$$
f\left(\sigma_{i j}, K_{i}\right)=f_{0}\left(\sigma_{i j}\right)-W=0
$$




\subsubsection{Lei de encruamento cinemático}

O modelo isotrópico implica que, se a tensão de escoamento em tensão e compressão forem inicialmente as mesmas, isto é, a superfície de escoamento é simétrica em relação aos eixos de tensão, elas permanecem iguais à medida que a superfície de escoamento se desenvolve com tensão plástica. Para modelar o efeito de Bauschinger e respostas similares, onde um encruamento em tensão levará a uma redução na tensão de escoamento em uma compressão subsequente, pode-se usar a regra de encruamento cinemático. [54] É onde a superfície de escoamento permanece da mesma forma e tamanho, mas se translada apenas no espaço de tensão, conforme a Figura 5.

Figura 5 - Encruamento cinemático.

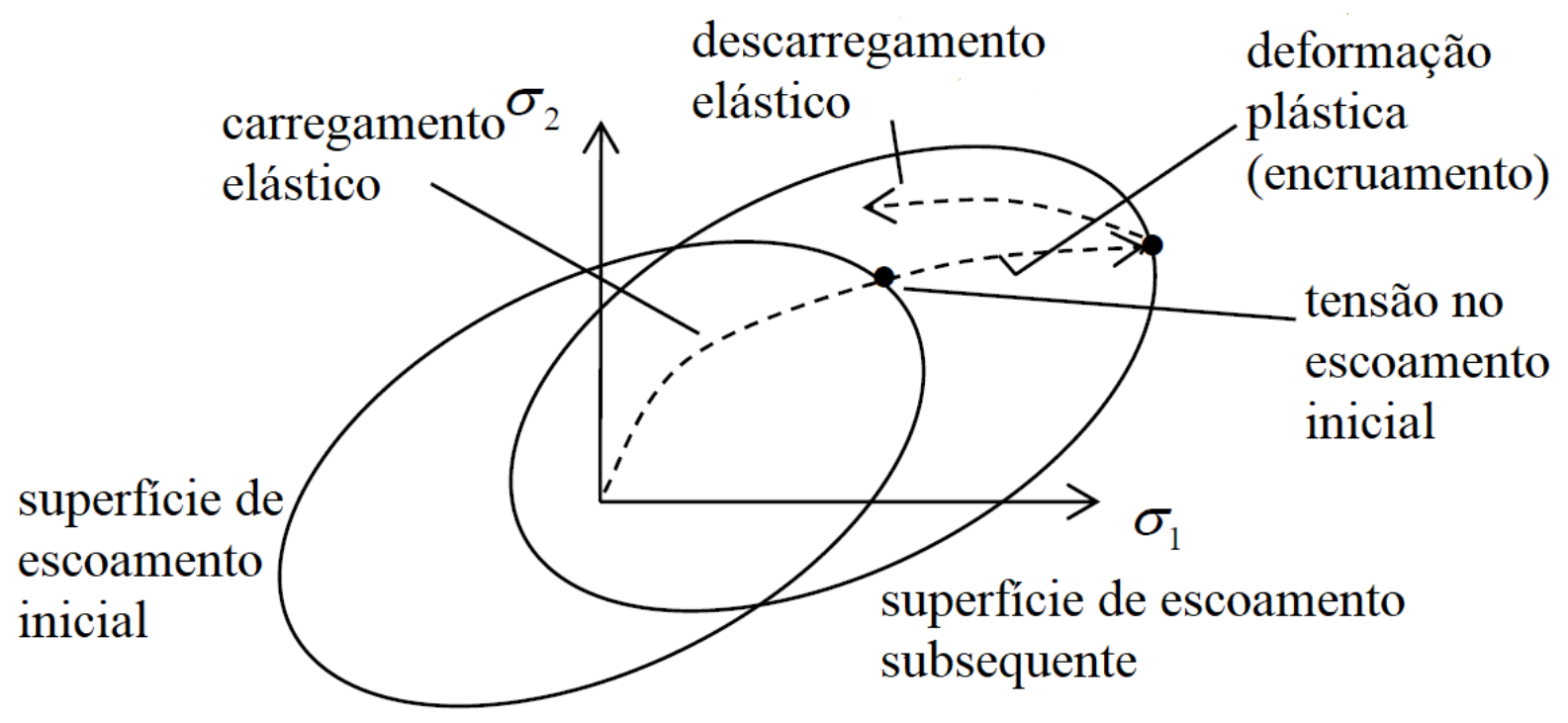

Fonte: Adaptado de Kelly, PA [54].

A função de encruamento agora assume a forma geral da Equação 10:

$$
f\left(\sigma_{i j}, K_{i}\right)=f_{0}\left(\sigma_{i j}-\alpha_{i j}\right)=0
$$

O parâmetro de encruamento aqui é a tensão $\alpha_{i j}$, conhecido como "backstress" ou tensão de deslocamento; a superfície de encruamento é deslocada em relação aos eixos do espaço de tensão por $\alpha_{i j}$. 


\subsubsection{Lei de encruamento combinado.}

Leis de encruamentos mais complexas podem ser usadas. Por exemplo, a regra de encruamento combinado que combina características dos modelos de encruamento isotrópico e cinemático, e a função de carregamento assume a forma geral:

$$
f\left(\sigma_{i j}, K_{i}\right)=f_{0}\left(\sigma_{i j}-\alpha_{i j}\right)-W=0
$$

Agora os parâmetros de encruamento são a escalar $W$ e o tensor $\alpha_{i j}$.

\subsection{Formas de inserção dos parâmetros do modelo no Abaqus ${ }^{\circledR}$}

No modelo de plasticidade para metais sujeitos a cargas cíclicas no Abaqus ${ }^{\circledR}$ estão disponíveis as leis de encruamento cinemático, isotrópico e combinado. Na lei de encruamento combinado pode ser inserido os dados do material de diversas formas. Essa seção será discutida essas formas.

\subsubsection{Inserção de dados: parametrizado}

A lei de evolução deste modelo consiste em dois componentes: um componente de encruamento cinemático não-linear, que descreve a translação da superfície de escoamento no espaço de tensão através do "backstress", $\alpha$; e um componente de encruamento isotrópico, que descreve a alteração da tensão equivalente que define o tamanho da superfície de escoamento, $\sigma_{0}$, como uma função da deformação plástica. [55]

Vários componentes de encruamento cinemático ("backstress") podem ser sobrepostos, o que pode melhorar consideravelmente os resultados em alguns casos. Quando as dependências de variáveis de temperatura e campo são omitidas, as leis de encruamento para cada "backstress" são: 


$$
\dot{\alpha}_{k}=C_{k} \frac{1}{\sigma_{0}}(\sigma-\alpha) \dot{\varepsilon}^{p l}-\gamma_{k} \alpha_{k} \dot{\varepsilon}^{p l}
$$

E o "backstress" geral é calculado a partir da relação do somatório:

$$
\alpha=\sum_{k=1}^{N} \alpha_{k}
$$

onde $N$ é o número de "backstress" e $C_{k}$ e $\gamma_{k}$ são parâmetros de material que devem ser calibrados a partir de dados de teste cíclicos. $C_{k}$ são os módulos iniciais de encruamento cinemático, e $\gamma_{k}$ determina a taxa na qual os módulos de encruamento cinemático diminuem com o aumento da deformação plástica. A Figura 6 mostra um exemplo de encruamento cinemático não-linear com três "backstress".

Figura 6 - Modelo de encruamento cinemático com três "backstress".

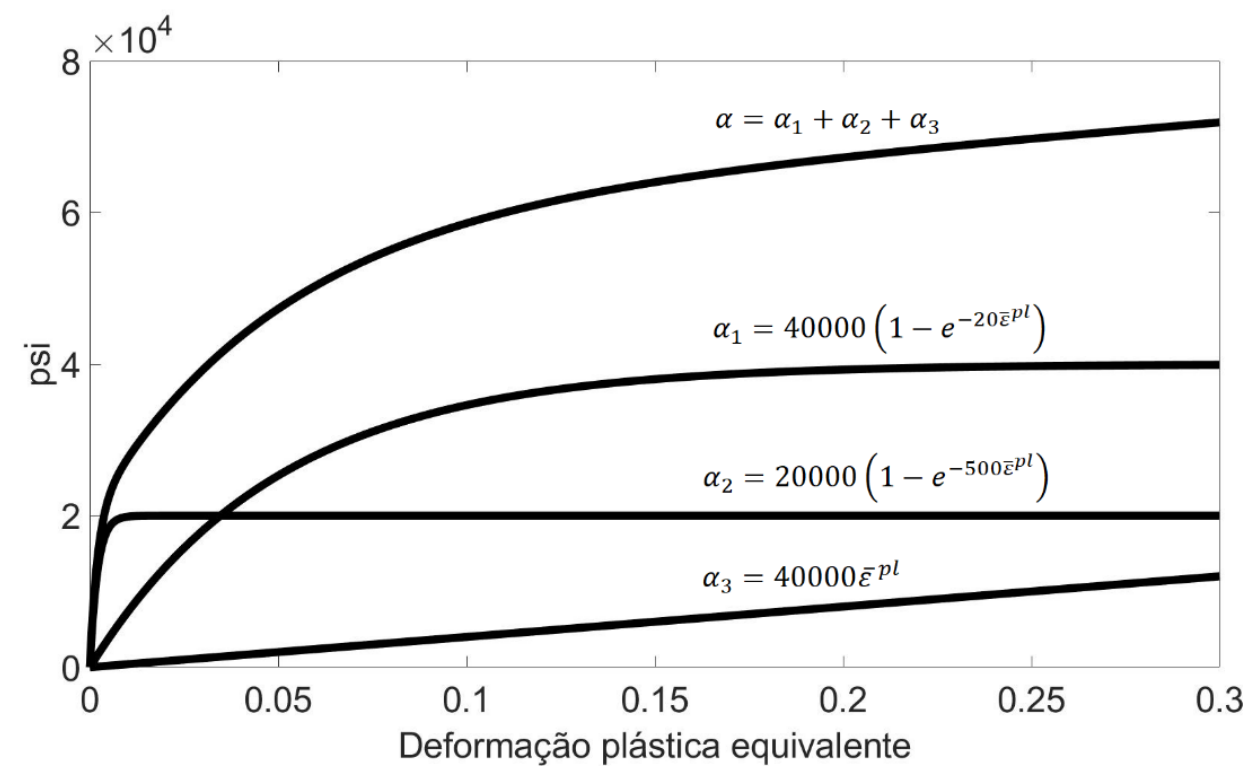

Fonte: Adaptado de Abaqus $^{\circledR}[55]$

\subsubsection{Inserção de dados: Meia vida}

Se as quantidades de ensaio são limitadas, $C_{k}$ e $\gamma_{k}$ podem ser baseados nos dados de tensão-deformação obtidos no ciclo de meia vida de uma experiência de tensão unidirecional ou compressão. Um exemplo de tais dados de teste é mostrado 
na Figura 7. Essa abordagem é geralmente adequada quando a simulação envolverá apenas alguns ciclos de carregamento. [55]

Figura 7 - Exemplo de dados de tensão e deformação de meia vida.

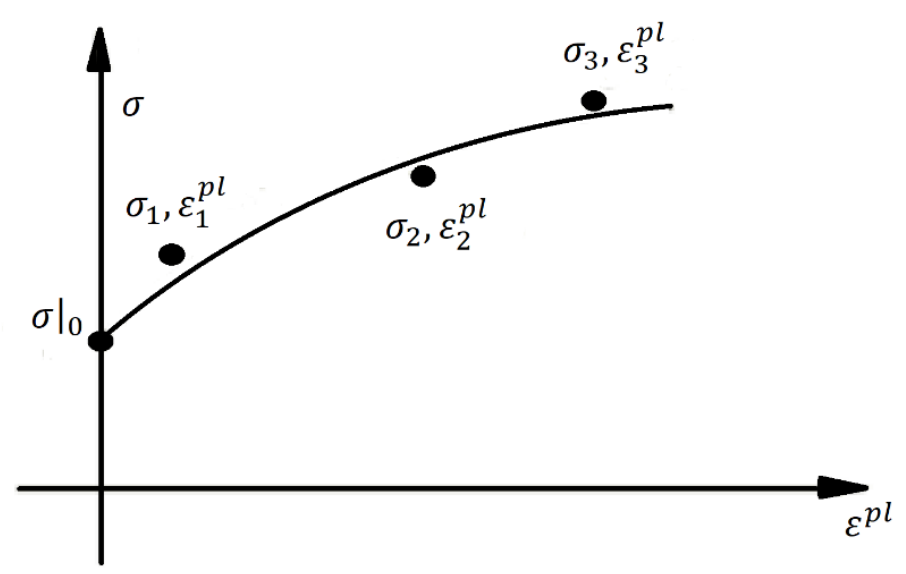

Fonte: Adaptado de Abaqus ${ }^{\circledR}[55]$

No software os dados são inseridos em forma de tabela, e os parâmetros $C_{k}$ e $\gamma_{k}$ são obtidos pelo software.

3.6.3 Inserção de dados: estabilizado

Os dados de tensão-deformação podem ser obtidos a partir do ciclo estabilizado de uma amostra que é submetida a ciclos de deformação simétricos. Um ciclo estabilizado é obtido pelo ciclo da amostra ao longo de uma faixa de deformação fixa $\Delta \varepsilon$ até que uma condição de estado estacionário seja alcançada; isto é, até que a curva tensão-deformação não mude mais de um ciclo para o outro. Esse ciclo estabilizado é mostrado na Figura 8.

No software é inserido os dados em forma de tabela, e os parâmetros $C_{k}$ e $\gamma_{k}$ são obtidos no próprio software. 
Figura 8 - Exemplo de dados de curva tensão deformação estabilizado.

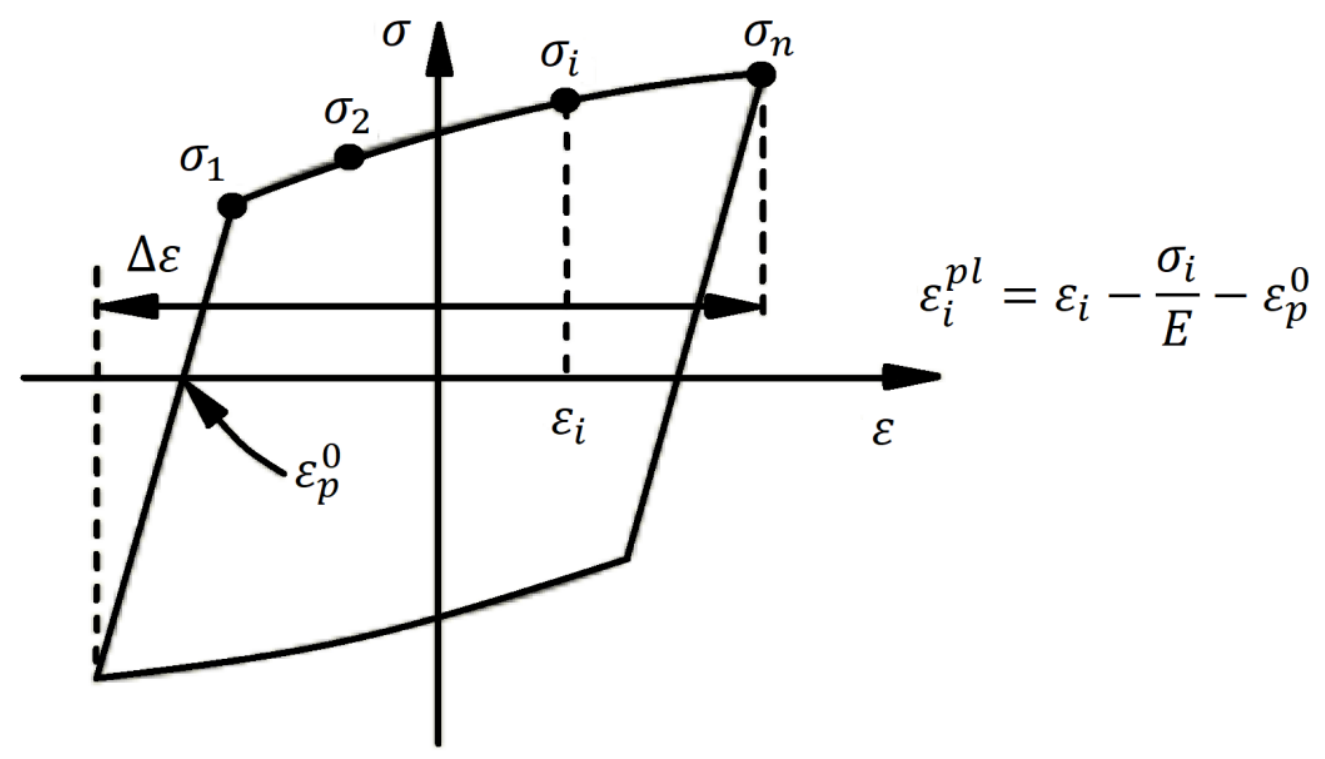

Fonte: Adaptado de Abaqus ${ }^{\circledR}[55]$

\subsection{Combinação de modelos constitutivos}

Abaqus $^{\circledR}$ fornece diversas relações constitutiva para descrever os comportamentos mecânico dos materiais. Um material é definido escolhendo os comportamentos apropriados para 0 propósito de uma análise. Alguns comportamentos dos materiais no Abaqus $^{\circledR}$ requerem a presença de outros comportamentos de materiais por exemplo, o comportamento de plasticidade requer a definição do comportamento elástico. Em alguns casos alguns comportamentos excluem o uso de outros comportamentos por exemplo uma equação de estado exclui todos os outros comportamentos de plasticidade independentes do tempo. [55]

Os comportamentos são atribuídos a categorias porque as exclusões são melhor descritas em termos dessas categorias. Algumas das categorias exigem explicação:

- "Comportamentos mecânicos completos" são aqueles comportamentos no Abaqus $^{\circledR}$ que, individualmente, definem completamente 0 comportamento mecânico do material (tensão-deformação). Um comportamento nessa categoria, portanto, exclui qualquer outro comportamento desse tipo e também exclui qualquer 
comportamento que defina parte do comportamento mecânico de um material: os comportamentos que pertencem às categorias elasticidade e plasticidade. [55]

- "Elasticidade, tecido e equação de comportamentos de estado" contém todos os comportamentos básicos de elasticidade no Abaqus ${ }^{\circledR}$. Se um comportamento da categoria "Comportamentos mecânicos completos" não for usado e o comportamento mecânico for necessário, um comportamento deve ser selecionado dessa categoria. Esta seleção então exclui qualquer outro comportamento de elasticidade. [55]

- "Aprimoramentos para comportamentos de elasticidade" contém comportamentos que estendem a modelagem fornecida pelos comportamentos de elasticidade do Abaqus $^{\circledR}$. [55]

- "Comportamentos de plasticidade independentes de taxa" contém todos os comportamentos básicos de plasticidade em Abaqus ${ }^{\circledR}$, exceto a plasticidade de deformação, que está na categoria "Comportamentos mecânicos completos" porque define completamente o comportamento mecânico do material. [55]

- "Comportamentos de plasticidade dependentes da taxa" contém comportamentos que estendem a modelagem fornecida pelos comportamentos de plasticidade independentes da taxa e pelo comportamento do material elástico linear. [55]

Neste caso é possível realizar a combinação do comportamento viscoplástico (Comportamentos de plasticidade dependentes da taxa) com o plástico (Comportamentos de plasticidade independentes de taxa) e elástico (Elasticidade, tecido e equação de comportamentos de estado), porém o modelo viscoelástico linear (Aprimoramentos para comportamentos de elasticidade) não é possível ser combinado com o modelo plástico pois o modelo viscoelástico não aceita a combinação com o plástico. [55]

\subsection{Previsão de vida em fadiga}

O trabalho de Zhang, et al. [56], propôs uma equação para previsão de vida em fadiga onde utilizava-se a energia de histerese de meia vida de ensaios de FBC e FTM para calibração do modelo de previsão de meia vida. A histerese de meia vida 
do ensaio de FBC utilizado neste trabalho foi na temperatura máxima de trabalho do ensaio de FTM, por exemplo se a variação utilizado no ensaio de FTM foi de 120 a $350^{\circ} \mathrm{C}$, o ensaio de $\mathrm{FBC}$ foi realizado a $350^{\circ} \mathrm{C}$ para o cálculo da energia de histerese.

Outra proposta de previsão de fadiga é o qual foi utilizado uma abordagem baseada na interligação de Morrow entre uma curva cíclica de tensão-deformação e a inclinação da curva de Wöhler [57]. A viabilidade deste método para carregamentos FBC, FAC e FTM-FF de ferro fundido nodular FFN-600 em uma ampla faixa de temperatura, foi apresentado em publicações de Jost, et al. [58-62]. Nestes trabalhos, a inclinação das curvas Wöhler é descrita usando dados de apenas um teste de deformação incremental de nome PhyBaLSIT (physically based fatigue life calculation method).

O método de cálculo da vida em fadiga, PhyBaLSIT, possibilita a avaliação das curvas de Wöhler para fadiga em controle de deformação, nos regimes de FBC e FAC com base em dados de fadiga determinados em acréscimos de deformação e testes de amplitude constante. As curvas de deformação total de Wöhler mostram uma mudança na inclinação entre o regime FAC e FBC, que pode ser descrita pelas equações:

$$
\begin{aligned}
& \varepsilon_{a, t}=\varepsilon_{B, M(F A C)}^{\prime}\left(2 N_{f}\right)^{b_{M}} \\
& \varepsilon_{a, t}=\varepsilon_{B, M(F B C)}^{\prime}\left(2 N_{f}\right)^{c_{M}}
\end{aligned}
$$

onde $\varepsilon_{a, t}$ representa a amplitude total de deformação, $\varepsilon_{B, M(F B C)}^{\prime}$ é o coeficiente de ductilidade da fadiga no regime de FBC, $\varepsilon_{B, M(F A C)}^{\prime}$ é o coeficiente de resistência de fadiga no regime de FAC, $N_{f}$ é o número de ciclos para a falha, $b_{M}$ é o expoente da resistência de fadiga generalizada e $c_{M}$ é o expoente de ductilidade de fadiga generalizada.

Enquanto no trabalho envolvendo FTM-FF [52] utilizou-se do mesmo princípio da Equação 15 onde a deformação total $\left(\varepsilon_{a, t}^{m e}\right)$ é a deformação mecânica total que o material é submetido representado na Equação 16.

$$
\varepsilon_{a, t}^{m e}=\varepsilon_{B, M(F B C)}^{\prime F T M}\left(2 N_{f}\right)^{c_{M(F T M)}}
$$




\section{METODOLOGIA}

\subsection{Material}

O material utilizado neste trabalho é um ferro fundido vermicular, FFV, da classe 450, retirado de cabeçotes de motores produzido pela Fundição Tupy. $O$ material foi obtido de cabeçotes de 13 litros, da face de combustão, da linha de produção da Fundição TUPY, seguindo todo o seu processo de controle de qualidade para assegurar a homogeneidade do material e atender as normas de classe do ferro fundido. A matriz é perlítica e a estrutura grafítica do vermicular com alguma nodularidade entre 7 e 10\%. A Figura 9 mostra uma microestrutura típica.

Figura 9 - Microestrutura do FFV testado nos experimentos, na imagem da esquerda apresenta o material sem ataque químico enquanto na imagem da direita com ataque.
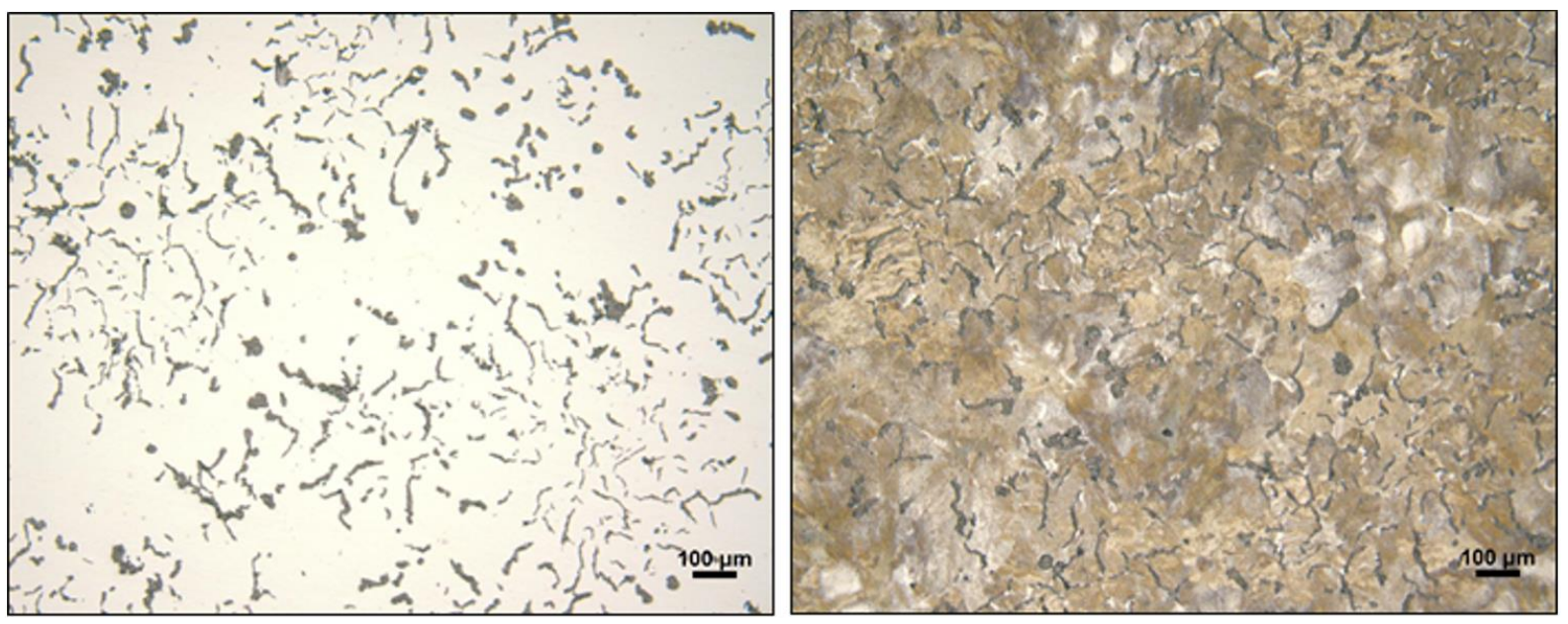

Fonte: Fundição Tupy.

\subsection{Equipamentos utilizados nos ensaios e CP}

Os ensaios foram realizados em um sistema universal de ensaios mecânicos da marca MTS, modelo 810, com capacidade de $250 \mathrm{kN}$, que possui garras especiais de superliga de níquel, sistema de refrigeração da garra e forno indutivo de alta 
frequência com bobinas de cobre para aquecimento dos corpos de prova. O sistema está esquematizado na Figura 10 e representado na Figura 11.

Figura 10 - Esquema representando o sistema de ensaio

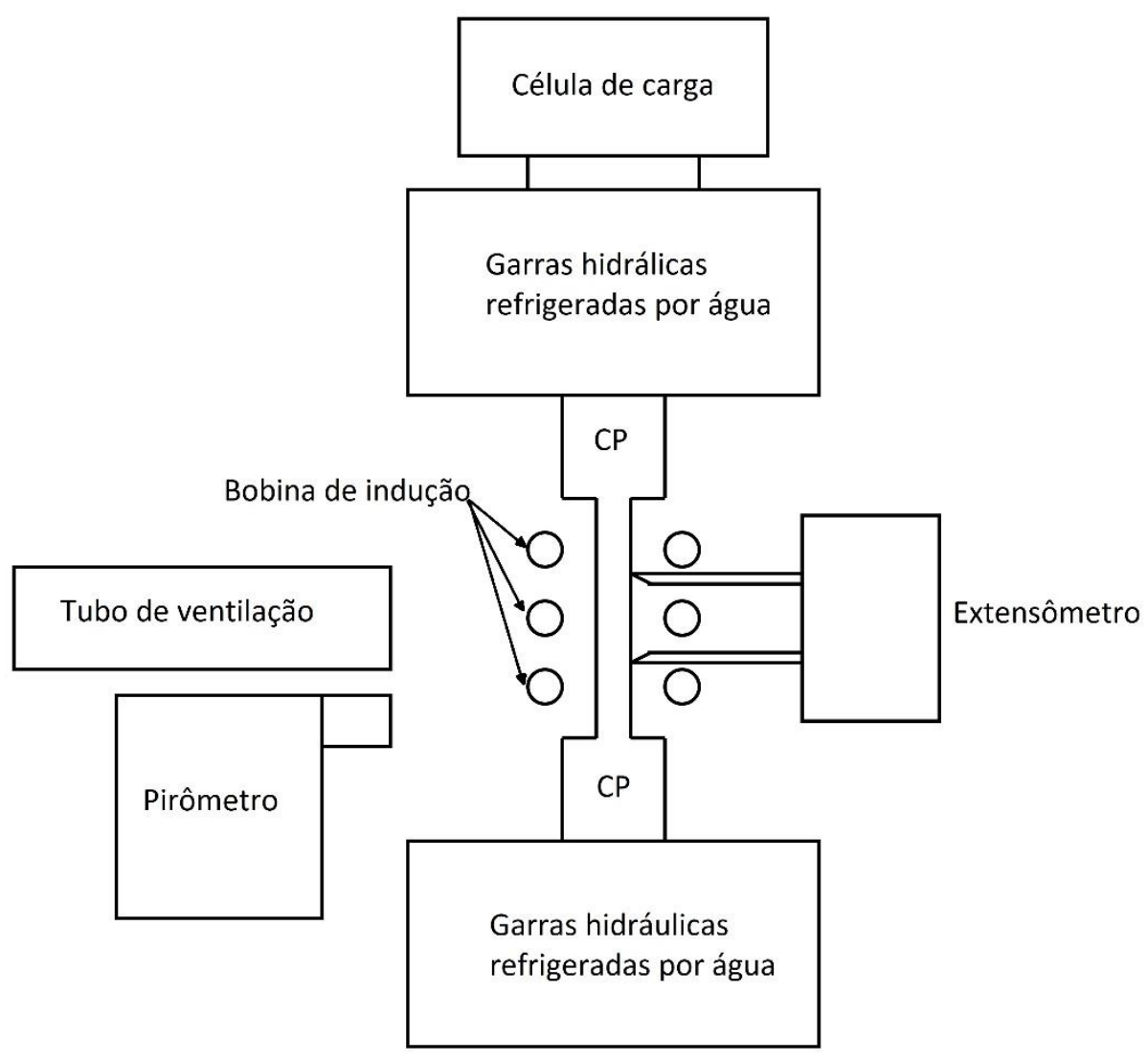

Fonte: Produção do próprio autor.

O sistema de aquecimento com forno indutivo possui frequência de $200 \mathrm{kHz}$ e potência de $7,5 \mathrm{~kW}$, da marca INDUCTOHEAT, que está interligado a um controlador de temperatura programável do tipo EUROTHERM. O aquecimento é feito por um indutor do tipo bobina, feita de cobre com filamento tubular de $5 \mathrm{~mm}$ de diâmetro, que circula água internamente para a sua refrigeração. O projeto desta bobina tem como principal característica a homogeneidade da temperatura na seção útil do corpo de prova e prover espaço entre as espiras para possibilitar a entrada das hastes do extensômetro.

O extensômetro de marca MTS, modelo 632.54F-14, com hastes de cerâmica e temperatura de trabalho de até $1200^{\circ} \mathrm{C}$, possui comprimento útil de $12 \pm 2,4 \mathrm{~mm}$ e 
mede a deformação axial do corpo de prova, de classe de acuracidade de 0,5. A célula de carga de marca MTS, modelo 661.20F-03, com capacidade de força de $100 \mathrm{kN}$ e precisão de $0,01 \mathrm{kN}$.

Figura 11 - Máquina de ensaio MTS com (A) tubo de ventilação, (B) pirômetro, (C) garras refrigeradas, $(D)$ bobina de indução e $(E)$ extensômetro

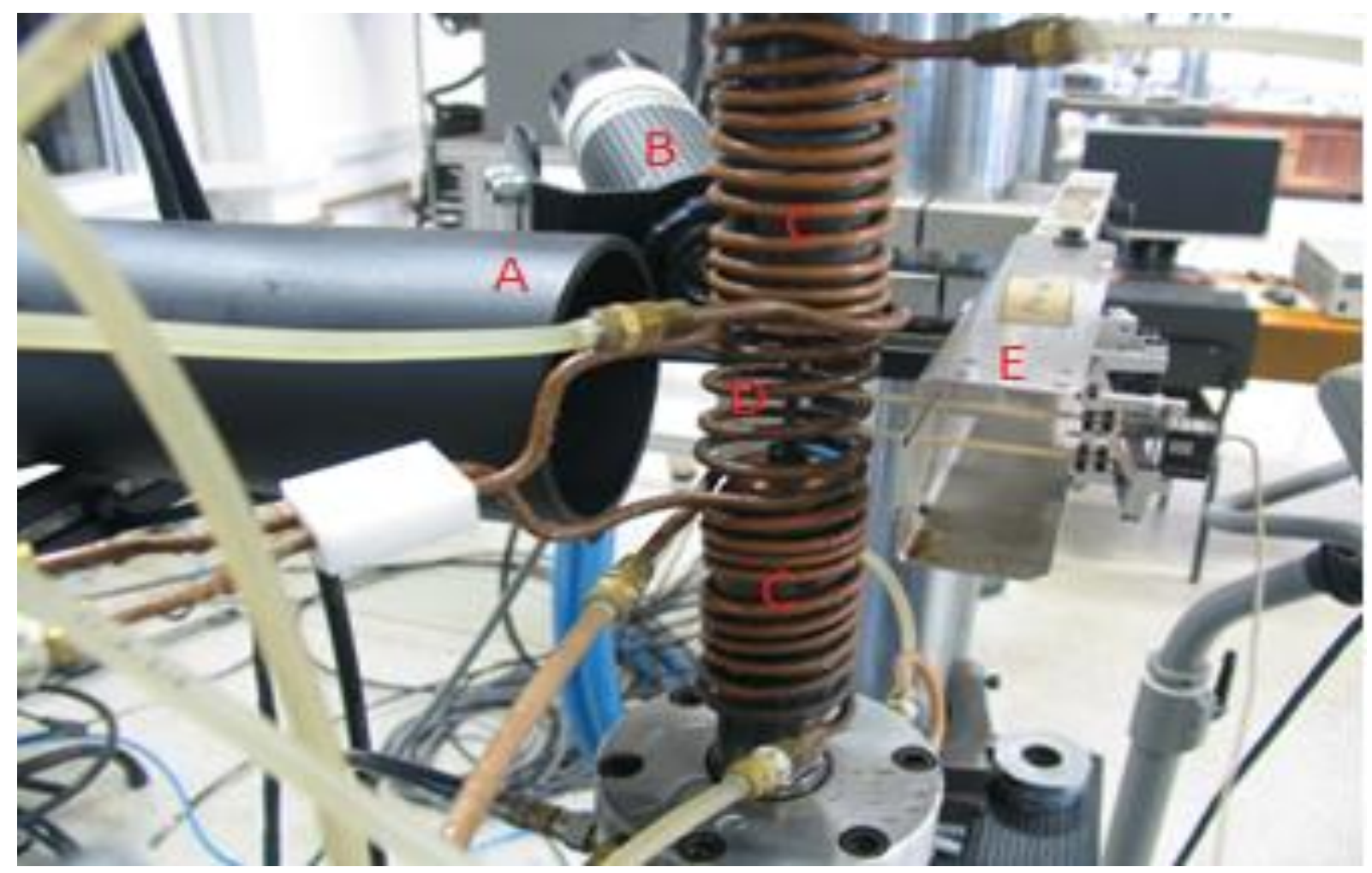

Fonte: Produção do próprio autor.

A medição da temperatura no corpo de prova durante o ensaio foi realizada por um pirômetro ótico infravermelho de marca RAYTEK modelo RAYSXSMTCF1L2, com faixa de trabalho de -18 a $500 \pm 2{ }^{\circ} \mathrm{C}$, posicionando a mira laser no centro do corpo de prova. Ainda dois termopares de cromel-alumel foram fixados no corpo de prova para garantia da homogeneidade da temperatura no comprimento útil deste. $\mathrm{O}$ sistema de refrigeração contém duas bobinas que estão em contato com as garras que circula líquido refrigerante e um soprador de ar.

Os ensaios de fadiga isotérmica, fadiga termomecânica, ensaio de carregamento cíclico crescente utilizaram os corpos de provas $(\mathrm{CP})$ que estão representados com suas dimensões na Figura 12. 
Figura 12 - Corpo de prova utilizado no ensaio de tração, fadiga isotérmica e termomecânica.

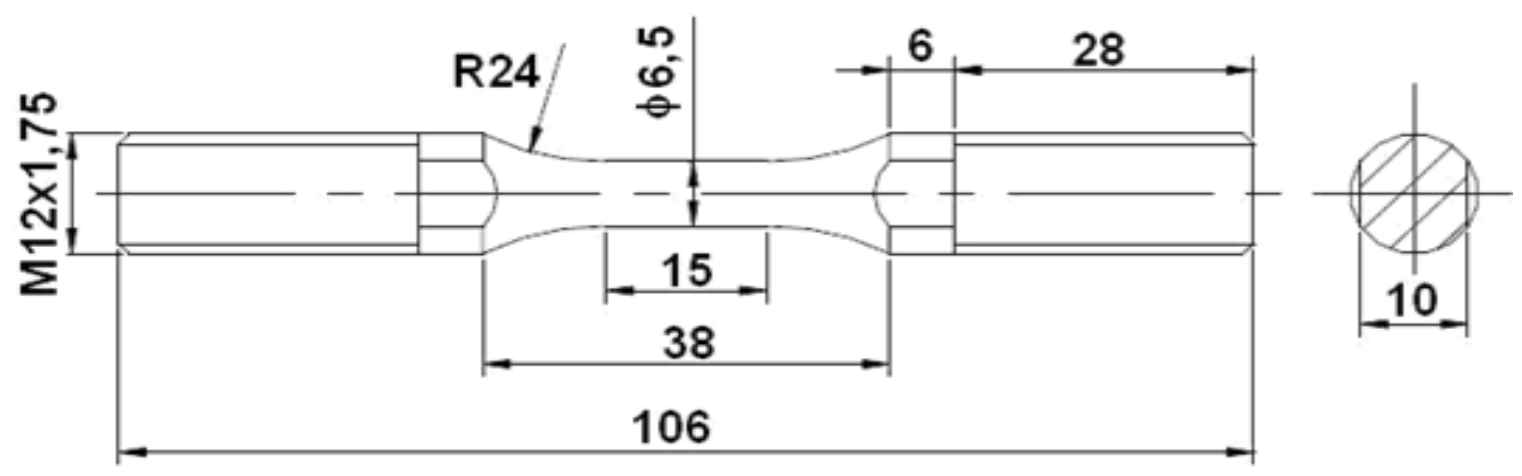

Fonte: ASTM E606-00 [63].

\subsection{Ensaio de tração}

Os ensaios de tração foram executados conforme a metodologia para ensaios de tração de materiais metálicos, em temperatura ambiente e elevadas, respectivamente das normas ASTM E8/E8M-16A [64] e ASTM E21 [65].

O ensaio de tração é realizado em controle de deformação com uma taxa de deformação do extensômetro de $0,016 \mathrm{~s}^{-1}$, essa taxa é mantida até a ruptura do CP. Foram realizados ensaio nas temperaturas de $50,150,250,350$ e $420^{\circ} \mathrm{C}$, sendo que em cada temperatura realizou-se quatro ensaios, foi mantido a temperatura no CP durante 5 minutos para garantir a sua estabilização, sendo imediatamente ensaiados após esse tempo.

\subsection{Ensaio de fadiga isotérmica}

O método escolhido para o ensaio foi o de fadiga com controle de deformação, para a obtenção da curva de encruamento cíclico que consiste no aumento gradativo da deformação imposta ao corpo de prova até atingir a deformação máxima definida, então a deformação diminui gradativamente até atingir a deformação mínima definida, registrando uma histerese estável para cada nível de deformação utilizado, conforme a Figura 13 representa um ensaio de fadiga por controle de deformação com razão $\mathrm{R}=$ 
-1, ou seja a deformação máxima aplicada é igual a deformação mínima aplicada em módulo.

Figura 13 - Ensaio característico de fadiga isotérmica em controle de deformação, a) histerese do ensaio (Tensão x deformação), b) deformação conforme o tempo, c) Tensão encontrada no ensaio.
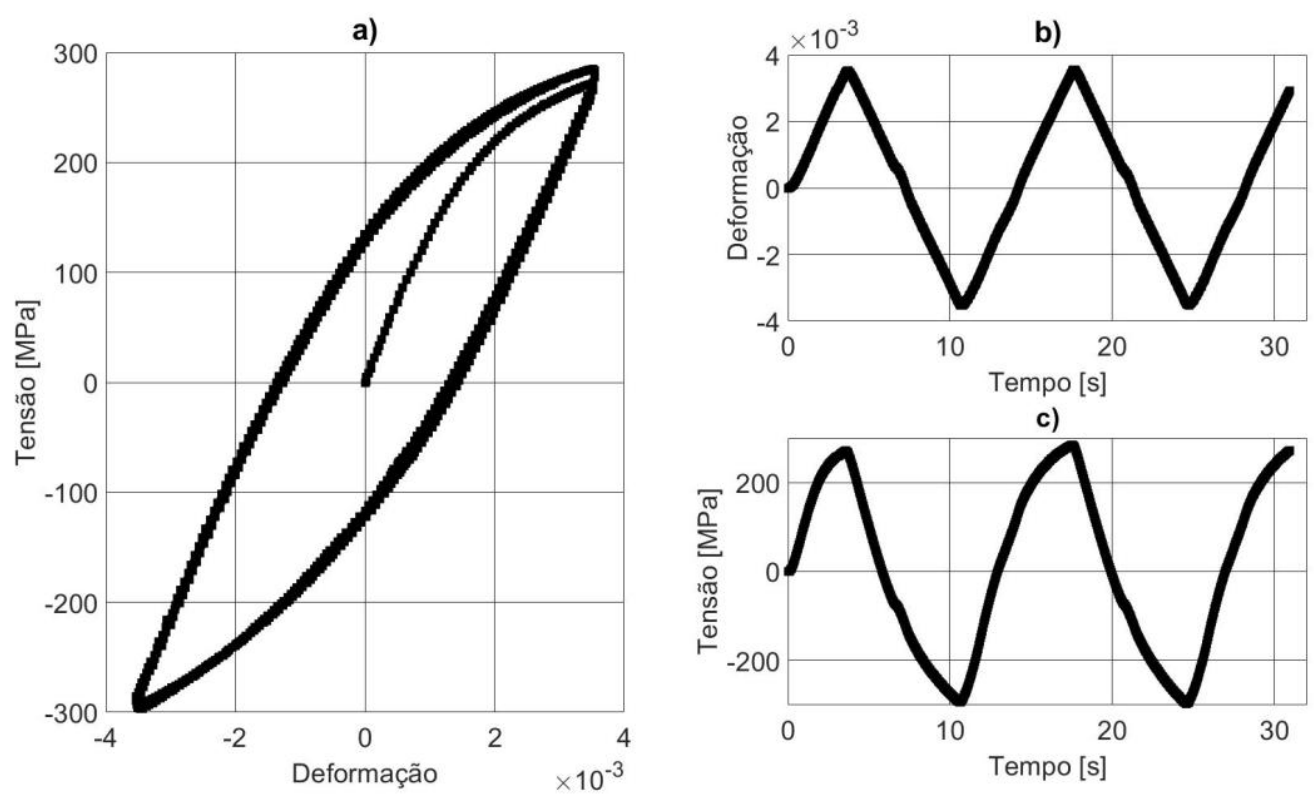

Fonte: Produção do próprio autor.

Os ensaios de fadiga isotérmica foram realizados conforme norma ASTM E606-00 [63]. As curvas de carregamento cíclico ( $\sigma$ versus $\varepsilon$ ) foram determinadas à 50 e $420^{\circ} \mathrm{C}$, em controle de deformação e taxa de deformação constante de $0,001 \mathrm{~s}^{-1}$ e forma de onda triangular.

A $50{ }^{\circ} \mathrm{C}$ foi realizado ensaios com amplitude total de deformação de $0,3 \%$, $0,4 \%, 0,5 \%, 0,6 \%$ e $0,7 \%$, enquanto na temperatura de $420{ }^{\circ} \mathrm{C}$ foi realizado com amplitude total de $0,3 \%, 0,5 \%, 0,6 \%$ e $0,7 \%$, com forma de onda senoidal e razão de deformação, $\mathrm{R}=-1$. 


\subsection{Ensaio de fadiga termomecânica}

Um ciclo de fadiga termomecânico é definido como uma condição em que os campos uniformes de temperatura e de deformação sobre o CP são simultaneamente variados e controlados independentemente.

Figura 14 - Exemplo de fadiga termomecânica com 75\% de restrição, a) tensão vs. deformação total, b) deformação mecânica total aplicada vs. tempo, c) Tensão vs. Tempo, d) Temperatura vs. Tempo.
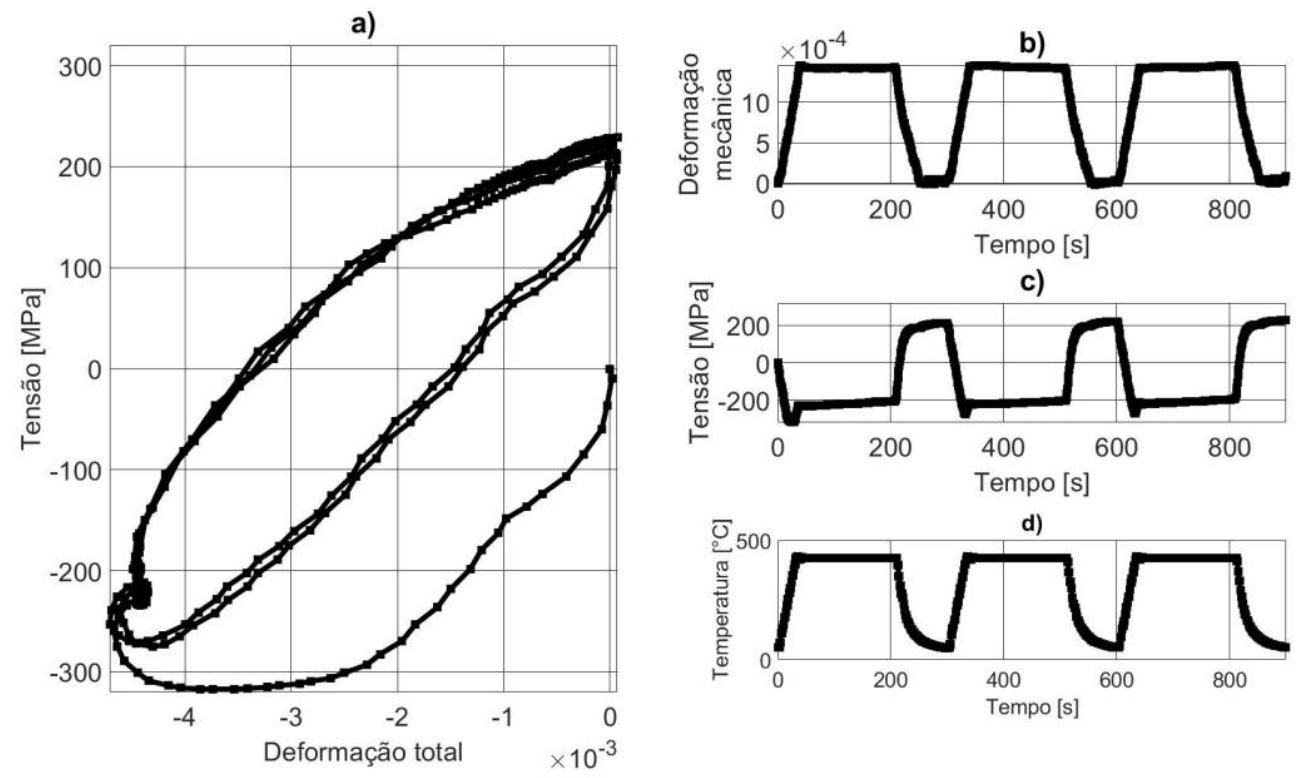

Fonte: Produção do próprio autor.

Os ensaios realizados respeitaram a norma ASTM E2368-10 [66]. Os testes se baseiam na variação térmica do CP, e então a máquina restringe a livre expansão do CP. Quando a máquina não aplica nenhuma deformação mecânica no CP consideramos como restrição $100 \%$ do CP, onde a deformação total do material é representada pela parcela térmica apenas. Além desse caso de fadiga termomecânica realizou-se um ensaio no qual foi aplicado uma variação na deformação mecânica para que a deformação total aplicada corresponde a 75\% do valor encontrado a $100 \%$ de restrição do $\mathrm{CP}$, esse caso está representado pela Figura 14.

Os ensaios foram realizados em controle de deformação, forma de onda trapezoidal, fora de fase, sob duas condições de restrição do corpo de prova: $75 \%$ e 
$100 \%$, enquanto a temperatura do corpo variava entre 50 e $420^{\circ} \mathrm{C}$. Os ciclos térmicos foram realizados com taxa de aquecimento e de resfriamento inseridos no controlador de 9 e $6 \mathrm{C} \% \mathrm{~s}$, respectivamente, e 180 segundos de patamar na temperatura de 420 ${ }^{\circ} \mathrm{C}$, e 90 segundos na de $50^{\circ} \mathrm{C}$. A Figura 15 apresenta o ciclo térmico registrado pelo pirômetro e a temperatura aplicada pelo controlador.

Figura 15 - Ciclo térmico do ensaio FTM

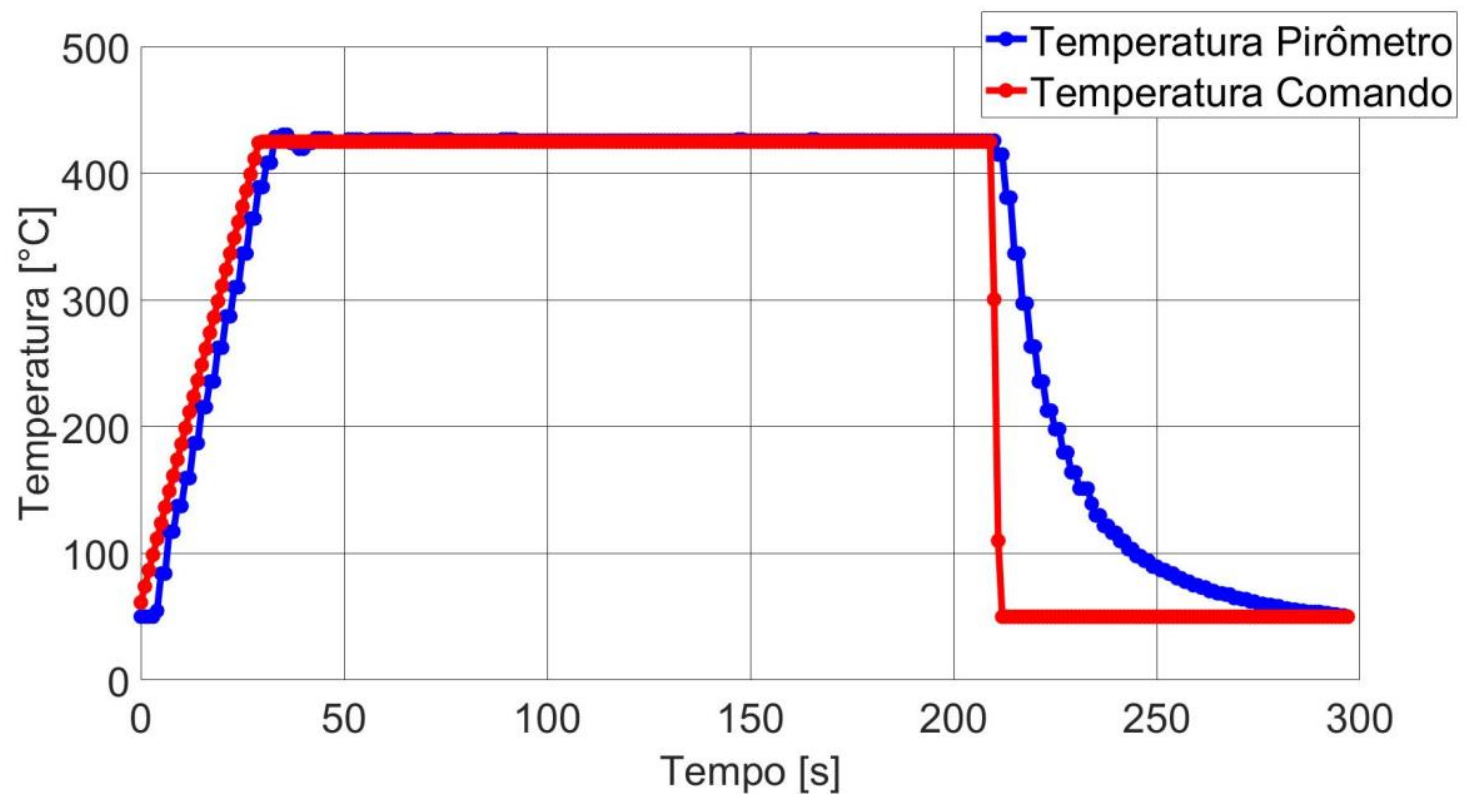

Fonte: Produção do próprio autor.

Antes do início do ensaio, propriamente dito, é realizado um procedimento para a estabilização da temperatura do sistema e da expansão térmica do material. Para isso, é iniciada o sistema em controle de força que é mantida em zero $(F=0 \mathrm{kN})$, enquanto a temperatura do corpo é elevada a $50^{\circ} \mathrm{C}$. Então se inicia 7 ciclos térmicos sem restrição do $\mathrm{CP}(\mathrm{F}=0 \mathrm{kN})$ realizando medida da expansão térmica, para posterior utilização na análise. Por fim, quando a temperatura atingir $50^{\circ} \mathrm{C}$, após esses ciclos, o corpo de prova é ensaiado em FTM em controle de deslocamento respeitando a necessidade do ensaio se a restrição do CP é de 100 ou $75 \%$. 


\subsection{Ensaios com carregamento cíclico crescente}

Esse ensaio tem o intuito de caracterizar a região plástica do material, com carregamentos cíclicos crescentes, onde obtêm-se a tensão de escoamento do material e sua deformação plástica correspondente.

Foi ensaiado um corpo de prova em tração a $50^{\circ} \mathrm{C}$ para a seleção e identificação do modelo de plasticidade. Com 8 ciclos de carregamentos e descarregamento com carregamentos a tração crescentes em cada ciclo e descarregamentos até tensão de $0 \mathrm{Mpa}$, esses carregamentos estão representados na Figura 16. Em todos os ensaios a taxa de carregamento e descarregamento foram de $350 \mathrm{~N} / \mathrm{s}$.

Figura 16 - Tensões aplicadas no ensaio de carregamento cíclico crescente.

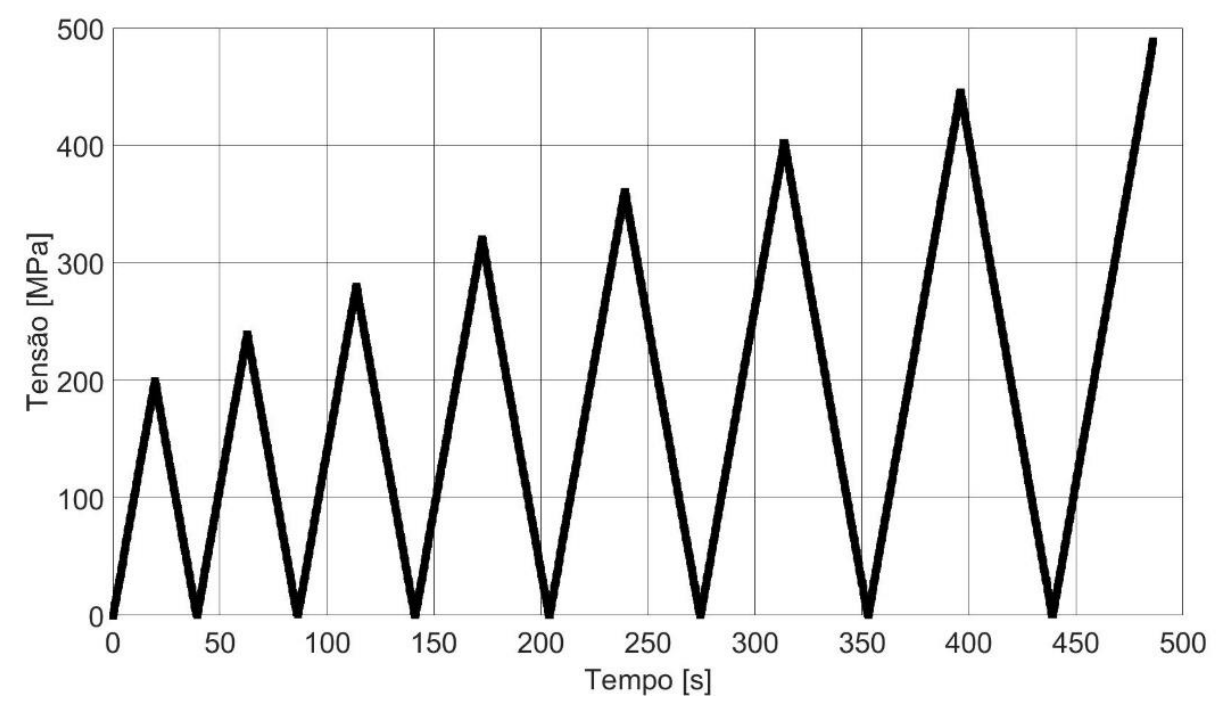

Fonte: Produção do próprio autor.

O ensaio foi realizado em controle de força, no qual introduziu no CP forças dependentes de sua área para gerar as tensões de engenharia que estão representadas na Tabela 1. 
Tabela 1 - Tensões geradas no corpo de prova no carregamento cíclico crescente

\begin{tabular}{cc}
\hline Ciclo & Carregamento (MPa) \\
\hline 1 & 200 \\
\hline 2 & 240 \\
\hline 3 & 280 \\
\hline 5 & 320 \\
\hline 6 & 360 \\
\hline 7 & 400 \\
\hline 4 & 440 \\
\hline
\end{tabular}

Fonte: Produção do próprio autor.

\subsection{Modelo computacional}

\subsubsection{Modelo em elementos finitos}

Utilizou-se o software de elementos finitos $A B A Q U S^{\circledR}$, da fabricante DASSAULT SYSTÈMES. Um modelo geométrico axissimétrico foi gerado no software, conforme a Figura 17 b), inserindo o raio do corpo de prova e a abertura do extensômetro, e o eixo central do CP foi considerado o eixo de simetria para o modelo axissimétrico. Neste modelo a condição de contorno na parte inferior do corpo restringe o movimento na direção $Y$, enquanto na parte superior do corpo é inserido o deslocamento encontrado no extensômetro nos ensaios em controle de deslocamento ou a força nos ensaios em controle de força. A malha foi gerada utilizando elementos quadrilaterais lineares com integração reduzida $(C A X 4 R)$ que está representado Figura $17 \mathrm{c})$.

Os modelos constitutivos utilizados nas simulações dos ensaios de fadiga isotérmico carregamento cíclicos crescentes e de tração são os modelos de elasticidade isotrópica e plástico com encruamento combinado independente do 
tempo (isotrópico e cinemático). $\mathrm{Na}$ análise de fadiga termomecânica além dos modelos mencionados anteriormente também se utilizou o modelo de expansão térmica e um caso que foi utilizado o modelo de viscoplasticidade de duas camadas.

Figura 17 - a) Corpo de prova, b) Modelo axissimétrico e condições de contorno e c) malha do modelo.

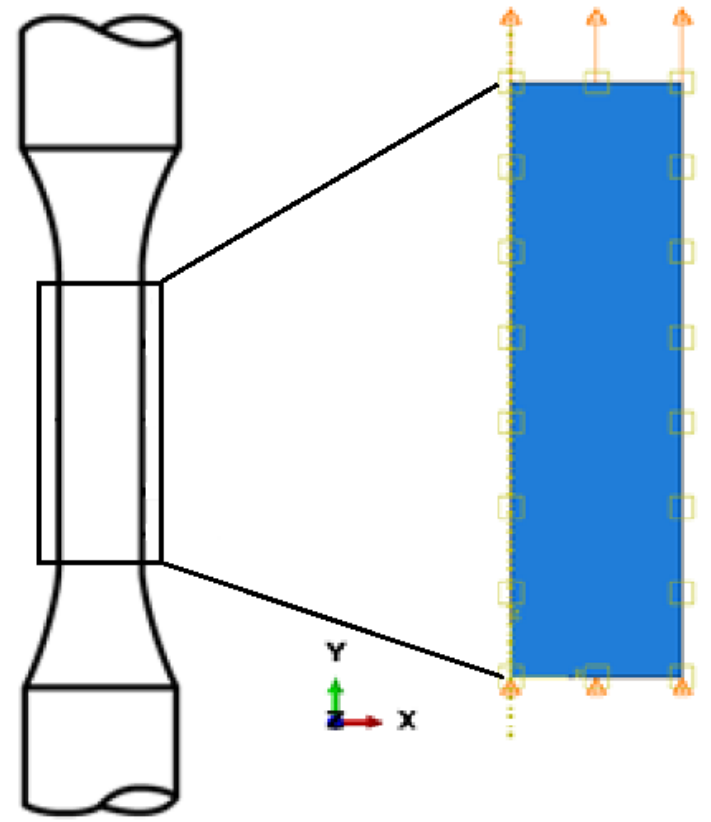

a) b)

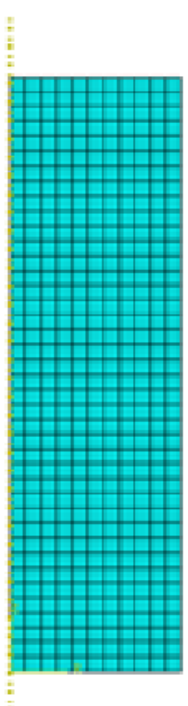

c)

Fonte: Produção do próprio autor.

4.7.2 Parâmetros dos materiais dos modelos constitutivos.

O modelo de elasticidade isotrópica pode ser descrito a partir das constantes do material que são o módulo de Young (E) e coeficiente de Poisson (v).

No modelo de plasticidade com encruamento combinado quando é selecionado as formas de inserir os dados estabilizado ou de meia vida é necessário inserir a deformação plástica com a sua respectiva tensão de encruamento. Para isso utilizou-se a equação reescrita de Ramberg-Osgood (Equação 8) para representar a curva. Uma representação da curva da Equação 8 está na Figura 18, com $\sigma_{Y}=195$, $K_{0}=6,37$ e $n=0,369$. 
No caso do modelo de plasticidade de dados parametrizados é preciso inserir a tensão de encruamento inicial e os parâmetros $C_{k}$ e $\gamma_{k}$, onde o índice $k$ representa o número de "backstress", conforme aumenta o número de "backstress", aumenta em dois os parâmetros para caracterização do modelo.

Figura 18 - Curva tensão de escoamento por deformação plástica

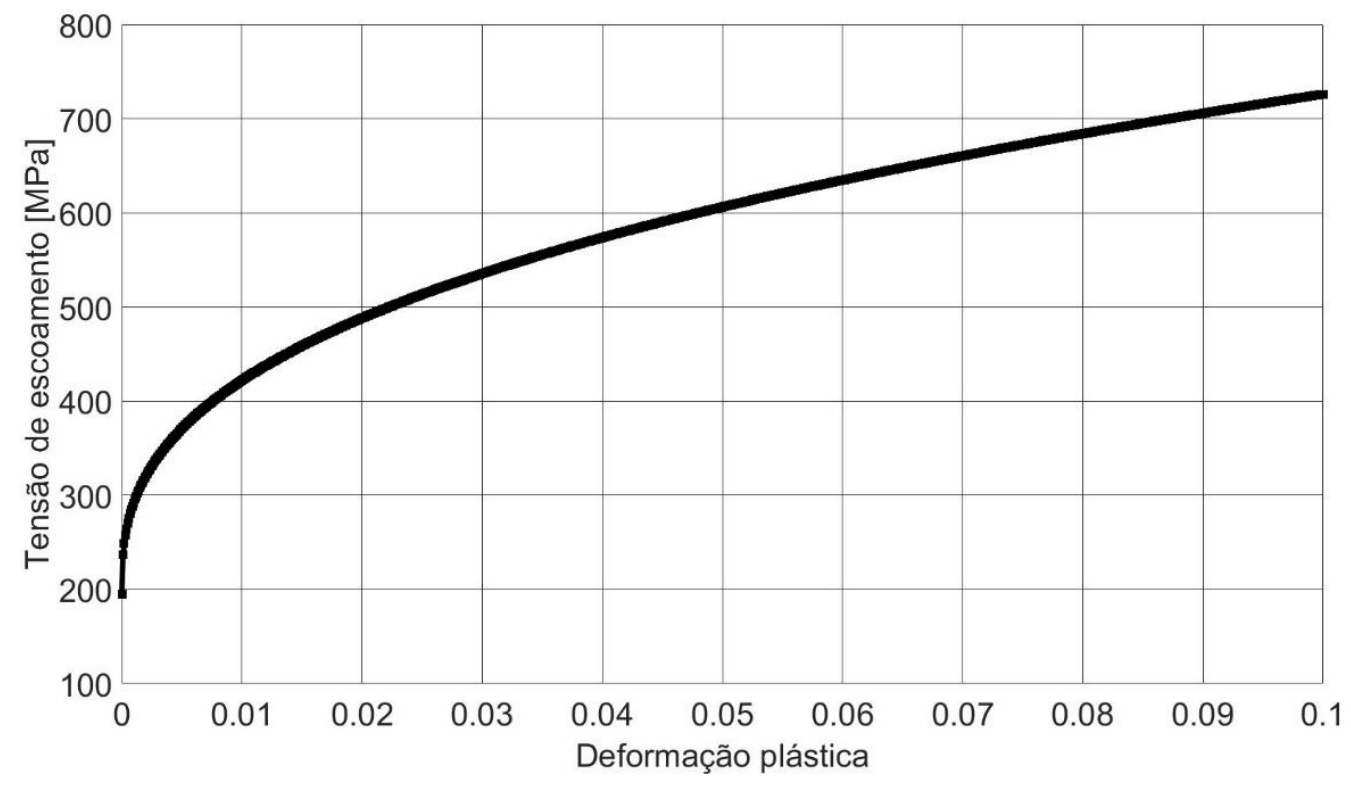

Fonte: Produção do próprio autor.

No modelo de expansão térmica é necessário inserir apenas o coeficiente de expansão térmica linear do material.

\subsubsection{Modelo de previsão de vida}

O modelo utilizado neste trabalho é baseado no do trabalho Jost, et al. [5868], no qual o material é caracterizado em fadiga isotérmica na temperatura de $50{ }^{\circ} \mathrm{C}$ e $420^{\circ} \mathrm{C}$ encontrando os parâmetros $\varepsilon_{B, M(F B C)}^{\prime}$ e $c_{M}$ da Equação 15.

Em ambas as temperaturas são caracterizados os parâmetros $\varepsilon_{B, M(F B C)}^{\prime}$ e $c_{M}$ em duas condições, considerando o ponto de $0,3 \%$ de deformação total e não o 
considerando. Isso se deve, pois, essa deformação está próxima do limiar entre fadiga de alto e baixo ciclo.

Para o caso de fadiga termomecânica utilizou-se a Equação 16, que necessita da caracterização dos parâmetros $\varepsilon_{B, M(F B C)}^{\prime F T M}$ e $c_{M(F T M)}$. Nesse trabalho considerou-se o parâmetro $\varepsilon_{B, M(F B C)}^{\prime F T M}$ sendo o mesmo valor que no caso de fadiga isotérmica $\left(\varepsilon_{B, M(F B C)}^{\prime}\right)$, A partir desse consideração foi necessário uma condição de carregamento termomecânico para a caracterização do parâmetro $c_{M(F T M)}$, isso foi realizado na condição de FTM com $100 \%$ de restrição do CP.

Por fim é utiliza-se a Equação 16 com os parâmetros caracterizados em uma condição de FTM com restrição de $75 \%$ do CP para prever a vida em fadiga e compara-se com a vida encontrada no ensaio.

\subsubsection{Ajuste dos parâmetros.}

Para ajustes dos parâmetros dos modelos constitutivos, as condições de contorno do ensaio são inseridas no programa de elementos finitos (FEM), essas condições de contorno são a temperatura, tempo e deslocamento do extensômetro (quando o ensaio é controle de deslocamento) ou a força aplicada (quando o ensaio é controle de força), uma tabela comparativa entre o ensaio e o controle da máquina se é realizado por deslocamento ou por de força pode ser visto na Tabela 2.

No programa de elementos finitos também é inserido os parâmetros iniciais dos modelos constitutivos como parâmetros iniciais. Os resultados do FEM são comparados com os do ensaio, para o ensaio de controle de deslocamento é comparado a força encontrada, enquanto em ensaio por controle de força é comparado o deslocamento do extensômetro encontrada. Se a diferença dos dois apresentar um grande erro, os parâmetros do modelo constitutivo são reajustados. Se o erro for o menor encontrado, então será utilizado os parâmetros como propriedade do material. O fluxograma está representado na Figura 19. 
Tabela 2 - Tabela dos ensaios e o controle utilizado na máquina de ensaio.

\begin{tabular}{cc}
\hline Ensaio & Controle \\
\hline Tração & Deslocamento \\
\hline Fadiga isotérmica & Deslocamento \\
\hline Fadiga termomecânico & Deslocamento \\
\hline $\begin{array}{c}\text { Carregamento cíclico } \\
\text { crescente }\end{array}$ & Força \\
\hline
\end{tabular}

Fonte: Produção do próprio autor.

Figura 19 - Fluxograma utilizando para o ajuste dos parâmetros.

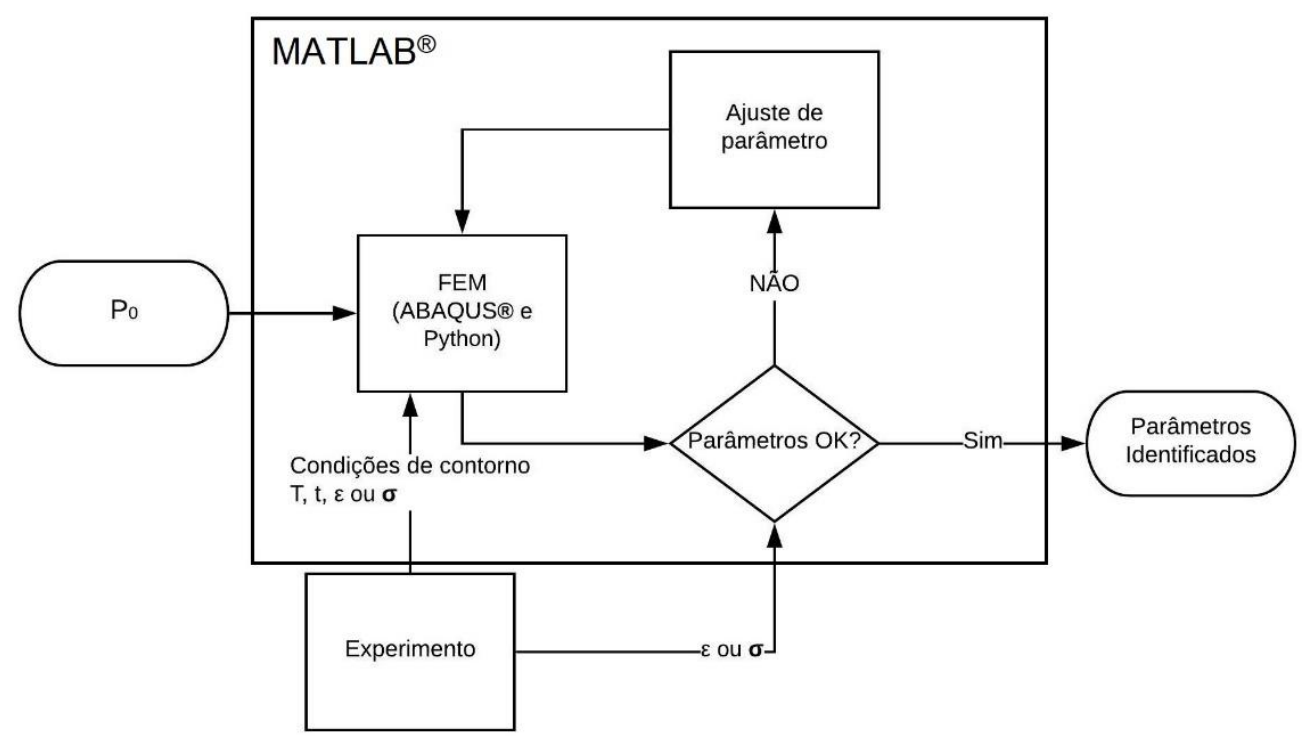

Fonte: Produção do próprio autor.

O problema de identificação dos parâmetros do modelo do material consiste em encontrar $p$ que minimiza o quadrado da diferença entre modelo e experimento. A função a ser minimizada pode ser descrita como a Equação 17:

$$
\chi(p)=\sum_{i=1}^{N}\left[y_{\exp }\left(t_{i}\right)-y_{f e m}\left(t_{i}, p\right)\right]^{2}
$$

sendo $t_{i}$ a variável tempo, $y_{\text {exp }}$ os dados experimentais (que podem ser deslocamento ou força) e $y_{f e m}$ a previsão do modelo para um conjunto de parâmetro $p$. O procedimento de identificação é conduzido a partir de um conjunto de scripts 
desenvolvidos em MATLAB ${ }^{\circledR}$ e Python. Uma visão geral do procedimento de identificação pode ser vista na Figura 19.

Foi utilizado a função Isqcurvefit do $\mathrm{MATLAB}^{\circledR}$, utilizando o algoritmo Trust reflective region, para realizar o processo de minimização e ajuste dos parâmetros. Essa função requer que o usuário forneça uma estimativa da matriz Jacobiana. $A$ matriz Jacobiana foi calculada a partir de uma aproximação em $1^{\text {a }}$ ordem da derivada, i. e., conforme a Equação 18:

$$
\begin{aligned}
& J_{i j}=\frac{\partial y_{f e m}}{\partial p_{j}} \\
& =\frac{\left\{y_{f e m}\left[t_{i,}\left(p_{1}, p_{2} \ldots, p_{j}+\delta p_{j}, \ldots, p_{n}\right)\right]-y_{f e m}\left[t_{i}\left(p_{1}, p_{2} \ldots, p_{j}, \ldots, p_{n}\right)\right]\right\}}{\delta p_{j}}
\end{aligned}
$$

Adotou-se $\delta p_{j}=0,01 p_{j}$ para cálculo das derivadas. Os parâmetros $p$ são:

$$
p=\left\{E, v, \alpha, \sigma_{y}, \ldots\right\}
$$

Tabela 3 - Tabela comparativa entre a forma de inserir os dados e os parâmetros.

\begin{tabular}{cc}
\hline \multicolumn{1}{c}{ Dados } & Parâmetros \\
\hline Parametrizado 1 Backstress & $\sigma_{y}, C_{1}, \gamma_{1}$ \\
\hline Parametrizado 2 Backstress & $\sigma_{y}, C_{1}, \gamma_{1}, C_{2}, \gamma_{2}$ \\
\hline Parametrizado 3 Backstress & $\sigma_{y}, C_{1}, \gamma_{1}, C_{2}, \gamma_{2}, C_{3}, \gamma_{3}$ \\
\hline Meia vida 1, 2 e 3 Backstress & $\sigma_{y}, K_{0}, n$ \\
\hline Estabilizados 1, 2 e 3 Backstress & $\sigma_{y}, K_{0}, n$ \\
\hline
\end{tabular}

Fonte: Produção do próprio autor.

onde $\mathrm{E}$ é o módulo de Young, $v$ o coeficiente de Poisson, $\alpha$ é o coeficiente de expansão linear do material, $\sigma_{y}$ é o limite de escoamento do material do modelo de plasticidade, os outros modelos de plasticidade depende da forma de inserir os dados de plasticidade. Na Tabela 3 tem um comparativo entre as formas de inserir os dados 
e a quantidade de "backstress" com os parâmetros de plasticidade a serem identificados por essa metodologia.

Para identificar o melhor modelo de plasticidade e a melhor forma de inserir os dados realizou-se diversas combinações das formas de inserir os dados e o número de "backstress" com isso foi possível selecionar o melhor modelo de plasticidade para o material. 


\section{RESULTADOS E DISCUSSÃO}

\subsection{Ensaios com carregamento cíclico crescente}

O resultado do ensaio com carregamento cíclico crescente a $50^{\circ} \mathrm{C}$ é apresentado na Figura 20. Com esse resultado foi possível obter os pontos referentes a evolução da tensão de escoamento com a deformação plástica. Com os pontos de tensão de escoamento por deformação plástica encontrados no ensaio foi possível ajustar uma curva com base na Equação 8. Os parâmetros que melhor se ajustaram a esses pontos estão descritos na Tabela 4 e a curva ajustada está representada na Figura 21. Com esse resultado foi possível inserir esses parâmetros como dados iniciais para o ajuste dos parâmetros no software.

Figura 20 - Resultado do ensaio de carregamento e descarregamento, a) tensão x deformação, b) deformação $x$ tempo e c) tensão $x$ tempo.

a)

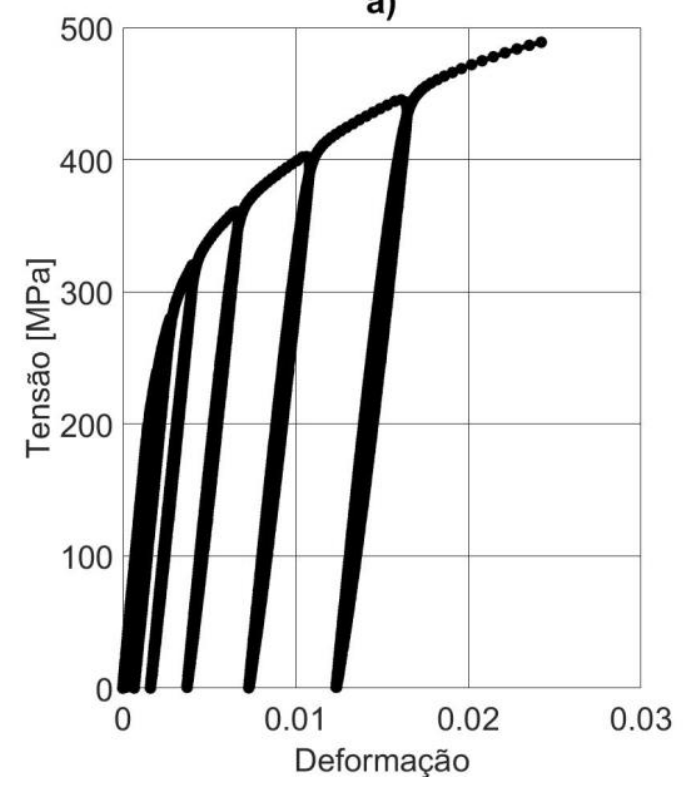

b)

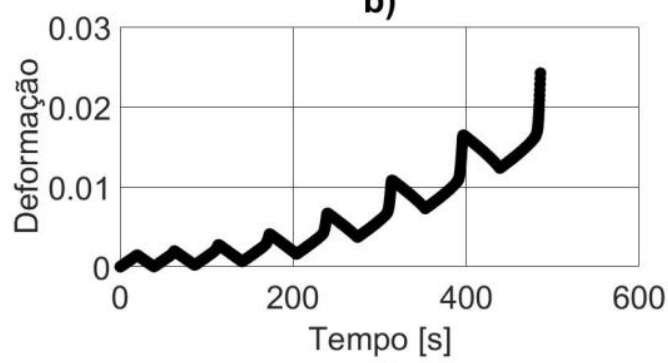

c)

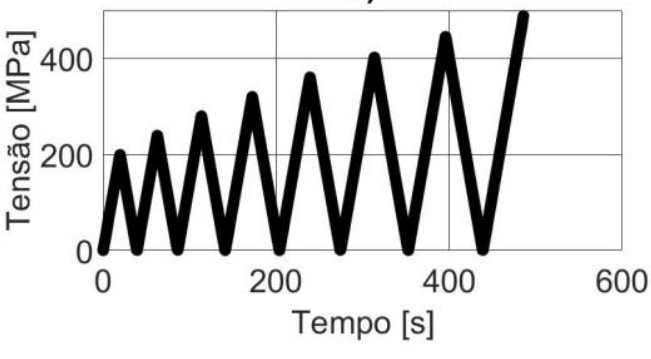

Fonte: Produção do próprio autor. 
Tabela 4 - Parâmetros da Equação 8 obtidos do ensaio.

\begin{tabular}{cc}
\hline Parâmetros & Valores \\
\hline $\boldsymbol{\sigma}_{\boldsymbol{Y}}$ & $195 \mathrm{MPa}$ \\
\hline $\boldsymbol{K}_{\mathbf{0}}$ & 6,37 \\
$\boldsymbol{n}$ & 0,369 \\
\hline
\end{tabular}

Fonte: Produção do próprio autor.

\subsubsection{Dados estabilizado}

Na forma de dados estabilizado, realizou-se a simulação com 1, 2 e 3 "backstress". Com um "backstress" (Figura 22), a simulação apresentou boa convergência e boa compatibilidade em altas deformações, pois apresentou pouca diferença entre a tensão na simulação e a tensão de ensaio. Porém em baixas deformações o limite de escoamento da simulação não apresentou bons resultados, devido a grande diferença observada entre a simulação e o ensaio. Isso ocorre pois com apenas um valor de "backstress" se consegue descrever somente uma curva em uma faixa de deformação, e esta foi em altos níveis de deformação do material. Os valores dos parâmetros ajustados foram: $\sigma_{Y}=50 M P a, K_{0}=16,37$ e $n=0,221$.

Figura 21 - Ajuste dos parâmetros do modelo a partir de dados experimentais.

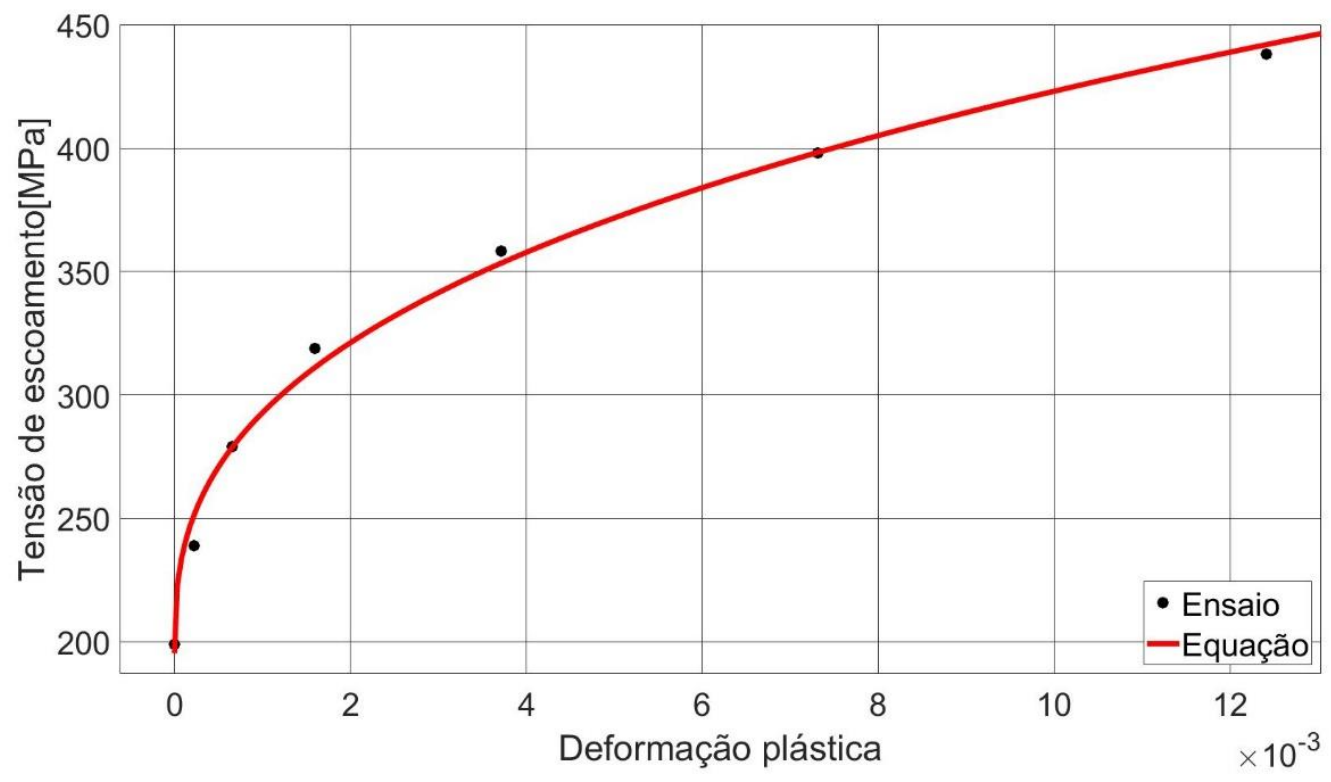

Fonte: Produção do próprio autor. 
Figura 22 - Comparação entre a simulação e o ensaio de carregamento cíclico crescente, considerando os dados estabilizados com um "backstress".

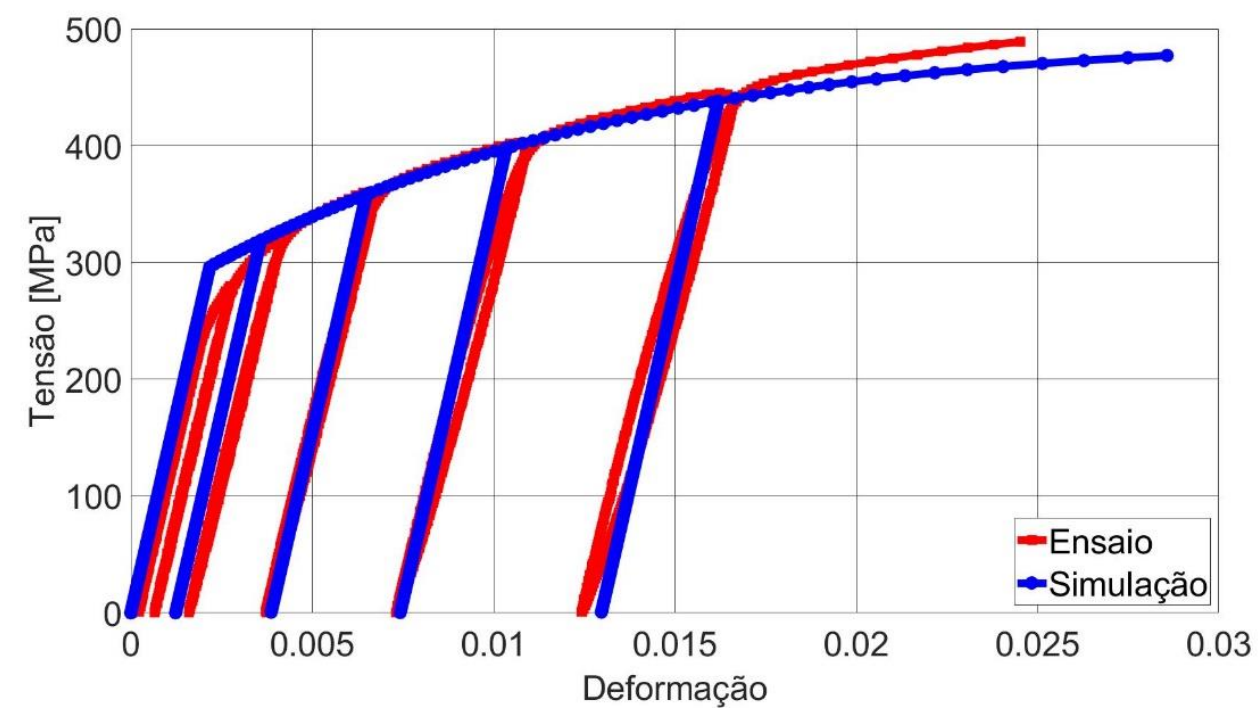

Fonte: Produção do próprio autor.

As simulações com dois e três "backstress" apresentaram problema de convergência, por isso não apresentando um ajuste dos parâmetros adequado. Apresentou uma grande disparidade entre o ensaio e a simulação.

\subsubsection{Dados de meia vida}

$\mathrm{Na}$ forma de dados de meia vida, realizou-se a simulação com 1, 2 e 3 "backstress" que estão representados nas Figura 23a, Figura 23b e Figura 23c respectivamente.

A simulação com um "backstress" (Figura 23a) apresentou boa representatividade em tensões perto da tensão de ruptura, pois há pouca diferença entre as tensões nessa região com a do ensaio, mas apresentou diferença em tensões inferiores perto da tensão de escoamento do CP. Apresentou diferença também nos pontos de descarregamentos elásticos e sua correspondente deformação plástica. Os valores dos parâmetros ajustados foram: $\sigma_{Y}=243 M P a, K_{0}=1,33$ e $n=0,154$. 
Figura 23 - Comparação entre a simulação e ensaio de carregamento cíclico crescente, considerando os dados de meia vida com a) um "backstress", b) dois "backstress" e c) três "backstress".

a)
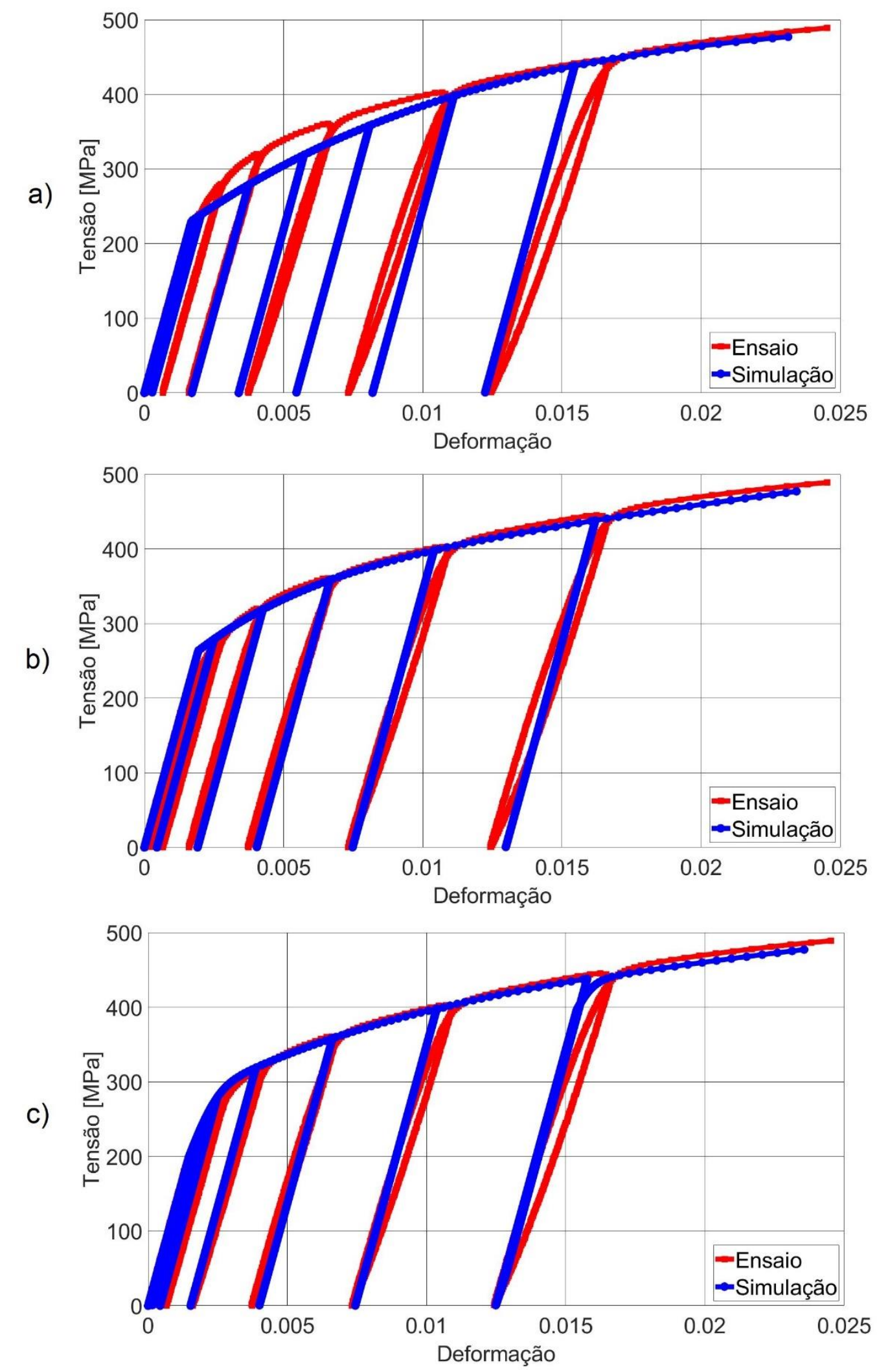

Fonte: Produção do próprio autor. 
A simulação com dois "backstress" (Figura 23b) apresentou uma melhoria na representação do comportamento mecânico, pois tanto nas tensões perto da ruptura quanto tensões inferiores a simulação conseguiu representar bem. Ainda houve uma melhora na representação dos seus pontos de descarregamentos e de deformações plásticas. Porém na tensão de escoamento inicial do material houve divergência comparada com o ensaio. Os valores dos parâmetros ajustados foram: $\sigma_{Y}=264 M P a$, $K_{0}=6,20$ e $n=0,518$.

A simulação que melhor representou o comportamento mecânico do CP foi a simulação com 3 "backstress" (Figura 23c), pois tanto em tensões elevadas, tensões de escoamento e tensões intermediárias o modelo plástico conseguiu representar bem o comportamento do CP. A simulação não conseguiu prever o comportamento de dano (redução do módulo elástico com o aumento da deformação plástico sofrido pelo material) do CP. Os valores dos parâmetros ajustados foram: $\sigma_{Y}=264 M P a, K_{0}=$ 6,20 e $n=0,518$.

Percebe-se que cada "backstress" melhora a simulação em uma determinada região de deformação do material, como exemplo, se pode observar na Figura 6 que cada "backstress" é mais relevante em uma parte da deformação plástica do material. Ao utilizar 3 "backstress" o modelo consegue descrever bem o comportamento mecânico do material.

\subsubsection{Dados parametrizado}

$\mathrm{Na}$ forma de dados parametrizado, realizou-se a simulação com 1, 2 e 3 "backstress". A simulação com um "backstress apresentou problema na sua convergência, pois as tensões na simulação apresentaram grande diferença comparadas com a do ensaio.

A simulação com dois "backstress" (Figura 24a) apresentou boa compatibilidade com o ensaio em tensões elevadas. Perto da tensão de ruptura, apresentou descarregamento elástico próximos dos pontos dos descarregamentos reais do ensaio e deformações plásticas também próximas. Mas mostrou problema perto da tensão de escoamento, apresentando uma diferença grande entre a tensão de escoamento da simulação e a tensão real de escoamento. Os valores dos 
parâmetros ajustados foram: $\sigma_{Y}=292 \mathrm{MPa}, C_{1}=5550, \gamma_{1}=53,5, C_{2}=13900$ e $\gamma_{2}=$ 110.

Figura 24 - Comparação entre a simulação e ensaio de carregamento cíclico crescente, considerando os dados de parametrizado com a) dois "backstress" e b) três "backstress".

a)
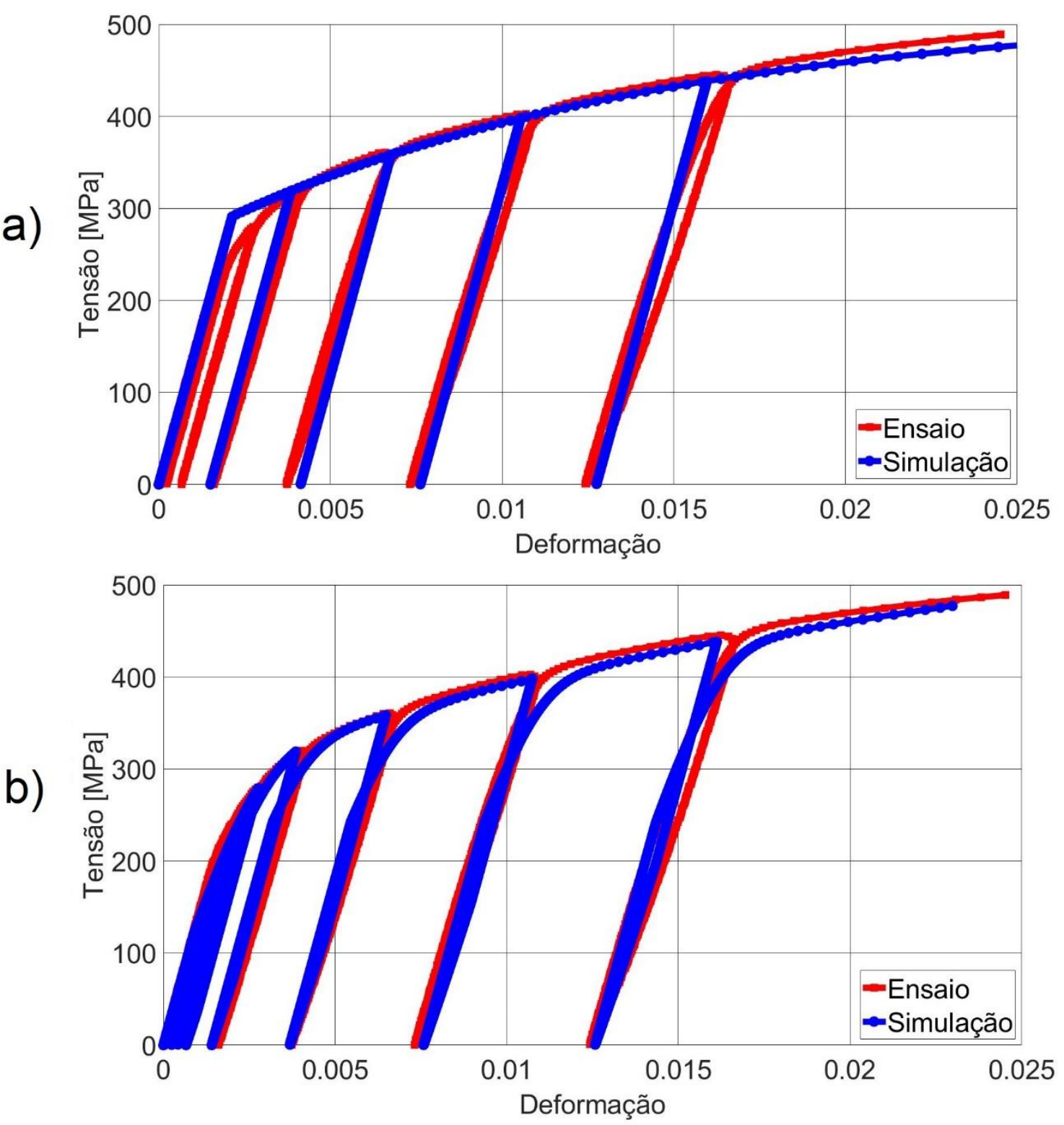

Fonte: Produção do próprio autor.

A simulação com 3 "backstress" (Figura 24b) apresentou tensões e deformações próximas ao do ensaio, também se obteve descarregamento elástico e deformações plásticas muito próximas comparados ao ensaio. Essa simulação apresentou um comportamento atípico de encruamento no carregamento logo após o 
descarregamento em tensões inferiores à tensão quando ocorre o descarregamento, isso se deve ao modelo constitutivo não representar o dano do material. Então com auxílio da metodologia criada de ajuste de parâmetros adaptou-se os parâmetros plásticos para tentar descrever esse comportamento do material. Os valores dos parâmetros ajustados foram: $\sigma_{Y}=121 M P a, C_{1}=110, \gamma_{1}=33,3, C_{2}=12900, \gamma_{2}=$ $45,2, C_{3}=401000$ e $\gamma_{3}=2090$.

A simulação com dados parametrizados que melhor representou 0 comportamento mecânico do material foi a simulação com 3 "backstress" (Figura 24b). Pode-se perceber que com o aumento do número de "backstress" a simulação representa melhor o comportamento mecânico do material, pois cada "backstress" caracteriza melhor o comportamento do material em uma região da sua deformação. Em contrapartida com o aumento do número de "backstress", há um aumento no número de parâmetros para identificação do material, e consequentemente o tempo de processamento computacional aumenta.

\subsection{Ensaio de fadiga isotérmica}

Os ensaios de fadiga isotérmica com variação de $0,3 \%$ de deformação não geraram deformações plásticas ou estas foram mínimas. Devido a isso foi possível obter o módulo elástico do material através de simulação que desconsiderou o modelo plástico, conforme Figura 25a e Figura 25b que representa os três primeiros ciclos para os ensaios de fadiga isotérmica a $50^{\circ} \mathrm{C}$ e $420^{\circ} \mathrm{C}$, respectivamente.

$\mathrm{Na}$ Figura 25a percebe-se que a simulação representou bem 0 comportamento elástico do material, apresentando uma leve diferença entre a simulação no carregamento compressivo do primeiro ciclo, mas essa diferença foi reduzida nos ciclos subsequentes, indicando assim um problema de medida transiente que ocorreu no começo do ensaio. Nesta simulação o módulo elástico apresentou valor de $136 \mathrm{GPa}$, esse valor está abaixo comparado com o valor da literatura (152 GPa) [67], entretanto está dentro do esperado considerando o processo de fabricação dos cabeçotes de motores e a heterogeneidade no seu resfriamento e consequentemente diferença nas propriedades mecânicas. 
$\mathrm{Na}$ Figura 25b, a simulação apresentou também uma diferença no carregamento compressivo, mas de forma geral a simulação representou bem 0 comportamento mecânico do $\mathrm{CP}$, nesta simulação o módulo elástico apresentou valor de $126 \mathrm{GPa}$, com valor próximo do esperado da literatura de $134 \mathrm{GPa}$. [67]

Esses módulos de elasticidade foram utilizados com os seus valores fixados nas simulações de fadiga isotérmica subsequentes para que o procedimento de ajuste de parâmetro focasse apenas nos parâmetros de plasticidade.

Figura 25 - Ensaio de fadiga isotérmica com variação de deformação de $0,3 \%$ sem modelo plástico dos três primeiros ciclos a a) $50^{\circ} \mathrm{C}$ e b) $420^{\circ} \mathrm{C}$.
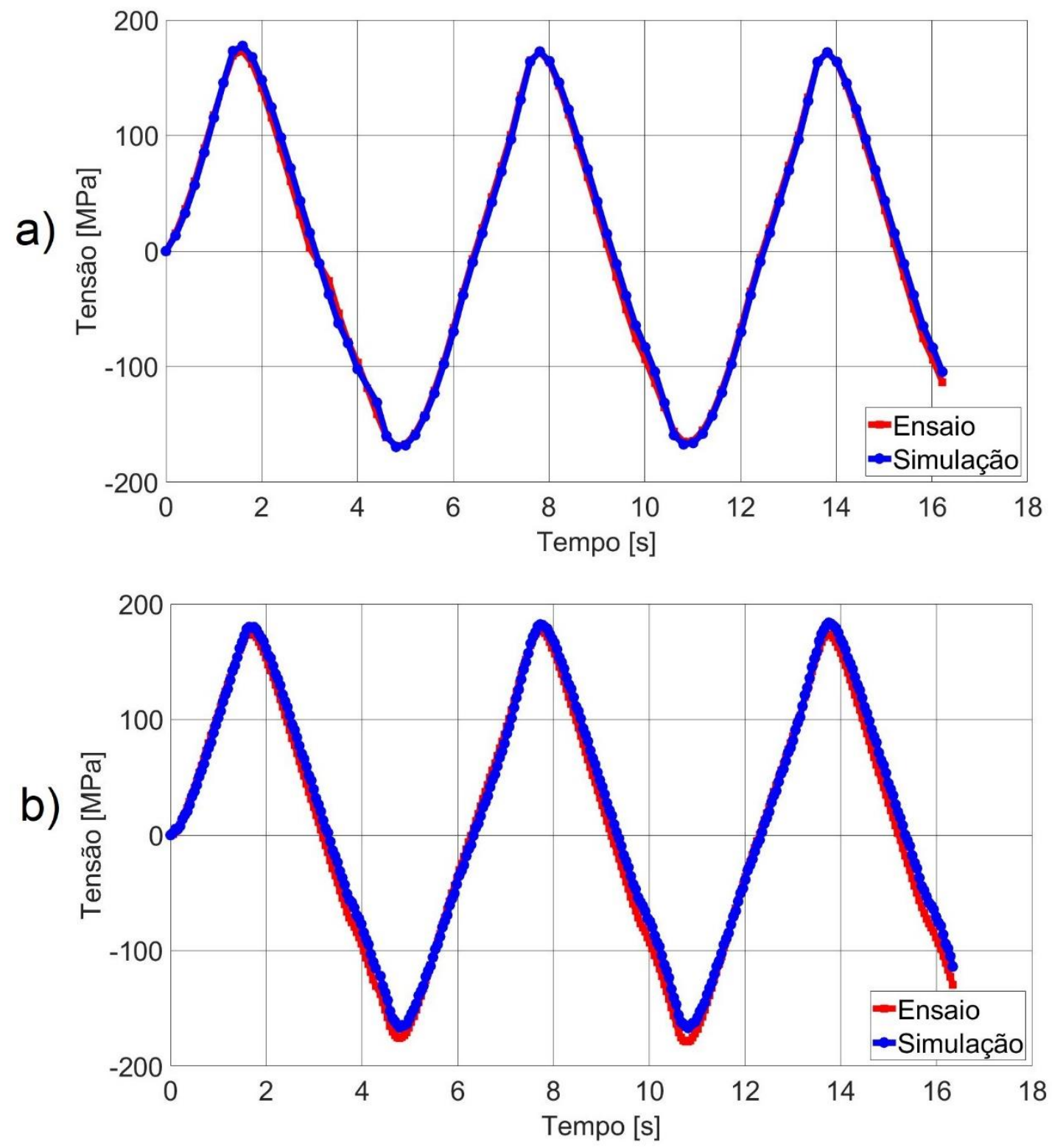

Fonte: Produção do próprio autor. 
Tendo como base os bons resultados obtidos do modelo de plasticidade dos dados de meia vida e o parametrizado ambos com três "backstress" foram então simulados nessas condições os ensaios isotérmicos para visualizar o comportamento do modelo em fadiga. Foram feitas simulações utilizando ensaio com 0,7\% de deformação, pois neste nível de deformação foi observada a maior deformação plástica, quando comparada com os outros ensaios realizados $(0,3 \%, 0,4 \%, 0,5 \%$, $0,6 \%$ e $0,7 \%)$.

Nas Figura 26a e Figura 26b pode-se observar a diferença entre os dados de meia vida e parametrizado, ambos com três "backstress", no ensaio de fadiga isotérmico a $50{ }^{\circ} \mathrm{C}$ com variação total de deformação de $0,7 \%$. Enquanto na Figura 27 a e Figura $27 \mathrm{~b}$ ocorre a mesma comparação no ensaio de fadiga isotérmica a $420^{\circ} \mathrm{C}$ e $0,7 \%$ de deformação. Todos os ensaios consideraram apenas os três primeiros ciclos.

Figura 26 - Ensaio de fadiga isotérmica a $50^{\circ} \mathrm{C}$ com variação de deformação de $0,7 \%$ dos três primeiros ciclos comparação com simulação de a) dados parametrizados com três "backstress", b) dados de meia vida com três "backstress".

a)

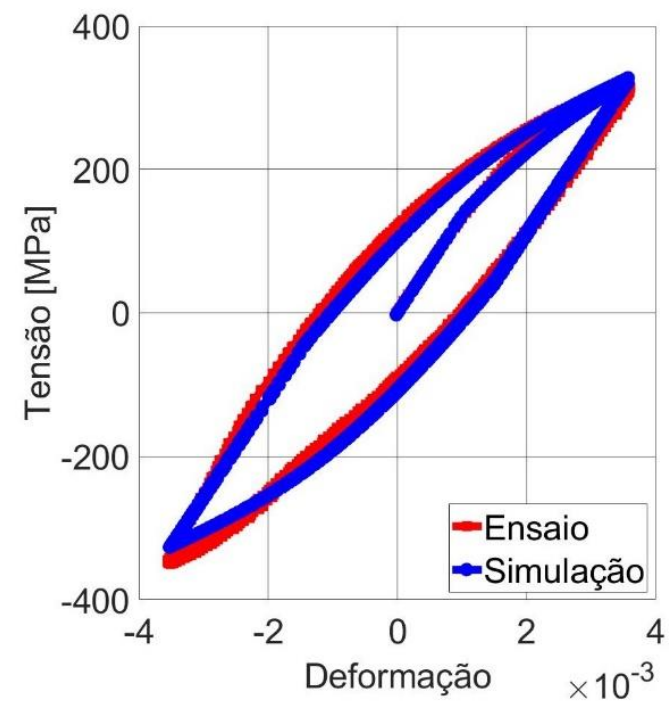

b)

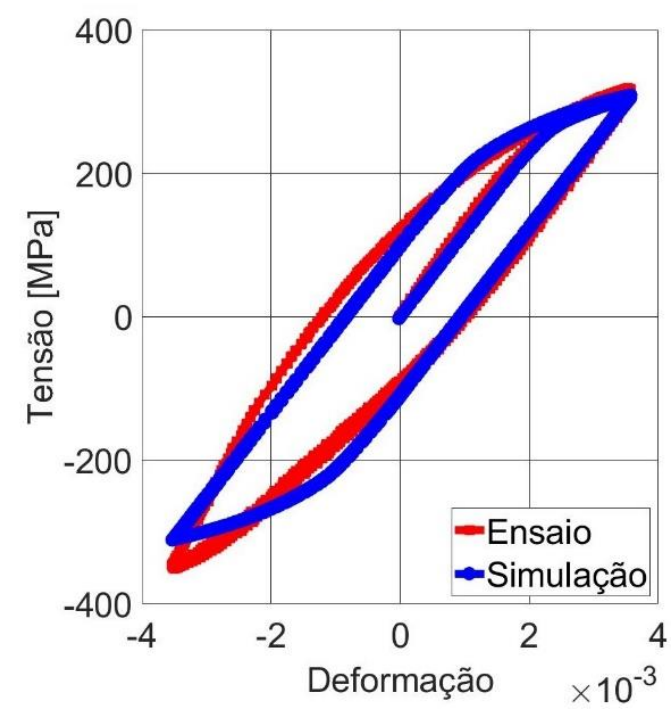

Fonte: Produção do próprio autor.

$\mathrm{Na}$ simulação com dados parametrizados a $50{ }^{\circ} \mathrm{C}$ (Figura 26a) apresentou boa representação do comportamento mecânico na parte trativa do ensaio, mas apresentou uma leva diferença na parte compressiva do mesmo, mas de uma forma 
geral o modelo conseguiu representar bem o comportamento apresentando pequenas diferenças entre simulação e ensaio. Os valores dos parâmetros ajustados foram: $\sigma_{Y}=$ $141 \mathrm{MPa}, C_{1}=26900, \gamma_{1}=0,048, C_{2}=30000, \gamma_{2}=7,46.10^{-4}, C_{3}=239000$ e $\gamma_{3}=$ 194.

$\mathrm{Na}$ simulação com dados de meia vida a $50{ }^{\circ} \mathrm{C}$ (Figura 26b) apresentou boa representação do comportamento mecânico na parte trativa comparado ao ensaio, mas apresentou uma grande diferença entre tensão de ensaio e de simulação na parte compressiva. Os valores dos parâmetros ajustados foram: $\sigma_{Y}=210 \mathrm{MPa}, K_{0}=3,66 \mathrm{e}$ $n=0,301$.

$\mathrm{Na}$ simulação com dados parametrizados a $420^{\circ} \mathrm{C}$ (Figura 27a) apresentou boa representação do comportamento mecânico na parte trativa e compressiva. Apresentou uma tensão de escoamento inicial menor que o de ensaio, mas de forma geral apresentou ótimos resultados. Os valores dos parâmetros ajustados foram: $\sigma_{Y}=$ $123 \mathrm{MPa}, C_{1}=3150, \gamma_{1}=0,0425, C_{2}=16700, \gamma_{2}=0,216, C_{3}=201000$ e $\gamma_{3}=1440$.

Figura 27 - Ensaio de fadiga isotérmica a $420^{\circ} \mathrm{C}$ com variação de deformação de $0,7 \%$ dos três primeiros ciclos comparação com simulação de a) dados parametrizados com três "backstress", b) dados de meia vida com três "backstress".

a)

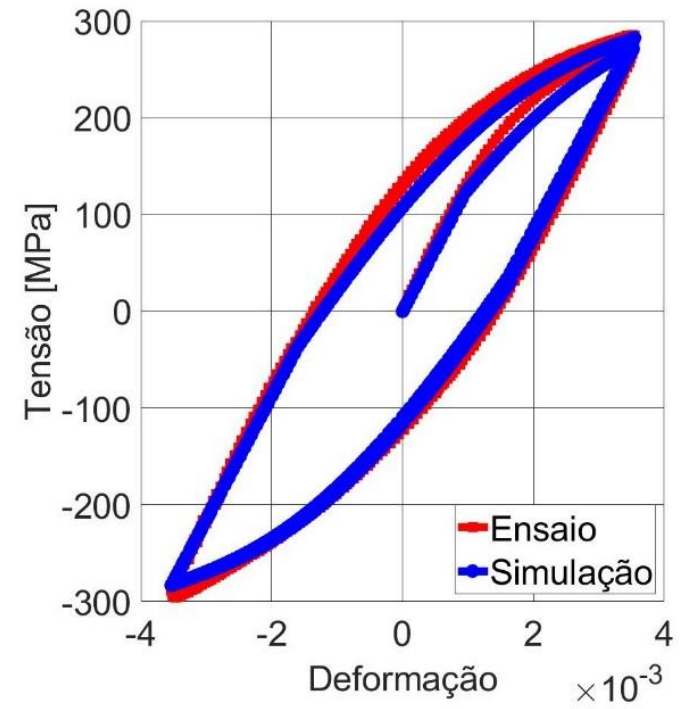

b)

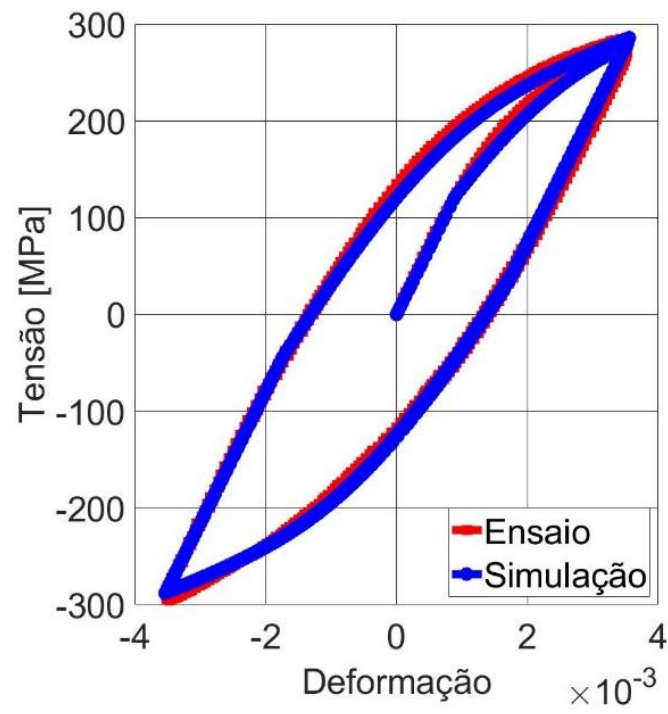

Fonte: Produção do próprio autor. 
Na simulação com dados de meia vida a $420^{\circ} \mathrm{C}$ (Figura 27b) da mesma forma que a simulação com dados parametrizados representou bem o comportamento mecânico na parte trativa e compressiva. Apresentou também uma tensão de escoamento inicial menor que o de ensaio, mas de forma geral apresentou ótimos resultados, sendo este melhor no primeiro ciclo comparado com os dados parametrizados. Os valores dos parâmetros ajustados foram: $\sigma_{Y}=121 \mathrm{MPa}, K_{0}=$ 25,3 e $n=0,462$.

No ensaio a $420{ }^{\circ} \mathrm{C}$ ambos os métodos apresentaram bons resultados, representando bem o comportamento mecânico nas condições de ensaio. Porém a $50{ }^{\circ} \mathrm{C}$ o modelo parametrizado apresentou resultados melhores comparado aos dados de meia vida. Isso se deve a maior flexibilidade na definição dos parâmetros $C_{k}$ e $\gamma_{k}$ dos "backstress", modelando melhor o comportamento do material.

\subsection{Ensaio de tração}

Com os resultados positivos dos dados parametrizados com três "backstress" no ensaio de fadiga isotérmica, partiu-se para a realização das simulações com os dados dos ensaios de tração nas temperaturas de 50, 150, 250, 350 e $420{ }^{\circ} \mathrm{C}$. Logo, na Figura 28 está representado um exemplo dos resultados obtidos de uma simulação e sua comparação com o ensaio, onde se pode observar pouca divergência entre os dois resultados.

Com os diversos ensaios realizados foi possível obter o parâmetro de elasticidade e os sete parâmetros de plasticidade do modelo de plasticidade parametrizado com três "backstress". Levantou-se a Tabela 5 com os parâmetros para cada CP, e suas temperaturas e a média entre os CP da mesma temperatura. Devido a problemas no ensaio alguns CP foram descartados.

Os parâmetros de elasticidade apresentam uma redução com o aumento da temperatura. A diferença de módulo de elasticidade entre 350 e $420{ }^{\circ} \mathrm{C}$ pode ser explicado pelo fato da média ser composta por 2 amostras na temperatura de $350{ }^{\circ} \mathrm{C}$ e 3 amostras a $420^{\circ} \mathrm{C}$. O limite de escoamento do material apresentou um aumento na temperatura de $350^{\circ} \mathrm{C}$, isso é condizente com a literatura (Guesser [68]). 
Figura 28 - Ensaio de tração a $250^{\circ} \mathrm{C}$ comparação com simulação de dados parametrizados com três "backstress".

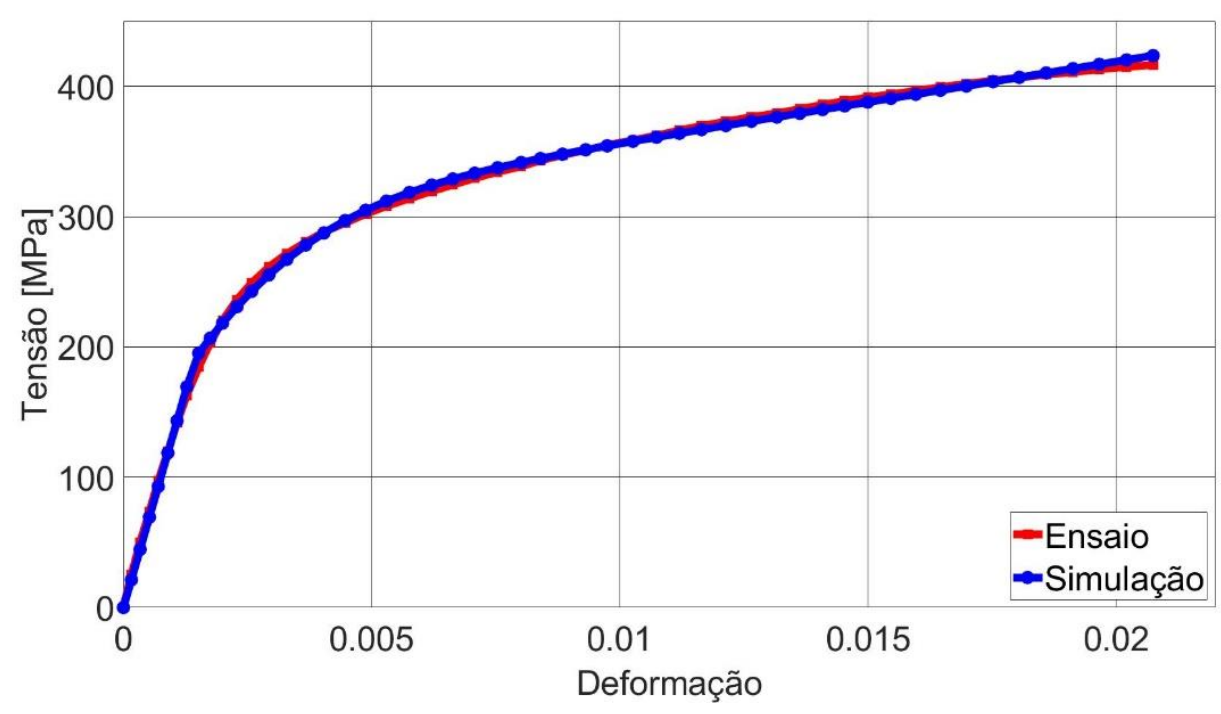

Fonte: Produção do próprio autor.

Os parâmetros de elasticidade apresentaram uma variação razoável dentro da mesma temperatura, enquanto os parâmetros de plasticidade apresentaram alta variação dentro dos seus grupos amostrais, para ambos as diferenças dos parâmetros pode ser atribuído a variação de resfriamento natural do cabeçote no seu processo de fabricação por fundição e a região da retirada do CP nesse cabeçote tem alta influência na sua microestrutura e consequentemente na sua propriedade mecânica, outro motivo para essa variação é a sensibilidade dos instrumentos e a caracterização uniaxial dos parâmetros plásticos, a obtenção desses em casos multiaxiais restringem a variação desses parâmetros.

\subsection{Ensaio de fadiga termomecânica}

Partindo dos resultados dos parâmetros obtidos no ensaio de tração, foi então inserido no software as médias em cada temperatura dos parâmetros elásticos e plásticos. Devido a isso os modelos apresentaram uma dependência da temperatura, e o software faz uma interpolação linear para as temperaturas não especificadas. 
Tabela 5 - Parâmetros obtidos nos ensaios de tração em diversas temperaturas e a média na temperatura.

\begin{tabular}{cccccccccc}
\hline $\mathbf{C P}$ & Temperatura & $\begin{array}{c}\mathrm{E} \\
(\mathbf{G p a})\end{array}$ & $\begin{array}{c}\boldsymbol{\sigma}_{\boldsymbol{Y}} \\
(\mathbf{M P a})\end{array}$ & $\boldsymbol{C}_{\mathbf{1}}$ & $\boldsymbol{\gamma}_{\mathbf{1}}$ & $\boldsymbol{C}_{\mathbf{2}}$ & $\boldsymbol{\gamma}_{\mathbf{2}}$ & $\boldsymbol{C}_{\mathbf{3}}$ & $\boldsymbol{\gamma}_{\mathbf{3}}$ \\
\hline $\mathbf{3 . 1}$ & $50^{\circ} \mathrm{C}$ & 171 & 190 & 183 & 0,120 & 6673 & 0,648 & 173057 & 1085 \\
\hline $\mathbf{3 . 9}$ & $50^{\circ} \mathrm{C}$ & 152 & 213 & 46 & 0,018 & 6627 & 0,648 & 110244 & 790 \\
\hline média & $50^{\circ} \mathrm{C}$ & 162 & 201 & 115 & 0,069 & 6650 & 0,648 & 141650 & 938 \\
\hline & & & & & & & & & \\
\hline $\mathbf{3 . 1 0}$ & $150^{\circ} \mathrm{C}$ & 167 & 173 & 58 & 0,007 & 6553 & 0,648 & 126526 & 867 \\
\hline $\mathbf{3 . 1 3}$ & $150^{\circ} \mathrm{C}$ & 135 & 264 & 159 & 0,127 & 873 & 0,010 & 21067 & 100 \\
\hline média & $150^{\circ} \mathrm{C}$ & 151 & 218 & 108 & 0,067 & 3713 & 0,329 & 73796 & 484 \\
\hline & & & & & & & & & \\
\hline $\mathbf{3 . 3}$ & $250^{\circ} \mathrm{C}$ & 115 & 200 & 870 & 0,127 & 4428 & 0,640 & 52354 & 470 \\
\hline $\mathbf{3 . 4}$ & $250^{\circ} \mathrm{C}$ & 139 & 194 & 873 & 0,004 & 6004 & 0,648 & 72820 & 548 \\
\hline $\mathbf{3 . 7}$ & $250^{\circ} \mathrm{C}$ & 133 & 191 & 722 & 0,029 & 5794 & 0,012 & 78297 & 665 \\
\hline $\mathbf{3 . 1 2}$ & $250^{\circ} \mathrm{C}$ & 133 & 246 & 61 & 0,008 & 6062 & 1,943 & 35320 & 333 \\
\hline média & $250^{\circ} \mathrm{C}$ & 130 & 208 & 632 & 0,042 & 5572 & 0,811 & 59698 & 504 \\
\hline & & & & & & & & & \\
\hline $\mathbf{2 . 6}$ & $350^{\circ} \mathrm{C}$ & 115 & 223 & 1533 & 0,003 & 5353 & 0,525 & 53813 & 465 \\
\hline $\mathbf{2 . 7}$ & $350^{\circ} \mathrm{C}$ & 135 & 217 & 120 & 0,016 & 7027 & 4,302 & 54864 & 445 \\
\hline média & $350^{\circ} \mathrm{C}$ & 125 & 220 & 826 & 0,010 & 6190 & 2,414 & 54338 & 455 \\
\hline & & & & & & & & & \\
\hline $\mathbf{1 . 2}$ & $420^{\circ} \mathrm{C}$ & 115 & 222 & 917 & 0,007 & 3151 & 1,930 & 31961 & 273 \\
\hline $\mathbf{3 . 5}$ & $420^{\circ} \mathrm{C}$ & 131 & 179 & 1939 & 0,101 & 3179 & 0,555 & 68256 & 484 \\
\hline $\mathbf{3 . 8}$ & $420^{\circ} \mathrm{C}$ & 137 & 217 & 271 & 0,003 & 3798 & 1,801 & 41972 & 341 \\
\hline média & $420^{\circ} \mathrm{C}$ & 128 & 206 & 1042 & 0,037 & 3376 & 1,429 & 47396 & 366 \\
\hline
\end{tabular}

Fonte: Produção do próprio autor.

As Figura 29 e Figura 30 apresentam a simulação em comparação aos três primeiros ciclos do seu ensaio correspondente. Na Figura 29 o ensaio de fadiga termomecânica ocorreu com $75 \%$ de restrição do corpo de prova, enquanto na Figura 30 apresenta o ensaio com restrição de $100 \%$.

A simulação apresentou algumas diferenças comparadas com o ensaio, mas de forma geral, pode-se notar uma certa representatividade do comportamento do material. No início do ensaio, ainda na parcela elástica, o material apresentou uma atípica não linearidade, isso pode ser explicada pela diferença da temperatura encontrada pelo pirômetro e a real temperatura do $\mathrm{CP}$, pois há uma diferença encontrado na temperatura do comando a temperatura do pirômetro indicando assim uma diferença entre as temperatura medidas e real. Ou seja, o ponto medido pelo 
pirômetro mostrou uma diferença em relação a temperatura real no $\mathrm{CP}$, até que houvesse a homogeneidade total de temperatura no $\mathrm{CP}$, que ocorre quando se mantem a temperatura a $420^{\circ} \mathrm{C}$ ou a $50^{\circ} \mathrm{C}$.

Figura 29 - Ensaio de fadiga termomecânica com 75\% de restrição do corpo de prova em comparação a simulação com dados parametrizados com três "backstress" dos três primeiros ciclos.

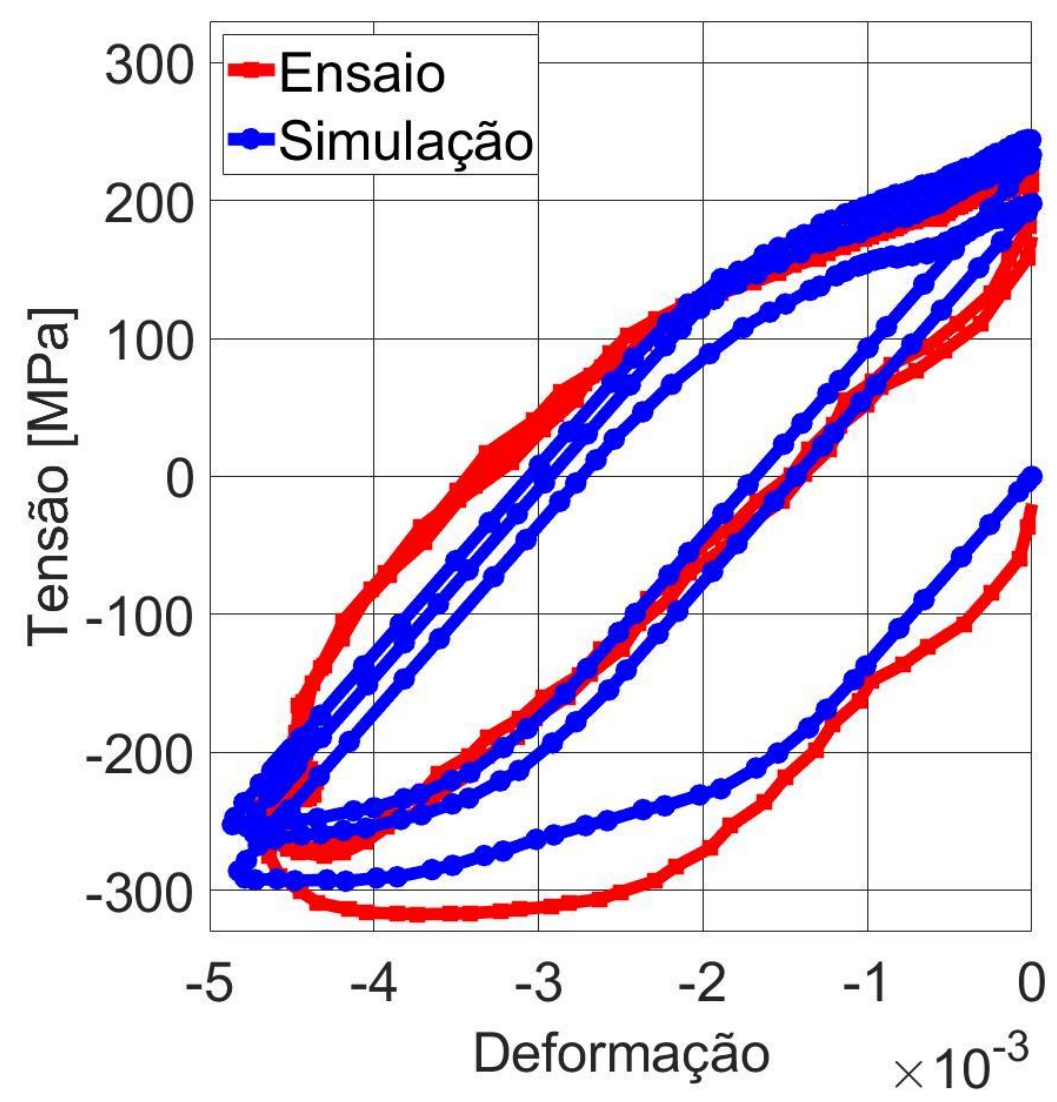

Fonte: Produção do próprio autor.

Ao comparar as tensões e deformações, onde ocorre pouco diferença dessas temperaturas (perto das tensões máximas e mínimas), a simulação apresentou bons resultados na sua parcela elástica e plástica com dependência da temperatura e independência do tempo, mas na temperatura de $420{ }^{\circ} \mathrm{C}$ apresentou relaxação de tensão no material e devido a essa relaxação de tensão apresentou uma grande diferença no comportamento mecânico do material na região de resfriamento do material (transição entre a parte compressiva para a parte trativa). A simulação não conseguiu prever o comportamento de relaxação de tensão, pois o modelo constitutivo 
não apresenta um modelo viscoso ou uma plasticidade dependente do tempo que consiga representar esse comportamento dependente do tempo.

Figura 30 - Ensaio de fadiga termomecânica com 100\% de restrição do corpo de prova em comparação a simulação com dados parametrizado com três "backstress" dos três primeiros ciclos.

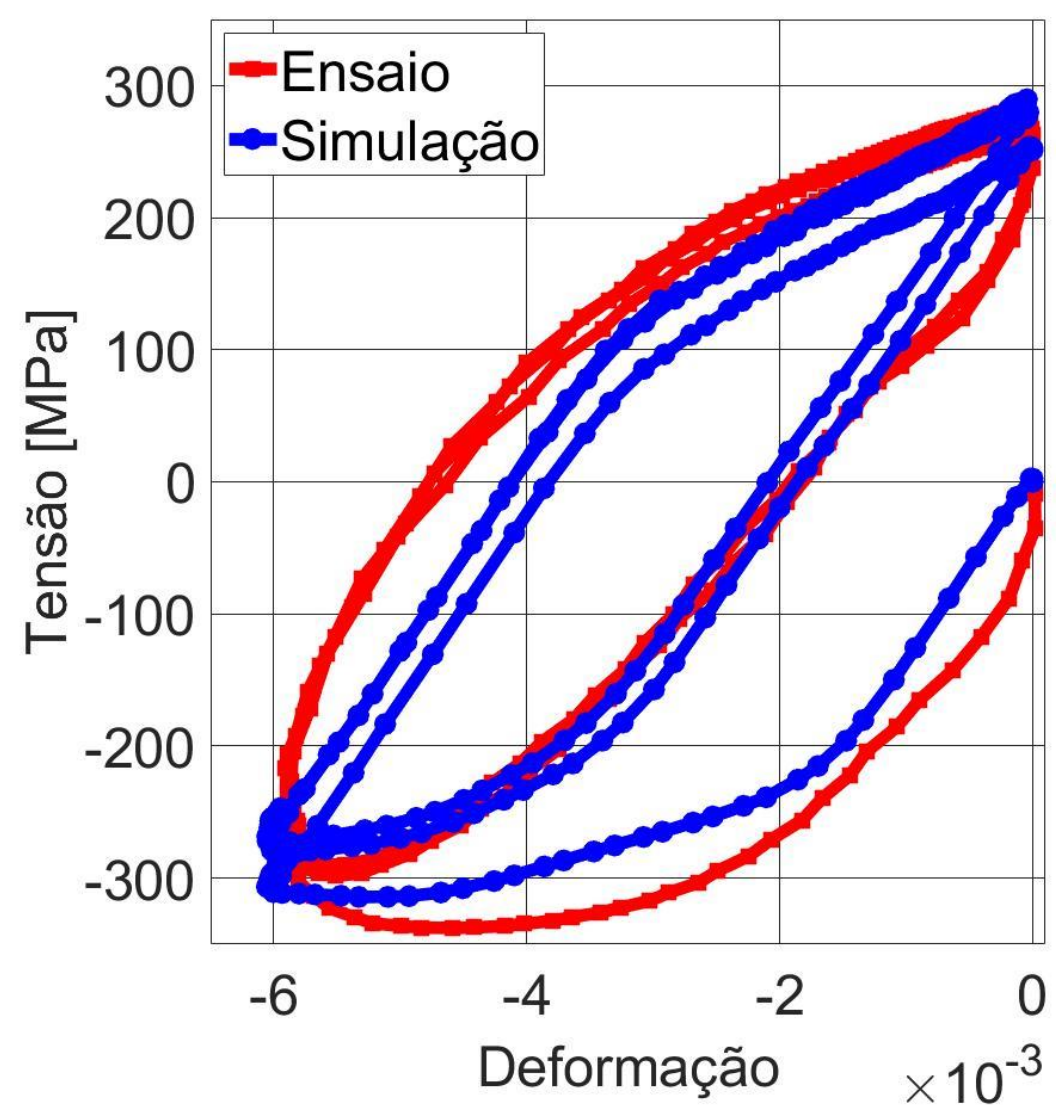

Fonte: Produção do próprio autor.

A relaxação de tensão do material está melhor representada na Figura 31, na qual a simulação apresenta a tensão relativamente constante desde o tempo 50 até 200 segundos, enquanto na curva do ensaio a tensão diminui no mesmo período de tempo. Nessa figura, ainda pode ser observada uma certa instabilidade na tensão mínima. Isso se deve ao controlador PID (proporcional integral derivativo) da temperatura, que apresenta essa instabilidade na temperatura medida, o que gera uma instabilidade na tensão. 
Devido a esses resultados que não foi possível representar a relaxação de tensão que o material possui, foi testado um modelo de viscoplasticidade para testar e tentar ajustar e adequar essa dependência do tempo no modelo constitutivo. $O$ modelo de viscoplasticidade não satisfez a necessidade para a simulação, pois a parcela viscosa que acrescentou a dependência do tempo atuou apenas no atraso no descarregamento em alta temperatura, não contribuindo assim para o comportamento de relaxação do material.

Figura 31 - Representação da relaxação de tensão que o material apresenta no ensaio de fadiga termomecânica com $100 \%$ de restrição do $\mathrm{CP}$ a) dos três primeiros ciclos, b) do primeiro ciclo.

a)
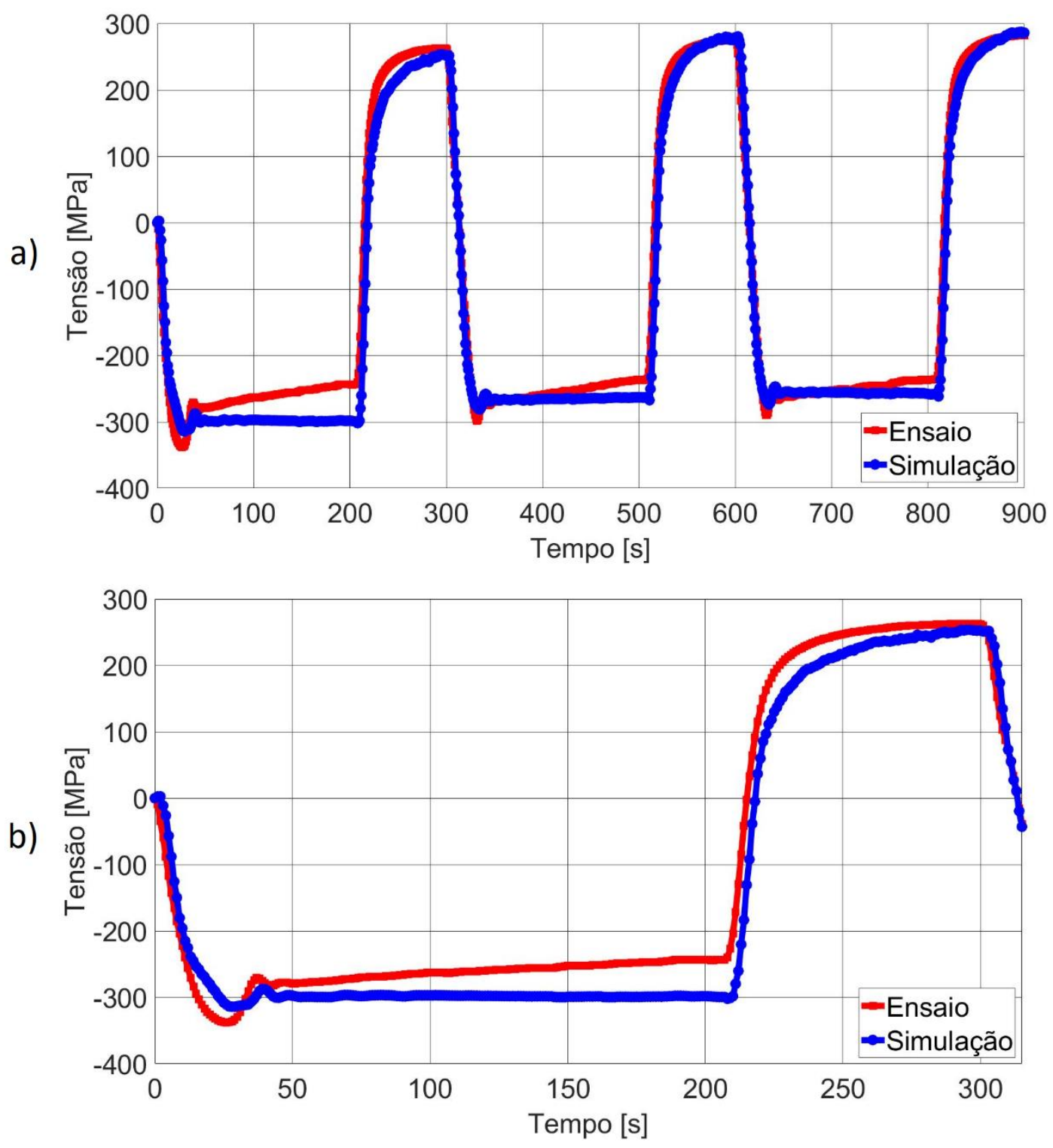

Fonte: Produção do próprio autor. 
Outros modelos foram inseridos para representar essa parcela no modelo, como por exemplo fluência, porém sem sucesso. Segundo a documentação do Abaqus $^{\circledR}$ [55] o modelo de viscoelasticadade pode ser calibrado com um ensaio de relaxação de tensão, mas a limitação do programa não permite a combinação de modelo viscoelástico com o modelo de plasticidade, impedindo assim realizar teste para ajustar um modelo viscoso juntamente com o modelo elastoplástico.

\subsection{Previsão de vida em fadiga em temperatura constante}

Com os ensaios de fadiga isotérmica, a 50 e $420^{\circ} \mathrm{C}$, se levantou os pontos de deformação total do material pelo número de ciclo de vida, cujos podem ser vistos nas Tabela 6 e Tabela 7, com as médias obtidas foi colocado em gráfico os pontos que estão na Figura 32 e Figura 33. Para ambas as temperaturas foram obtidos os parâmetros da Equação 15 em dois casos, um caso considerando os pontos de 0,3\%, 0,4\%, 0,5\%, 0,6\% e 0,7\% (para simplificação denominado com 0,3\%) deformação total e outro considerando os pontos $0,4 \%, 0,5 \%, 0,6 \%$ e $0,7 \%$ (para simplificação denominado sem $0,3 \%$ ) de deformação total. Isso se deve ao fato a deformação total de $0,3 \%$ estar perto do limiar entre a FBC e FAC.

Figura 32 - Gráfico de deformação mecânica total pelo número de ciclos até a fadiga em fadiga isotérmica a $50^{\circ} \mathrm{C}$ comparado as curvas da equação 17 considerando e não considerando o ponto 0,3 .

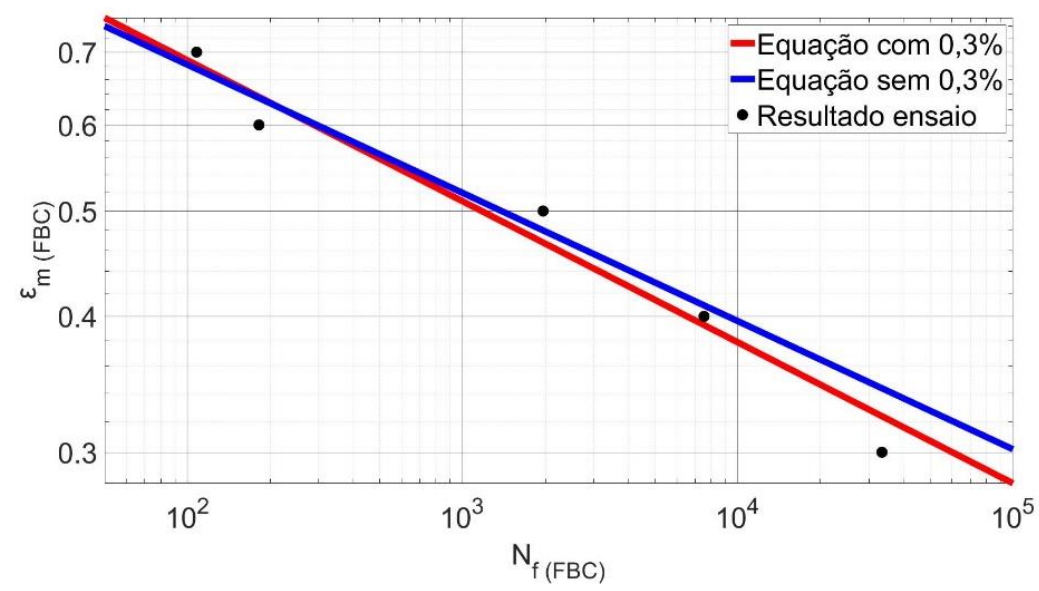

Fonte: Produção do próprio autor. 
Tabela 6 - Comparação da deformação com a vida em fadiga isotérmica a $50{ }^{\circ} \mathrm{C}$ de diversos corpos de prova.

\begin{tabular}{ccc}
\hline $\mathbf{C P}$ & Deformação (\%) & Vida em ciclos \\
\hline $\mathbf{2}$ & 0,7 & 274 \\
\hline $\mathbf{1 0}$ & 0,7 & 131 \\
\hline $\mathbf{1 4}$ & 0,7 & 108 \\
\hline Média & 0,7 & 171 \\
\hline $\mathbf{1 3}$ & 0,6 & 133 \\
\hline $\mathbf{4}$ & 0,6 & 232 \\
\hline Média & 0,6 & 182,5 \\
\hline $\mathbf{9}$ & 0,5 & 344 \\
\hline $\mathbf{8}$ & 0,5 & 495 \\
\hline $\mathbf{1}$ & 0,5 & 2512 \\
\hline $\mathbf{1 2}$ & 0,5 & 4495 \\
\hline Média & 0,5 & 1961,5 \\
\hline $\mathbf{1 6}$ & 0,4 & 1486 \\
\hline $\mathbf{6}$ & 0,4 & 5936 \\
\hline $\mathbf{3}$ & 0,4 & 15195 \\
\hline Média & 0,4 & 7539 \\
\hline $\mathbf{1 1}$ & 0,3 & 33922 \\
\hline $\mathbf{1 5}$ & 0,3 & 32954 \\
\hline Média & 0,3 & 33438 \\
\hline
\end{tabular}

Fonte: Produção do próprio autor.

Com os parâmetros caracterizados em fadiga isotérmica utilizou-se o parâmetro de coeficiente de ductilidade da fadiga isotérmica e aplicou-se no o mesmo parâmetro no caso de fadiga termomecânica a 100\% de restrição do corpo de prova para a caracterização do expoente da Equação 16.

O primeiro ensaio de FTM com 100\% de restrição do CP apresentou vida de 158 ciclos, enquanto o segundo ensaio apresentou vida de 226 ciclos, apresentando assim uma média de 192 ciclos, valores adequados comparado aos encontrados no trabalho de Ghodrat, et al.[36]. O ensaio de FTM apresentou uma deformação total de $0,6 \%$. Foram então encontrados os parâmetros para os quatro casos onde se considera ou não, o ponto de $0,3 \%$ de deformação total do ensaio isotérmico para a temperatura de 50 e $420^{\circ} \mathrm{C}$. Estes dados estão descritos na Tabela 8. 
Tabela 7 - Vida em fadiga isotérmica a $420^{\circ} \mathrm{C}$ de diversos corpos de prova.

\begin{tabular}{ccc}
\hline $\mathbf{C P}$ & Deformação (\%) & Vida em ciclos \\
\hline $\mathbf{5 . 2}$ & 0,7 & 75 \\
\hline $\mathbf{5 . 6}$ & 0,7 & 60 \\
\hline média & 0,7 & 67,5 \\
\hline $\mathbf{5 . 3}$ & 0,6 & 272 \\
\hline $\mathbf{5 . 1 5}$ & 0,6 & 180 \\
\hline média & 0,6 & 226 \\
\hline $\mathbf{5 . 4}$ & 0,5 & 1157 \\
\hline $\mathbf{5 . 1 2}$ & 0,5 & 446 \\
\hline média & 0,5 & 801,5 \\
\hline $\mathbf{5 . 1 3}$ & 0,3 & 10295 \\
\hline $\mathbf{5 . 1 6}$ & 0,3 & 13327 \\
\hline média & 0,3 & 11811 \\
\hline
\end{tabular}

Fonte: Produção do próprio autor.

Figura 33 - Gráfico de deformação mecânica total pelo número de ciclos até a fadiga em fadiga isotérmica a $420^{\circ} \mathrm{C}$ comparado as curvas da equação 17 considerando e não considerando o ponto 0,3 .

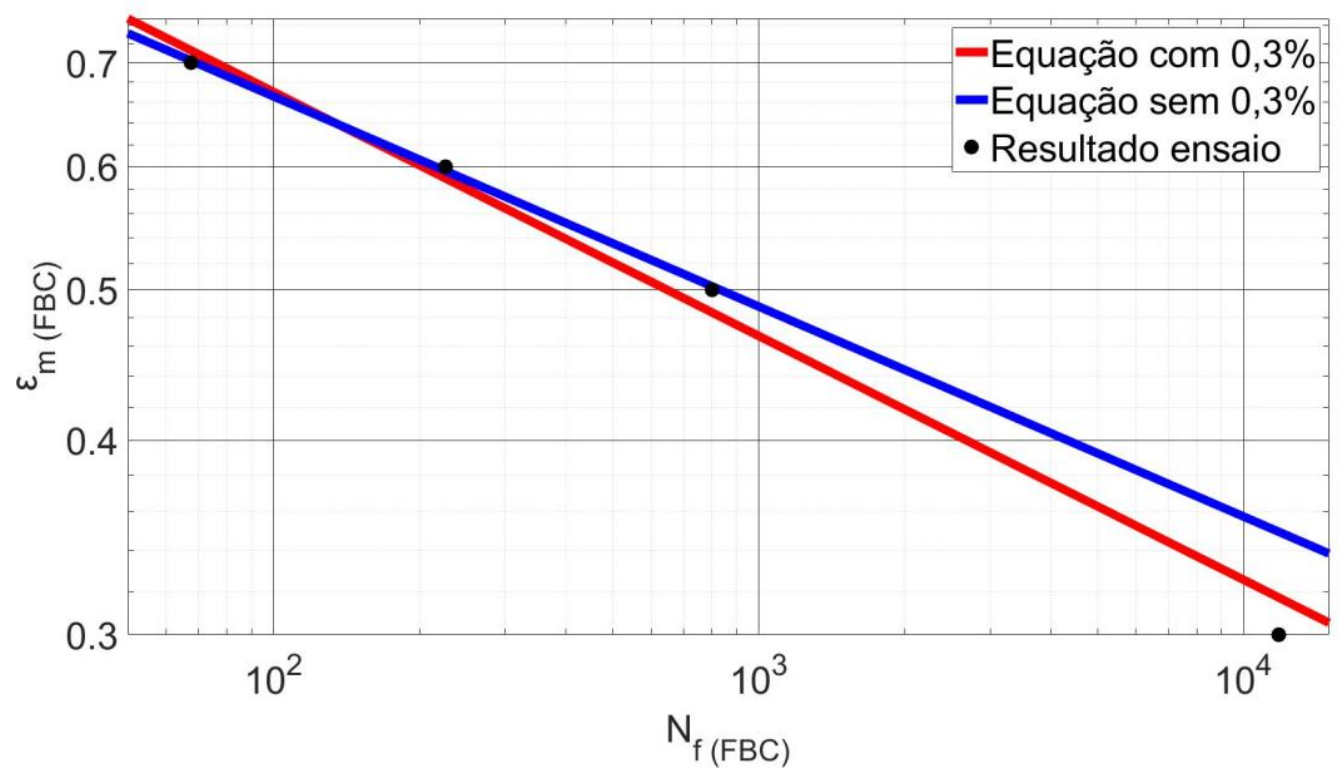

Fonte: Produção do próprio autor.

Depois da caracterização do expoente da Equação 16 na condição de $100 \%$ de restrição do $\mathrm{CP}$ na fadiga termomecânica foi calculado a vida em fadiga termomecânica na condição de $75 \%$ de restrição do CP considerando o coeficiente de ductilidade nos casos com e sem $0,3 \%$ de deformação total e nas temperatura de 
50 e $420{ }^{\circ} \mathrm{C}$ na fadiga isotérmica e os coeficientes encontrando na fadiga termomecânica com $100 \%$ de restrição do CP. As vidas calculadas com $75 \%$ de restrição do CP está na Tabela 8.

Tabela 8 - Dados da Equação 15 e 16 para o ensaio FTM e isotérmico

\begin{tabular}{cccccccc}
\hline Temperatura & $\begin{array}{c}\text { Considera } \\
\mathbf{0 , 3 \%} \text { de } \\
\text { deformação }\end{array}$ & $\boldsymbol{\varepsilon}_{\boldsymbol{B}, \boldsymbol{M}(\boldsymbol{F B C})}^{\prime}$ & $\boldsymbol{c}_{\boldsymbol{M}(\boldsymbol{F B C})}$ & $\begin{array}{c}\boldsymbol{c}_{\boldsymbol{M}(\boldsymbol{F T M})} \mathbf{1 0 0 \%} \\
\text { restrição }\end{array}$ & $\begin{array}{c}\text { Vida } \\
\text { Calculada } \\
\text { em ciclos } \\
\mathbf{7 5 \%} \\
\text { restrição }\end{array}$ & $\begin{array}{c}\text { Vida em } \\
\mathbf{7 5 \%} \\
\text { restrição } \\
\text { em } \\
\text { ciclos }\end{array}$ & $\begin{array}{c}\text { Erro } \\
\text { relativo }\end{array}$ \\
\hline $\mathbf{5 0 ^ { \circ } \mathbf { C }}$ & Sim & 1,37 & $-0,130$ & $-0,139$ & 1532 & 1296 & $18 \%$ \\
\hline $\mathbf{5 0}^{\circ} \mathbf{C}$ & Não & 1,27 & $-0,118$ & $-0,126$ & 1869 & 1296 & $44 \%$ \\
\hline $\mathbf{4 2 0}^{\circ} \mathbf{C}$ & Sim & 1,54 & $-0,157$ & $-0,158$ & 1182 & 1296 & $9 \%$ \\
\hline $\mathbf{4 2 0}^{\circ} \mathbf{C}$ & Não & 1,36 & $-0,135$ & $-0,138$ & 1550 & 1296 & $20 \%$ \\
\hline
\end{tabular}

Fonte: Produção do próprio autor.

A condição em que os parâmetros mais se aproximaram do ensaio de FTM, com $75 \%$ de restrição, é no caso da temperatura de $420{ }^{\circ} \mathrm{C}$ considerando o ponto de deformação total de $0,3 \%$, e este caso apresentou erro de $9 \%$. Por estarmos considerando uma previsão, esta variação de $9 \%$ pode ser considerada como um resultado adequado para a previsão de vida, pois estudos como de Ghodrat, et al.[36], Seifert, et al. [35], Metzger, et al [20], apresentaram erros maiores dentro dos grupos amostrais.

Devido ao trabalho de Zhang, et al. [56] é razoável a possibilidade da calibração da Equação 16 utilizando-se o mesmo coeficiente de ductilidade da fadiga no regime $\mathrm{FBC}\left(\varepsilon_{B, M(F B C)}^{\prime}\right)$ para o caso de fadiga isotérmica na máxima temperatura do ensaio de FTM, indicando assim que o efeito dominante do dano é em alta temperatura neste material.

Esse modelo apresenta uma possibilidade de previsão de vida em fadiga termomecânica carecendo assim de mais dados estatísticos para a confirmação de sua eficiência. 


\section{CONCLUSÃO E RECOMENDAÇÕES PARA TRABALHOS FUTUROS}

Este trabalho avaliou a previsão de comportamento mecânico do ferro fundido vermicular de classe 450 pelo meio da simulação computacional para os casos de ensaio de tração, fadiga isotérmica e fadiga termomecânica e a previsão de vida nos casos de fadiga. Os modelos constitutivos utilizados foram o de elasticidade e plasticidade com encruamento combinado. As seguintes conclusões foram obtidas:

1) $O$ modo de inserção de dados do modelo de plasticidade que melhor representou os ensaios de fadiga é na forma de inserção dos parâmetros $C_{k}$ e $\gamma_{k}$ com três "backstress", pois esses parâmetros apresentam melhor flexibilidade para descrever a curva de encruamento comparado com a equação de Ramberg-Osgood.

2) É possível calibrar o modelo elato-plástico de ensaios de fadiga termomecânica utilizando ensaios de tração em várias temperaturas.

3) A simulação computacional representou de forma adequada 0 comportamento mecânico do material nas condições de ensaio de tração e fadiga isotérmica.

4) A simulação computacional da fadiga termomecânica apresentou resultados adequados em tensões máximas e mínimas comparado ao ensaio, mas devido ao modelo computacional não representar a dependência do tempo a simulação não previu a relaxação de tensão que o material sofreu no ensaio.

5) A previsão de vida em fadiga é possível ser obtida utilizando a equação de Wöhler para os carregamentos isotérmicos. Enquanto nos carregamentos termomecânicos é possível prever utilizando equações modificadas de Wöhler, que podem ser calibrado o coeficiente de ductilidade da fadiga por ensaios isotérmicos na temperatura máxima do ciclo termomecânico e o expoente é encontrado nos ensaios de fadiga termomecânica com apenas um patamar de restrição do corpo de prova.

Para trabalhos futuros recomenda-se:

1) A utilização de modelos constitutivos com dependência do tempo para descrever a relaxação de tensão e a variação da taxa de carregamentos, utilizando para isso o User material, que consiste na programação do modelo constitutivo do material. 
2) Aumentar o número de ensaios de fadiga termomecânica para um melhor estudo estatística dos resultados da previsão de vida encontrados nesse trabalho para caracterizar a eficiência desta proposta.

3) Estudar o comportamento mecânico e previsão de vida em fadiga para outras classes de ferros fundidos utilizados na indústria automobilística.

4) Utiliza modelos constitutivos de crescimento de trinca para melhor prever a vida em fadiga termomecânica em componentes automobilísticos.

5) Possibilitar a implementação destes resultados na prática dentro da indústria. 


\section{REFERÊNCIAS}

[1] H. Sehitoglu, Thermal and thermomechanical fatigue of structural alloys, ASM Handbook - Fatigue and Fracture, Ohio, v. 9, 1996.

[2] J. C. Pina, Elevated temperature thermos-mechanical behavior of cast irons: a numerical-experimental investigation, Eindhoven: technische Universiteit Eindhoven, 2015.

[3] S. GHODRAT. Thermo-Mechanical Fatigue of Compacted Graphite Iron in Diesel Engine Components, Ph. D. Thesis, Delft University of Technology, 2013.

[4] Li J., Wang P., Cui X., Li K., Yi R., Gray Cast Iron Cylinder Head Thermal Mechanical Fatigue Analysis, Proceedings of the FISITA 2012 World Automotive Congress Lecture Notes in Electrical Engineering, Berlin, Germany, 2013, 189, pp. 243-257.

[5] Mirsalim S.M., Chamani H.R., Rezaloo Y., Keshavarz M., Jafarabadi M., Analysis of Cracked Cylinder Head of Diesel Engine due to Fatigue and Improvement its Design, 6th International Conference on Internal Combustion Engines, Tehran, Iran, 2009.

[6] Azadi M., Winter G., Farrahi G.H., Eichlseder W., Design of cylinder head and block in international combustion engines based on fatigue strength of materials, 8th International Conference on Internal Combustion Engines and Oil, Tehran, Iran, 2012.

[7] Zahedi F., Azadi M., Low-cycle fatigue life analysis of magnesium alloy diesel engine cylinder head, 20th Annual International Conference on Mechanical Engineering, Shiraz, Iran, 2012, Paper No. ISME2012-2063.

[8] A. Malakizardi, H. Chamani, S. N. Shahangian, S. A. Jazayeri, I. Sattarifar. Thermomechanical fatigue life prediction of a heavy duty diesel engine liner. Proceedings of the ASME Internal Combustion Engine Division 2007 Fall Technical Conference, ICEF2007, USA, 2017.

[9] Kajiwara H, Fujioka Y, Suzuki T, Negishi H. An analytical approach for prediction of piston temperature distribution in diesel engines. JSAE Rev 2002;23(4):429-34.

[10] Payri F, Benajes J, Margot X, Gil A. CFD modeling of the in-cylinder flow in directinjection diesel engines. Comput Fluids 2004;33(8):995-1021.

[11] Mogilewski R, Brian SR, Wolbach WS, Krucek TW, Maier RD, Shoemaker DL, Chabala JM, Soni KK, Levi-Setti R. Reactions at the matrix-reinforcement interface in aluminum alloy matrix composites. Mater Sci Eng A 1995;191:209-22.

[12] Huang YD, Hort N, Kainer KU. Thermal behavior of short fiber reinforced AISi12CuMgNi piston alloys. Composites A 2004;35(2):249-63.

[13] Baxter WJ, Alostaz A, Jasiuk I. The effect of shot particles on the fatigue of Kaowool fibre-reinforced 339 Aluminum. Met Mater Trans A 1999;30:95.

[14] Friedrich C, Berg G, Broszeit E, Rick F, Holland J. PVD CrxN coatings for tribological application on piston rings. Surf Coat Technol 1997;97(1-3):661-8.

[15] Pinedo CE. The use of selective plasma nitriding on piston rings for performance improvement. Mater Des 2003;24(2):131-5. 
[16] Cho JR, Joo YS, Jeong HS. The Al-powder forging process: its finite element analysis. J Mater Processing Technol 2001; 111(1-3):204-9.

[17] Vijaya Babu M, Krishna Kumar R, Prabhakar O, Gowri Shankar N. Fracture mechanics approaches to coating strength evaluation. Eng Fract Mech 1996;55(2):235-48.

[18] Nakajima K, Otaka H, Kashimura T, Sakuma S, Tanaka M. Newly developed hollow ring groove insert piston - part 2: producing technology of new piston. JSAE Rev 1996;17(4):448.

[19] Sulaiman S, Hamouda AMS, Gethin DT. Experimental investigation for metalfilling system of pressure diecasting process on a cold chamber machine. J Mater Processing Technol 2001;119(1-3):268-72.

[20] J.R. Davis (editor). ASM Specialty Handbook: Cast Irons. ASM International, United States of America, 1996.

[21] K.B. Rundman. Cast Irons. Encyclopedia of Materials: Science and Technology, pages 1003 - 1010, 2001.

[22] F. lacovello, O. Di Bartolomeo, V. Di Cocco, and V. Piacente. Damaging micromechanisms in ferritic-pearlitic ductile cast irons. Materials Science and Engineering A, 478:181-186, 2008.

[23] T. Sjögren, D. Holmgren, and M. Rinvall. Study of the mechanical and termal properties of pearlitic and ferritic cast iron matrices. International Foundry Research/Giessereiforschung, 59(3):14-21, 2007.

[24] S.Y. Buni, N. Raman, and S. Seshan. The role of graphite morphology and matrix structure on the low frequency thermal cycling of cast irons. Sadhana, 29(1):117-127, 2004.

[25] R.B. Gundlach. Elevated temperature properties of alloyed gray irons for diesel engine components. AFS International Cast Metal Journal, 4(3):11-20, 1979.

[26] R.B. Gundlach. Thermal Fatigue resistance of alloyed gray irons for diesel engine components. Transactions of the American Foundrymen's Society, 87:551 - 560, 1980.

[27] R.B. Gundlach. The effect of alloying elements on the elevated temperature properties of gray irons. Transactions of the American Foundrymen's Society, 91:389422, 1983.

[28] J.R. Kattus and B. McPherson. Report on Properties of Cast Iron at Elevated Temperatures - ASTM Special Technical Publication No. 248. American Society for Testing Materials, Philadelphia, 1959.

[29] K. Roehrig. Thermal fatigue of gray and ductile cast irons. Transactions of the American Foundrymen's Society, 86:75-88, 1978.

[30] D.G. White. Growth and Scaling Characteristics of Cast Irons with Undercooled and Normal Flake Graphite. BCIRA Journal, 11(Report 689):223-230, 1963.

[31] V.M. Yuzvak, I.P. Volchok, and V.I. Gontarenko. Micromechanism of fracture of cast irons. Metal Science and Heat Treatment, 25(8):569-573, 1983. 
[32] M. Metzger, B. Nieweg, C. Schweizer, T. Seifert, Lifetime prediction of cast iron materials under combined thermomechanical fatigue and high cycle fatigue loading using a mechanism-based model. International journal of Fatigue 53 (2013) 58-66.

[33] O. Mallet, C.C. Engler-Pinto Jr., F. Rézaï-Aria, R.P. Skelton, K. Nikbin and G.A. Webster, Influence of material stress-strain characteristics on thermomechanical fatigue analysis of IN100 superalloy, Materials at High Temperatures, vol. 13, no 1 , 1995, p. 47-54.

[34] T.J. Smith, H.J. Maier, H. Sehitoglu, E. Fleury, and J. Allison, Modeling hightemperature stress-strain behavior of cast aluminum alloy, Metallurgical Materials. Transactions, vol. 30A, 1999, p. 133-146.

[35] Engler-Pinto Júnior, C. C., Spinelli, D.. Fadiga Isotérmica E Termomecânica de uma Superliga À Base De Niquel. Tecnol. Metal. Mater. Miner., São Paulo, v. 11, n. 2, p. 125-130, abr./jun. 2014.

[36] S. Ghodrat, A. C. Riemslag, M. Jassen, J. Sietsma, L.A.I. Kestens, Measurement and characterization of Thermo-Mechanical Fatigue in Compacted Graphite Iron, International Journal of Fatigue 48 (2013) 319-329.

[37] T. Seifert, H. Riedel, "Mechanical-based thermomechanical fatigue life prediction of cast iron. Part I: Models", Int J Fatigue, 32, 1358-1367,2010.

[38] Chaboche JL. Time-independent constitutive theories for cyclic plasticity. Int $J$ Plast 1986;2:149-88.

[39] Chaboche JL. Constitutive equations for cyclic plasticity and cyclic viscoplasticity. Int J Plast 1989;5:247-302.

[40] Chaboche JL. A review of some plasticity and viscoplasticity constitutive theories. Int J Plast 2008;24:1642-93.

[41] ABAQUS ${ }^{\circledR}$ Theory Manual, version 6.8, Dassault Systèmes; 2008.

[42] ANSYS Theory Reference, release 11.0, ANSYS, Inc.; 2007.

[43] Gurson AL. Continuum theory of ductile rupture by void nucleation and growth- I: yield criteria and flow rules for porous ductile media. J Eng Mater Technol 1977;99:215.

[44] Neu RW, Sehitoglu H. Thermomechanical fatigue, oxidation and creep: part I. Damage mechanisms. Metall Trans A 1989;20A:1755-67.

[45] Neu RW, Sehitoglu H. Thermomechanical fatigue, oxidation and creep: part II. Life prediction. Metall Trans A 1989;20A:1769-83.

[46] Sehitoglu $\mathrm{H}$, Boismier DA. Thermo-mechanical fatigue of Mar-M247: part 2 - life prediction. J Eng Mater Technol 1990;112:80-9.

[47] Sehitoglu $\mathrm{H}$. Thermo-mechanical fatigue life prediction methods. In: Mitchell MR, Landgraf RW, editors. Advances in fatigue lifetime predictive techniques, ASTM STP 1122, Philadelphia; 1992. p. 47-76.

[48] Ebi G, Riedel H, Neumann P. Fatigue life prediction based on microcrack growth. In: van Elst HC, Bakker A, editors. Proceedings of the sixth European conference on fracture. Warley: EMAS; 1986. p. 1587-98. 
[49] Hoffmeyer J, Döring R, Seeger T, Vormwald M. Deformation behaviour, short crack growth and fatigue lives under multiaxial nonproportional loading. Int $J$ Fatigue 2006;28:508-20.

[50] Sidey D, Coffin L. Low-cycle fatigue damage mechanisms at high temperature. In: Fong JT, editor. Fatigue mechanisms, ASTM STP 675; 1979. p. 528-658.

[51] Riedel H. Fracture at high temperatures. 1st ed. Berlin (Heidelberg, NY): SpringerVerlag; 1987.

[52] Suresh S. Fatigue of materials. Cambridge University Press; 1991.

[53] Lemaitre J, Chaboche J. L. Mechanics of solid materials. Cambridge University Press, 1990.

[54] Kelly, P. (2018). Solid mechanics part I: An introduction to solid mechanics. Solid mechanics lecture notes, University of Auckland.

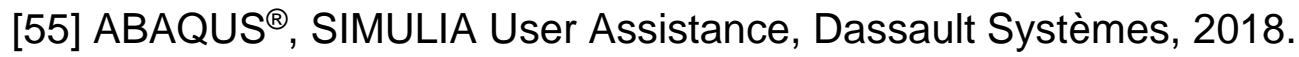

[56] M. X. Zhang, J. C. Pang, Y. Qiu, S. X. Li, M. Wang, Z. F. Zhang, "Thermomechanical fatigue property and life prediction of vermicular graphite iron", Mate. Scien. \& Engng, A 698, 63-72, 2017.

[57] Cyclic Morrow J. Plastic strain energy and fatigue of metals. ASTM Int. 1965. STP 378.

[58] Jost B, Klein M, Eifler D. PHYBALSIT - fatigue assessment and life time calculation of the ductile cast iron EN-GJS-600 at ambient and elevated temperatures. Characterization of minerals. Metals Mater 2015:711-8.

[59] Jost B, Klein M, Beck T, Eifler D. Temperature dependent cyclic deformation and fatigue life of EN-GJS-600 (ASTM 80-55-06) ductile cast iron. Int J Fatigue 2017;96:102-13.

[60] Jost B, Klein M, Beck T, Eifler D. Cyclic deformation behavior and Physically Based Lifetime Calculation (PhyBaL) of The Ductile Cast Iron EN-GJS-600 (ASTM 8055- 06) at Low Frequency Fatigue in Temperature Range AT $-400{ }^{\circ} \mathrm{C}$. Proc. Eighth International Conference on Low Cycle Fatigue (LCF8); 2017.

[61] Jost B, Klein M, Beck T, Eifler D. Temperature and frequency influence on the cyclic deformation behavior of EN-GJS-600 (ASTM 80-55-06) ductile cast iron at 0.005 and $5 \mathrm{~Hz}$. Int J Fatigue 2018;110:225-37.

[62] Jost B, Klein M, Beck T, Eifler D. Out-of-Phase TMF lifetime calculation of ENGJS-600 (ASTM 80-55-06) ductile cast iron based on strain increase tests and evaluation of cyclic deformation behavior in isothermal measuring intervals. Int $\mathrm{J}$ Fatigue 2018;117:274-282.

[63] ASTM E606-12 Standard Test Method for Strain-Controlled Fatigue Testing1, American Society for Testing of Materials, West Conshohocken, PA, 2004.

[64] ASTM E8/E8M-16a Standard Test Methods for Tension Testing of Metallic Materials. ASTM International, West Conshohocken, PA, 2016.

[65] ASTM E21-17 Standard Test Methods for Elevated Temperature Tension Tests of Metallic Materials. ASTM International, West Conshohocken, PA, 2017. 
[66] ASTM E2368-10 Standard Practice for Strain Controlled Thermomechanical Fatigue Testing, American Society for Testing of Materials, West Conshohocken, PA, 2004.

[67] Ferreira, M. H. Análise da vida em fadiga termomecânica de ferros fundidos cinzentos e vermiculares. Dissertação (Mestrado em Ciência e Engenharia de Materiais) - Universidade de São Paulo, São Carlos, 2017.

[68] Guesser, W. L. Propriedades Mecânicas dos Ferros Fundidos. Blucher, 2009. 